Oberdan Miguel Rodrigues de Souza

\title{
Modelo de PDF Presumida com Cinética \\ Química Tabulada Aplicada para a Combustão em sprays
}

Tese de Doutorado

Tese apresentada como requisito parcial para obtenção do grau de Doutor pelo Programa de Pós-Graduação em Engenharia Mecânica do Centro Técnico Científico da PUC-Rio

Orientador

Prof. Sergio Leal Braga

Co-Orientador: Prof. Wladimyr Mattos da Costa Dourado 


\title{
Oberdan Miguel Rodrigues de Souza
}

\section{Modelo de PDF Presumida com Cinética Química Tabulada Aplicada para a Combustão em sprays}

Tese apresentada ao Programa de Pós-Graduação em Engenharia Mecânica do Departamento de Engenharia Mecânica do Centro Técnico Científico da PUC-Rio como requisito parcial para obtenção do grau de Doutor em Engenharia Mecânica. Aprovada pela Comissão Examinadora abaixo assinada.

\section{Prof. Sergio Leal Braga}

Orientador

Departamento de Engenharia Mecânica - PUC-Rio

\author{
Prof. Wladimyr Mattos da Costa Dourado \\ Co-Orientador \\ Instituto de Aeronáutica e Espaço - IAE
}

Profa. Angela Ourivio Nieckele

Departamento de Engenharia Mecânica - PUC-Rio

Prof. José Alberto dos Reis Parise

Departamento de Engenharia Mecânica - PUC-Rio

Prof. Marcio Teixeira de Mendonça Instituto de Aeronáutica e Espaço - IAE

Prof. Alexandre Alves

Universidade Federal da Integração Latino-Americana - UNILA

Prof. Márcio da Silveira Carvalho Coordenador Setorial do Centro Técnico Científico - PUC-Rio 
Todos os direitos reservados. É proibida a reprodução total ou parcial do trabalho sem autorização da universidade, do autor e do orientador.

Oberdan Miguel Rodrigues de Souza

Graduou-se em Matemática na Universidade Federal Rural do Rio de Janeiro, em Julho de 2009. Mestre em Engenharia Mecânica pelo Instituto Militar de Engenharia em 2011. Desde 2008 atua na área de dinâmica dos fluidos computacional.

Ficha Catalográfica

Souza, Oberdan Miguel Rodrigues de

Modelo de PDF Presumida com Cinética Química Tabulada Aplicada para a Combustão em sprays / Oberdan Miguel Rodrigues de Souza; orientador: Sergio Leal Braga; co-orientador: Wladimyr Mattos da Costa Dourado. - Rio de Janeiro PUC-Rio, Departamento de Engenharia Mecânica, 2016.

v., $90 \mathrm{f:} \mathrm{il.} \mathrm{(color)} \mathrm{;} 30 \mathrm{~cm}$

Tese (doutorado) - Pontifícia Universidade Católica do Rio de Janeiro, Departamento de Engenharia Mecânica.

Inclui referências bibliográficas.

1. Engenharia Mecânica - Tese. 2. PDF Presumida; Spray Diesel; Flamelet; Cinética Química Tabulada; Motor Diesel. I. Braga, Sérgio Leal. II. Dourado, Wladimyr Mattos da Costa. III. Pontifícia Universidade Católica do Rio de Janeiro. Departamento de Engenharia Mecânica. IV. Título. 
Dedico este trabalho aos meu pais, Antonio e Heloisa, que me apoiaram e a minha noiva Gerusa pela compreensão e incentivo. 


\section{Agradecimentos}

A Deus, que me concedeu força, sabedoria e sustento para a realização desse trabalho.

Ao meus orientadores Professor Sérgio Leal Braga e Professor Wladimyr Mattos da Costa Dourado pela confiança e parceria e ajuda em momentos difíceis durante a realização dessa tese.

A PUC - Rio e a CAPES, pelo suporte financeiro e auxílios concedidos para o desenvolvimento.

Ao INMETRO, Dra. Maria Helena Farias e Dr. Renan Teixeira pelo auxílio na utilização de computadores para a geração de resultados.

Ao IAE por pelo suporte e a utilização de suas instalações.

Aos meus amigos do INPE Bruno Trevisan, Guilherme Sempionato, Danilo Oliveira e Rafael Siqueira pela amizade, apoio e compressão. 


\section{Resumo}

Souza, Oberdan Miguel Rodrigues de; Braga, Sérgio Leal; Dourado, Wladimyr Mattos da Costa. Modelo de PDF Presumida com Cinética Química Tabulada Aplicada para a Combustão em sprays. Rio de Janeiro, 2016. 90p. Tese de Doutorado - Departamento de Engenharia Mecânica, Pontifícia Universidade Católica do Rio de Janeiro.

Neste trabalho, foi desenvolvida uma modificação do modelo para simulação de sprays Diesel com o método de PDF presumida e cinética química tabulada. Através do acoplamento entre a parte química e a parte turbulenta, avaliou-se os efeitos do spray com a metodologia flamelet. Onde o conceito flamelet trata a chama difusiva e transiente como um conjunto de chamas unidimensionais, utilizando o modelo de PDF presumida para a avaliação dos valores turbulentos. A validação do modelo foi realizada com dados experimentais do laboratório Sandia, em uma câmara a volume constante. A validação e a aplicação do modelo foram conduzidas em diferentes tipos de ensaios experimentais: avaliação e comparação para diferentes modelos de cinética química do n-heptano, validação do método para o modelo de turbulência $k-\epsilon$ na câmara de volume constante do Sandia para o n-heptano não reativo, validação e comparação do modelo para o spray reativo e aplicação de modelo para o estudo comprimento do ancoramento de chama e para o tempo de atraso de ignição do n-heptano para diferentes temperaturas ambientes. Em geral,a modelagem proposta tem demonstrado excelente capacidade de previsão para a combustão com spray Diesel numa vasta gama de aplicações e é um candidato altamente promissor para outras aplicações em motores Diesel.

\section{Palavras-chave}

PDF Presumida; Spray Diesel; Flamelet; Cinética Química Tabulada; Motor Diesel 


\section{Abstract}

Souza, Oberdan Miguel Rodrigues de; Braga, Sérgio Leal(Advisor); Dourado, Wladimyr Mattos da Costa (Co-advisor). Presumed PDF Model with Tabulated Chemical Kinetic applied for Spray Combustion. Rio de Janeiro, 2016. 90p. Thesis - Departamento de Engenharia Mecânica, Pontifícia Universidade Católica do Rio de Janeiro.

In this work, a modification of the model for the simulation of diesel sprays with the presumed PDF method and tabulated chemical kinetics was developed. Through the coupling between the chemical part and the turbulent part, the effects of the spray were evaluated for the flamelet methodology. Where the textit flamelet concept treats the diffusive and transient flame as a set of one-dimensional flames, using the presumed PDF model for the evaluation of turbulent values. The validation of the model was performed with experimental data from the Sandia laboratory, in a chamber at constant volume. The validation and application of the model were conducted in different types of experimental trials: evaluation and comparison for different chemical kinetics models of n-heptane, validation of the method for the turbulence model $k-\epsilon$ in the constant volume chamber of the Sandia for non-reactive n-heptane, validation and comparison of the model for the reactive spray and model application for the study of the flame anchoring length and for the ignition delay time of n-heptane at different ambient temperatures. In general, the proposed modeling has demonstrated excellent predictive capacity for diesel spray combustion in a wide range of applications and is a highly promising candidate for other applications in diesel engines.

\section{Keywords}

Presumed PDF; Diesel Spray; Flamelet; Tabulated Chemistry Kinetics; Diesel Engine 


\section{Sumário}

1 Introdução $\quad 17$

1.1 Objetivo 20

2 Revisão Bibliográfica $\quad 21$

2.1 Modelagem Flamelet Laminar estacionária e transiente para a combustão não-pré-misturada turbulenta $\quad 21$

2.2 Simulação computacional de sprays Diesel 24

2.3 Softwares disponíveis para a simulação do spray Diesel 26

2.3.1 FlameMaster 26

$\begin{array}{ll}\text { 2.3.2 OpenFoam } & 27\end{array}$

2.4 Descrição Experimental 28

3 Fundamentos de Spray Líquido $\quad 31$

3.1 Regimes do Spray 31

3.2 Quebra de Jatos 32

3.2.1 Quebra de Jatos Primários $\quad 32$

3.2.2 Quebra de Jatos Secundários 34

3.3 Fundamentos da Combustão Diesel 36

$4 \quad$ Modelagem do Spray Diesel $\quad 39$

4.1 Fase Gasosa 39

4.1.1 Equação de Continuidade 39

4.1.2 Equação de Quantidade de Movimento 39

4.1.3 Equação de Energia 40

4.1.4 Modelagem da Turbulência 40

4.1.5 Modelagem Flamelet 41

4.1.6 Chamas difusivas no espaço da fração de mistura 44

$4.2 \beta$-PDF presumida $\quad 45$

4.3 Modelos de spray 46

4.3.1 Características da Injeção 46

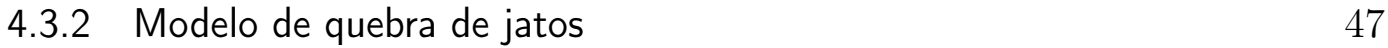

4.3.3 Modelo de Arraste $\quad 50$

4.3.4 Modelo de Evaporação $\quad 51$

4.3.5 Modelo de Transferência de Energia 51

5 Metodologia $\quad 53$

5.1 Modelo PaSR 53

5.2 Modelo Flamelet 55

5.3 Condições de Contorno e Propriedades Físicas 59

5.4 Volumes Finitos e Algoritmos de solução 60

5.4.1 Esquemas de discretização $\quad 62$

5.5 Configuração da Malha 64 
6 Resultados $\quad \mathbf{6 5}$

6.1 Avaliação do Mecanismo de Cinética Química Através do Contrafluxo 66

$\begin{array}{lll}6.2 \text { Validação para o spray não reativo } & 69\end{array}$

6.2.1 Verificação das constantes do modelo de turbulência do modelo $k-\epsilon \quad 69$

$\begin{array}{lll}6.2 .2 & \text { Teste de malha } & 72\end{array}$

6.2.3 Variação do número de Courant 73

6.2.4 Comparação entre sprayFoam e flameletsprayFoam 74

6.3 Validação para o escoamento reativo 75

6.3.1 Comparação entre sprayFoam e flameletsprayFoam 75

$\begin{array}{lll}\text { 6.3.2 Atraso de Ignição } & 78\end{array}$

6.3.3 Comprimento de ancoramento da chama-CAC 80

7 Conclusões e Recomendações $\quad \mathbf{8 2}$

7.1 Recomendações Finais para Trabalhos Futuros 83

$\begin{array}{ll}\text { Referências Bibliográficas } & 84\end{array}$ 


\section{Lista de figuras}

2.1 Estrutura do OpenFoam [1]. 27

2.2 Esquema da implementação do flameletFoam [2] 28

2.3 Esquema do corte transversal do SNL [3] 30

2.4 Simulação de combustão para o experimento SNL, com as seguintes condições: temperatura ambiente $T_{a}=1000 \mathrm{~K}$, densidade ambiente $\rho_{a}=14.8 \mathrm{~kg} / \mathrm{m}^{3}$, fração molar de oxigênio de $21 \% \mathrm{O}_{2}$ [3]. 30

3.1 Estrutura do spray Diesel [4] 32

3.2 Diagrama de Ohnesorge (adaptado de [5]) 33

3.3 Esquema da ruptura de jatos e seus respectivos regimes [6] 34

3.4 Esquema dos diferentes processos de quebra de jato 36

3.5 Esquema da sequência temporal da evolução da combustão do spray Diesel para uma queima controlada (reproduzida e adaptada a partir de [7] 37

4.1 Configuração contra-corrente

4.2 Taxa de injeção para o experimento SNL [3], onde a temperatura ambiente $T_{a}=1000 \mathrm{~K}$, densidade ambiente $\rho_{a}=14.8 \mathrm{~kg} / \mathrm{m}^{3} \mathrm{e}$ fração molar de oxigênio de $21 \% O_{2}$ [3]

4.3 Esquema do modelo KH-RT de quebra de gotas [4] 50

5.1 Esquema de construção das bibliotecas flamelet 56

5.2 Curvas de perfis de temperatura em função da fração de mistura para $T_{a}=1000 \mathrm{~K}, T_{f}=373 \mathrm{~K} . \quad 57$

5.3 Curvas de fração de massa dos reagentes em função da fração de mistura para $T_{a}=1000 \mathrm{~K}, T_{f}=373 \mathrm{~K}$ e e $21 O_{2} \%$. 57

5.4 Curva-S para $T_{a}=1000 K, T_{f}=373 K$

5.5 Geometria da câmara de combustão 64

5.6 Seção transversal do domínio de malha 64

6.1 Configuração do Contrafluxo [8] 65

6.2 Evolução temporal da Temperatura para diversos valores de $\chi$ para a cinética química com 43 espécies [9] 66

6.3 Evolução temporal da Temperatura para diversos valores de $\chi_{s t}$ para a cinética química com 68 espécies [9] 67

6.4 Evolução temporal da Temperatura para diversos valores de $\chi_{s t}$ para a cinética química com 188 espécies [9] 68

6.5 Curva-S para diversos mecanismos de cinética química 68

6.6 Evolução da fase líquida e da fase vapor comparando com dados experimentais [3] para diferentes valores de constantes de turbulência do modelo $k-\epsilon$

6.7 Evolução da fração de mistura comparando com dados experimentais [3] para diferentes valores de constantes de turbulência do modelo $k-\epsilon$ a $20 \mathrm{~mm}$ do ponto de injeção em $t=0,7 \mathrm{~ms}$ 
6.8 Evolução da fração de mistura comparando com dados experimentais [3] para diferentes valores de constantes de turbulência do modelo $k-\epsilon$ a $20 \mathrm{~mm}$ do ponto de injeção em $t=1,15 \mathrm{~ms}$

6.9 Evolução da fração de mistura comparando com dados experimentais [3] para diferentes valores de constantes de turbulência do modelo $k-\epsilon$ a $40 \mathrm{~mm}$ do ponto de injeção em $t=1,15 \mathrm{~ms}$

6.10 Convergência de malha variando o número de pontos e comparando com dados experimentais [3] para a fase líquida e fase vapor

6.11 Convergência de malha variando o número de pontos e comparando com dados experimentais [3] para a fase líquida e fase vapor

6.12 Evolução da fase líquida e da fase vapor comparando com dados experimentais [3] para diferentes valores do número de Courant

6.13 Evolução da fase líquida e da fase vapor comparando sprayFoam e flameletsprayFoam

6.14 Evolução da fase líquida e da fase vapor comparando o tempo computacional entre o sprayFoam e flameletsprayFoam

6.15 Tempo de execução para sprayFoam e flameletsprayFoam com $T_{a}=1000 \mathrm{~K}, T_{f}=373 \mathrm{~K}$ e $21 \mathrm{O}_{2} \%$.

6.16 Spray Experimental(topo), flameletsprayFoam(meio) e sprayFoam(baixo) no instante de $1 \mathrm{~ms} T_{a}=1000 \mathrm{~K}, T_{f}=373 \mathrm{~K} \mathrm{e}$ $21 \mathrm{O}_{2} \%$, com a marcação (pontilhado) a $54 \mathrm{~mm}$ do injetor.

6.17 Spray Experimental(topo), flameletsprayFoam(meio) e sprayFoam(baixo) no instante de $1,5 \mathrm{~ms} T_{a}=1000 \mathrm{~K}, T_{f}=373 \mathrm{~K} \mathrm{e}$ $21 \mathrm{O}_{2} \%$, com a marcação (pontilhado) a $69 \mathrm{~mm}$ do injetor.

6.18 Spray Experimental(topo), flameletsprayFoam(meio) e sprayFoam(baixo) no instante de $2 \mathrm{~ms} T_{a}=1000 \mathrm{~K}, T_{f}=373 \mathrm{~K} \mathrm{e}$ $21 O_{2} \%$, com a marcação (pontilhado) a $80 \mathrm{~mm}$ do injetor.

6.19 Atraso de ignição para a variação da temperatura ambiente

6.20 comprimento de ancoramento da chama para a variação da temperatura ambiente 


\section{Lista de tabelas}

2.1 Modelos de Combustão Turbulenta, adaptado de [10] 22

3.1 Tabela de valores do número de Weber para diferentes regimes de quebra de gota 34

3.2 Tabela de valores do número de Weber para diferentes processos de quebra de gota. 35

4.1 Tabela com as constantes do modelo KHRT 50

5.1 Tabela de condições iniciais e condições de contorno para o sprayFoam 59

5.2 Tabela de condições iniciais e condições de contorno para o flameletsprayFoam

5.3 Tabela com os Esquemas de discretização para o sprayFoam e flameletsprayFoam

6.1 Tabela com os casos e condições experimentais utilizados para a validação

6.2 Constantes empíricas do modelo de turbulência $k-\epsilon$ 


\section{Lista de símbolos}

\section{Símbolos Romanos}

$a_{s} \quad$ Taxa de Estiramento

$B_{0} \quad$ Constante

c Concentração do reator para uma determinada zona

C Constante ajustada Experimentalmente

Co Número de Courant

$C_{p} \quad$ Calor específico

CAC Comprimento de Ancoramento de Chama

CMC Conditional Moment Closure

$C_{a} \quad$ Coeficiente de Contração

$C_{d} \quad$ Coeficiente de Descarga

$C_{v} \quad$ coeficiente de Velocidade

CSEM Conserved Scalar Equilibrium Model

CSP Computational Singular Perturbations

d Diâmetro das Gotas

D Coeficiente de Difusão

DFC Dinâmica dos Fluidos Computacionais

DIC Diagonal incomplete Cholesky

DILU Diagonal Incomplete LU

EBU Eddy Break-Up

ECN Engine Combustion Network

EDM Eddy Dissipation Model

EPFM Eulerian Particle Flamelet Model

$f_{j}^{s} \quad$ Taxa de Momento Devido a Interação Entre a Fase Líquida e Gasosa

$h \quad$ Entalpia

HCCI Homogeneous Charge Compression Ignition

ILDM Intrinsic Low-Dimensional Manifold

$j_{i}^{q} \quad$ Difusividade Térmica do Fluido

$k \quad$ Energia Cinética Turbulenta

$k^{*} \quad$ Fração de Massa da Mistura que Reage

$K_{g} \quad$ Coeficiente de Transferência de Massa

KH Kelvin-Helmholtz

$L_{b u} \quad$ Comprimento de Ruptura

LFM Lagrangian Flamelet Model 


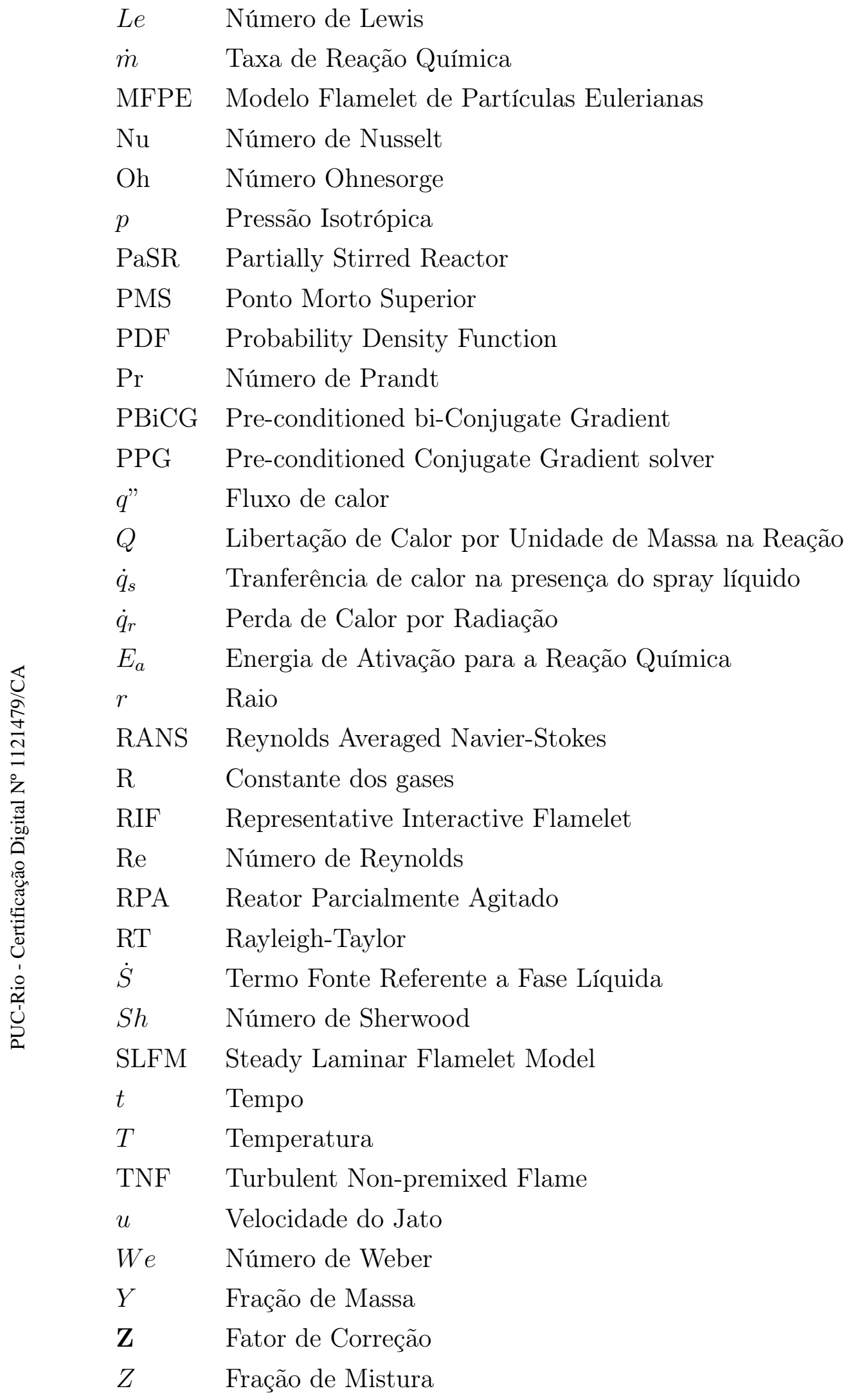

\section{Símbolos Gregos}




$\begin{array}{ll}\alpha & \text { Ângulo da Pendente de Subida } \\ \chi & \text { Taxa de Dissipação Escalar } \\ \delta_{i j} & \text { Delta de Kronecker } \\ \epsilon & \text { Dissipação Turbulenta } \\ \rho & \text { Densidade } \\ \mu & \text { Viscosidade Dinâmica } \\ \Lambda & \text { Comprimento de Onda } \\ \Omega & \text { Taxa de Crescimento } \\ \sigma & \text { Tensão superficial } \\ \tau & \text { Tensor Simétrico } \\ \dot{\omega} & \text { Taxa de Reação }\end{array}$

Sub-índice

a Ambiente

C Combustível

eff Efetiva

$i$ Direção Espacial Genérica

inj Injeção

j Direção Espacial Genérica

$l \quad$ Propriedade do Líquido

$O \quad$ Oxidante

$P \quad$ Produto

ref Referência

st Estequiométrico

$t \quad$ Turbulento 


\section{Introdução}

Nas últimas décadas, aumentou-se a demanda em pesquisas automotivas, principalmente referentes a motores Diesel, visando principalmente a redução de emissões decorrente da combustão. O sucesso do motor Diesel se deve à sua alta eficiência energética, confiabilidade, durabilidade e baixo custo de produção. Infelizmente a combustão Diesel é afetada por significativas emissões que levam a formação de fuligem e óxidos de nitrogênio. Recentemente com as exigências de legislações mais rigorosas para emissões de poluentes, surgiu a necessidade de uma compreensão mais profunda dos fenômenos de combustão com o objetivo de desenvolver ferramentas que auxiliem na redução dessas emissões.

Assim, pesquisas na área de combustão Diesel seguem duas vertentes: pesquisas experimentais e numéricas, as quais devem sempre ser desenvolvidas em paralelo. O foco principal desse trabalho é a pesquisa numérica. Pesquisas em Dinâmica dos Fluidos Computacionais (DFC) fornecem um apoio para ampliar o conhecimento do fenômeno físico auxiliando no desenvolvimento industrial e metodológico. Estudos numéricos favorece uma compreensão dos processos físicos, especialmente aqueles que são de difíceis medições ou que não possuem um processo de medição eficaz.

A modelagem da combustão turbulenta é uma tarefa particularmente difícil devido ao número de reações químicas que interagem com a difusão e o movimento turbulento. A turbulência envolve uma grande variedade de escalas de comprimento, tempo e velocidade dos menores vórtices, que são muito menores do que as escalas dos maiores vórtices e esta diferença cresce com o aumento do número de Reynolds.

O fenômeno da combustão é governada pelas equações conservação de massa,quantidade de movimento, energia e de espécies químicas, resultando em um grande conjunto de equações diferenciais parciais. As equações de conservação podem ser discretizadas utilizando diferentes técnicas como volumes finitos, diferenças finitas e elementos espectrais. A modelagem do escoamento turbulento está associada a dificuldade adicional na qual a escala de menor comprimento é descrita por Kolmogorov como a escala proporcional ao número 
de Reynolds $R e^{-3 / 4}$. Tipicamente, o escoamento em motores Diesel ocorre a altos números de Reynolds com a presença de escalas de comprimento muito pequenas, levando a necessidade de um número de pontos da malha muito elevado para a resolução completa do problema [11]. Consequentemente, para o estudo de motores Diesel, a resolução de todas as escalas turbulentas é inviável, devido ao limite computacional para a resolução dessas escalas. A impossibilidade de resolver todas as escalas requer a utilização um modelo de turbulência.

Os modelos de turbulência baseados nas equações de Navier Stokes médias no tempo, RANS reduzem drasticamente o tempo de execução. Com a abordagem RANS une-se os valores médios do conjunto das propriedades instantâneas ao longo do escoamento, fazendo com que o modelo tenha um custo reduzido. Isso faz com que o RANS seja um candidato ideal para simulações com um elevado número de Reynolds podendo ser utilizados pela indústria para produzir soluções mais rápidas [12]. Assim, o requisito de refinamento da malha em RANS é massivamente reduzida.

A utilização de modelos químicos para combustíveis Diesel convencionais, derivados do petróleo, é altamente complexo, pois os combustíveis contém centenas a milhares de compostos. Modelos que consideram todos esses componentes atualmente são computacionalmente inviáveis. Assim, o combustível real é modelado com uma mistura de combustíveis simplificados consistindo de um número reduzido de componentes puros correspondentes a características físicas do combustível alvo.

Para o Diesel derivado do petróleo, cinco principais componentes são identificados: n-alcanos, iso-alcanos, cicloalcanos e aromáticos [13]. Para hidrocarbonetos superiores (por exemplo n-heptano ou n-dodecano), até mesmo mecanismos detalhados [14] de um único componente ainda são inviáveis para aplicações em CFD. Estes modelos são geralmente empregadas para configurações de reatores perfeitamente agitados.

Apesar de existirem vários hidrocarbonetos substitutos do Diesel, o nheptano é o mais utilizado devido ao seu índice de cetano semelhante ao óleo Diesel, mas também por causa da grande disponibilidade de mecanismos de redução compactos na faixa de 30-60 espécies. Note-se que o mecanismo detalhado LLNL n-heptano [15] tem 561 especies e 2539 reações. O modelo ERCv2 [16] desenvolvido na Universidade de Wisconsin com uma ampla aplicação para simulações de motor utiliza um mecanismo com 29 espécies e 52 reações e foi inicialmente validado para a combustão HCCI. O mecanismo desenvolvido por Liu et al.[9] tem sido aplicado com sucesso para sprays Diesel a volume constante [3], assim como em motores a diesel. Outro mecanismo utilizado em simulações Diesel é o mecanismo de Golovichev et al. [17] aplicado 
a sprays.

A taxa de reação química abrange uma ampla gama de escalas de tempo e,neste caso, a química não pode ser tratada em separado da turbulência. Aqui, a noção de interação entre a turbulência e a química é introduzida e está geralmente relacionada com o termo fonte da química. Nas últimas décadas, este foi um dos principais desafios na modelagem de combustão turbulenta [18]. A dificuldade inerente é que as reações químicas ocorrem no nível molecular, adicionando um termo de origem química, é fortemente não linear obedecendo a uma expressão de Arrhenius, com dependência exponencial da temperatura. Uma vez que, na modelagem em RANS nem todas as escalas espaciais são resolvidas, algumas flutuações ainda estão presentes. Assim, a avaliação da taxa de reação média utilizando termos médios pode levar a erros consideráveis [10]. Isto coloca um enorme desafio e diferentes estratégias de modelagem.

Para o estudo do processo de auto-ignição em motores diesel, a abordagem mais utilizada no passado foi para resolver as equações de transporte usando termos de origem química com expressões semi-empíricas de Arrhenius [19], mas negligenciando completamente as flutuações turbulentas. Uma justificativa para uma ampla adoção do "modelo Shell"era que a química da auto-ignição é lenta em relação à escala de tempo turbulento.

Diferentes abordagens têm sido aplicadas para a simulação da combustão Diesel, sendo que as mais promissoras baseiam-se no conceito flamelet, onde trata-se a chama difusiva e transiente como um conjunto de chamas unidimensionais. Com o desenvolvimento do modelo flamelet na década de 90, teorias de combustão turbulentas mais avançadas com diferentes estratégias de interação entre a turbulência e a química começaram a aparecer em CFD para motor Diesel. Estas incluem, por exemplo, reator perfeitamente agitado, reator parcialmente agitado (RPA) [17], modelos Flamelet com variáveis de progresso [20], flamelet com transporte de PDF [21] e Conditional Moment Closure(CMC)[22].

Uma versão estendida do modelo perfeitamente agitado é o modelo Chalmers PaSR que se baseia na ideia de que cada célula computacional pode ser dividida em uma parte reagente e uma parte não reagente. A parte de reagente é tratada como um reator perfeitamente agitado e a difusão da submalha com a parte não reativa, devido a micro-mistura, é aproximada com a ajuda de um micro tempo de mistura, tipicamente utilizada em métodos PDF. O PaSR, para a interação entre a turbulência e a química, é semi-sofisticado, com uma popularidade considerável para sprays disponível no software aberto no OpenFoam no código sprayFom.

Um dos métodos de interação entre a turbulência e a química mais 
utilizados é o modelo laminar flamelet, originalmente introduzido por Peters como modelo flamelet laminar estacionaria (MFLE) [23] em um contexto RANS e estendido para LES posteriormente [24]. O principal incremento do modelo foi a extensão para flamelet não estacionário conhecido como Flamelet Representativo Iterativo (FRI) [25]. Onde o flamelet é representativo para todo o domínio, mas o campo do escoamento é atualizado a cada passo de tempo e, assim, uma evolução temporal da taxa de dissipação de escalar é considerada. Outros desenvolvimentos se devem ao modelo Modelo Flamelet de Partículas Eulerianas (MFPE) [26], que subdivide o domínio computacional e atribui estes domínios para diferentes flamelets associados com marcadores eulerianos.

\section{1}

\section{Objetivo}

O objetivo específico da tese é :

1. Construção, validação e adaptação do modelo de PDF presumida para simulação de sprays Diesel utilizando a cinética química reduzida do nHeptano.

2. Comparação do modelo com dados experimentais para a penetrabilidade das fases líquidas e vapor no modelo de turbulência RANS $k-\epsilon$. Avaliando também, a influência radial da fração de mistura para o mesmo modelo de turbulência.

3. Estudar os efeitos do atraso de ignição e do comprimento de ancoramento de chama (CAC) sobre a combustão do spray Diesel na cinética química reduzida do n-heptano.

A fim de atingir os objetivos desta pesquisa as seguintes sub-tarefas foram estabelecidas:

1. Reescrever as equações de governo para utilizar a PDF presumida com sprays;

2. Modificação e acoplamento das bibliotecas lagrangianas e eulerianas;

3. Geração das tabelas flamelets usando o código FlameMaster. 


\section{2 Revisão Bibliográfica}

Este capítulo fará uma breve revisão bibliográfica para a modelagem da combustão não-pré-misturada turbulenta aplicada a chamas difusivas e, em específico, para sprays.

\section{1}

\section{Modelagem Flamelet Laminar estacionária e transiente para a combus- tão não-pré-misturada turbulenta}

A modelagem de chamas não pré-misturadas turbulentas pode ser subdividida em dois grupos em termos de modelagem química. Os dois principais modelos químicos utilizam processos com taxa de reação química finita e a taxa de reação química infinita. O Modelo de Equilíbrio do Escalar Conservado (em inglês, Conserved Scalar Equilibrium Model(CSEM)) é o modelo de combustão mais popularmente usado com a reação química infinitamente rápida para as chamas não pré-misturadas. O modelo Bray-Musso-Libby [18, 27] é utilizado na categoria pré-misturada para a reação química infinitamente rápida. Os modelos de combustão amplamente utilizados são baseados na taxa de reação química finita com modelagem flamelet. A Tab. 2.1 mostra um resumo dos principais modelos combustão. CSEM é a combinação de modelo de equilíbrio com a abordagem PDF presumida com a taxa de reação química infinitamente rápida para a combustão não pré-misturada. Este modelo químico é o mais simples tendo sido utilizado no passado, mas não é capaz de prever as emissões corretamente. Nos modelos de taxa de reação química finita, o PDF é o modelo mais avançado e usado em ambos os modos pré-misturados e não pré-misturados. No entanto, a grande desvantagem reside no tempo de cálculo necessário, uma vez que envolve um elevado número de mecanismos de reação químicas na sua solução. O Fechamento de Momento Condicional (em inglês, Conditional Moment Closure(CMC)) é o modelo flamelet para a combustão não pré-misturada e tem provado ser o modelo mais utilizado em pesquisas, mas o modelo CMC não é recomendado para aplicações na indústria devido ao elevado tempo computacional necessário para o calculo químico. O modelo flamelet inclui uma taxa de reação química detalhada e permite a separação 
numérica dos cálculos de turbulência e de reações químicas. Reduzir o tempo de processamento e possibilitando uma maior precisão nos resultados.

Tabela 2.1: Modelos de Combustão Turbulenta, adaptado de [10]

\begin{tabular}{|c|c|c|}
\cline { 2 - 3 } \multicolumn{1}{c|}{} & $\begin{array}{c}\text { Combustão Pré- } \\
\text { Misturada }\end{array}$ & $\begin{array}{c}\text { Combustão Não- } \\
\text { Pré-Misturada }\end{array}$ \\
\hline $\begin{array}{c}\text { Cinética Química } \\
\text { Infinitamente Rápida }\end{array}$ & $\begin{array}{c}\text { Modelo Bray-Moss-Libby } \\
\text { Modelo Coherent }\end{array}$ & $\begin{array}{c}\text { Modelo de Equilibrio de } \\
\text { Conservação Escalar } \\
\text { (MECE) }\end{array}$ \\
\hline \multirow{4}{*}{$\begin{array}{c}\text { Cinética Química } \\
\text { Finita }\end{array}$} & $\begin{array}{c}\text { Modelo Flamelet Baseado } \\
\text { na Equação-G }\end{array}$ & $\begin{array}{c}\text { Modelo Flamelet Baseado } \\
\text { na Fração de Mistura }\end{array}$ \\
\cline { 2 - 3 } & $\begin{array}{c}\text { Conditional Moment } \\
\text { Closure (CMC) }\end{array}$ \\
\cline { 2 - 3 } & \multicolumn{2}{|c|}{ Modelo de Equação de Transporte de PDF } \\
\cline { 2 - 3 }
\end{tabular}

A pesquisa em combustão não pré-misturada é focada no conceito de difusão, pois este é um parâmetro de controle da velocidade de chama. O princípio flamelet, para a modelagem de chamas difusivas, foi introduzido por Peters [23], conhecido como steady laminar flamelet model (SLFM), ou em português, modelagem flamelet laminar estacionária. A SLFM é baseada no conceito deselvolvido por Williams [28] que define a chama turbulenta difusiva como um conjunto de chamas laminares estacionárias, chamadas flamelets. Assumindo que cada flamelet possui a estrutura de cada chama difusiva que a compõe. A parcela turbulenta é incorporada a esses flamelets laminares através de métodos estatísticos de funções de densidade de probabilidade, ou em inglês, probability density function (PDF). A derivação e a utilização da PDF para descrever processos difusivos foi utilizada a princípio por Curl [29] e modificado por Pope [21] para descrever fenômenos de interações entre partículas.

Liew et al.[30] utilizaram a modelagem flamelet para o jato difusivo turbulento metano/ar, demonstrando que o efeito do estiramento é muito escasso em todo o campo de escoamento. No entanto, o modelo foi bem sucedido na predição da penetração do oxigênio através do local da zona de queima do combustível. Isso leva à conclusão de que as alterações são necessárias no modelo para explicar o processo de pós tratamento flamelet no estudo onde a mistura parcial dos reagentes ocorre. Rogg et al.([31]) estenderam o modelo para ter em conta chamas parcialmente pré-misturadas. Os resultados representaram uma razoável previsão da concentração de $O_{2}$, mas não houve melhora para a previsão da concentração de $C O$, comparados aos dados experimentais.

Peters [23] validou a teoria da existência de flamelets laminares em 
chamas turbulentas de forma sistemática, através de uma abordagem numérica. Além disso, Robert e Moss [32] e Drake [33] realizaram estudos experimentais para verificar a existência de flamelets laminares em chamas difusivas e turbulentas. O parâmetro de referência no alongamento das flamelets é a taxa de dissipação escalar e, todas as propriedades termo-químicas são expressas em função da taxa de dissipação escalar e da distribuição da fração de mistura. A principal vantagem da utilização do modelo flamelet é que efeitos realistas da cinética química podem ser incorporados em chamas turbulentas. O modelo flamelet, é limitado a modelagem de combustão com a química relativamente rápida. Portanto, o modelo mostrou-se incapaz de prever os efeitos de não equilíbrio, como extinção, reignição e processos químicos para a formação de $N O x$. Esta incapacidade de modelo flamelet foi minimizada com a substituição do modelo de PDF, por um modelo baseado na função densidade de probabilidade conjunta (em inglês, joint probability density function (jointPDF)). A avaliação da PDF pode ser simplificada ao introduzir a hipótese de independência estatística dos parâmetros e presumindo a forma da PDF para a fração de mistura, que obedece a uma função $\beta$ e a dissipação escalar, que obedece a uma distribuição log-normal, na maioria dos casos.

Na solução das equações de flamelet, conforme proposto por Peters [10], o termo dependente do tempo na maioria dos modelos SLFM e, resultando nos flamelets laminares estacionárias. Isto envolve a dependência da taxa de dissipação de escalar e da fração mistura estequiométrica. Em geral todas as chamas de combustão turbulenta têm altas flutuações na taxa de dissipação de escalar que precisa ser contabilizadas. Portanto, investigações para incluir o termo não estacionário nas equações flamelet. Haworth et al. [34] foram os primeiros a mostrarem a importância do termo temporal na modelagem flamelet. Dentro de um jato difusivo, modificaram a modelagem flamelet para incluir efeitos de estiramento da chama, comparando com dados experimentais do jato difusivo $\mathrm{CO} / \mathrm{H}_{2} / \mathrm{N}_{2}$. Os efeitos de reignição e extinção da chama foram estudados por Mauss et al. [35], onde um tempo característico lagrangiano foi acrescido ao modelo flamelet.

Pitsch e Peters [36] desenvolveram uma abordagem flamelet nãoestacionária validando com experimentos para uma chama difusiva no jato turbulento, incluindo nos flamelets efeitos da radiação. Nesta abordagem os efeitos transitórios foram introduzidos com o objetivo de retardar o processo de produção de $N O$. Uma comparação qualitativa com os resultados experimentais mostraram que o modelo flamelet tem uma boa concordância com a temperatura e com outras espécies como $O H$, mas não conseguiu reproduzir a formação de $N O x$. Uma observação importante de seu trabalho foi que a 
inserção de um termo fonte de radiação nas equações flamelet estacionárias acarreta na indeterminação do efeito de perda de calor por radiação, que é um fenômeno físico lento. No entanto, quando inserção de um termo fonte de radiação é feito nas equações flamelet não-estacionárias acarreta na melhora dos resultados para a concentração de NO. Pitsch and Steiner [24] estenderam o estudo para o Modelo flamelet Lagrangiano(em inglês, Lagrangian Flamelet Model (LFM)) para contabilizar efeitos de difusão na turbulência estacionária $\mathrm{CH}_{4} / \mathrm{H}_{2} / \mathrm{N}_{2}$ - ar e encontrou uma boa concordância com dados experimentais. Três mecanismos químicos diferentes foram testado e considerado para provar a concordância com os dados experimentais. Os resultados sugerem ainda, que o efeito do diferencial de difusão influenciam até mesmo perto do injetor.

Em vez de reduzir o número de espécies nos mecanismos químicos, a tabulação química mantém os mecanismos detalhados inalterada, mas reduz o número de variáveis independentes a serem resolvidos em simulações de CFD para um número manejável. Portanto, a tabulação química é muito atraente, tanto para sua eficiência computacional quanto para manter uma alta precisão química. A redução de variáveis independentes pode ser conseguida usando, por exemplo, o método computacional de perturbações singulares (em inglês, Computational Singular Perturbations (CSP))[37] e o método Intrinsic LowDimensional Manifold (ILDM))[38]. Estes métodos suprimem estas reações químicas rápidas colocando as espécies envolvidas no estado estacionário. Assim, o sistema depende de um número muito menor de variáveis. Essas variáveis são frequentemente combinações de concentrações de espécies. Bibliotecas multi-dimensionais são utilizadas para armazenar os estados termoquímicos como uma função destas variáveis. Estes métodos são particularmente adequados para os cálculos de cinética química [39]. Infelizmente, estes métodos não incluem quaisquer variáveis de fluxo (por exemplo fluxo de taxa de deformação, a curvatura chama, e taxa de dissipação escalar) na construção das bibliotecas dos estados termoquímicos. Como resultado, eles são limitados quando aplicados a chamas não pré-misturados, onde o fluxo reação local é regida pelo equilíbrio químico e pela difusão.

\section{2}

\section{Simulação computacional de sprays Diesel}

Os processos de ignição e de combustão em motores de combustão interna têm sido modelados de várias formas. Modelos simplificado com um ou dois tempos de combustão, como o modelo de dissipação Eddy [40]( em inglês, Eddy Dissipation Model (EDM)), e as suas variantes, têm sido utilizados em conjunto com modelos de ignição. Nestes métodos, o modelo de ignição atua 
como um interruptor que aciona o modelo de combustão em algum ponto do tempo. Este modelo utiliza uma equação que se origina a partir da modelagem de Livengood e $\mathrm{Wu}$ [41] ou o modelo de oito equações de Halstead et al. [19] (também conhecido como o modelo de ignição "shell"). Esses modelos contêm parâmetros ajustáveis que precisam ser adaptados para o combustível em questão.

Com a introdução do modelo Eddy Break-Up (EBU) por Magnussen e Hjertager [40] foi possível dar um tratamento difusivo turbulento a maioria das simulações de computacionais de combustão em motores. Neste modelo, o sucesso de sua aplicação atribuiu-se, principalmente, à simplicidade do modelo e a falta de outros modelos de difusão de chama. O conceito Reator parcialmente agitado (em inglês, Partially Stirred Reactor(PaSR)) por Karlsson [42] é uma extensão da abordagem EBU. Esse modelo funciona muito bem para a combustão de spray Diesel turbulenta e fornece um tratamento químico complexo para o problema. A grande desvantagem desse modelo é a necessidade de resolução de uma equação diferencial para cada espécie, a cada passo de tempo, o que demanda um alto custo computacional.

Para modelar as propriedades do combustível, deve-se utilizar mecanismos de reação química detalhada. Assim como, o verdadeiro mecanismo de cinética química do diesel é pouco conhecido, os chamados combustíveis de referência (PRF) [15] e substitutos de combustíveis são muitas vezes introduzidas para modelar a ignição.

A aplicação do modelo flamelet para motores de combustão interna e sprays Diesel, foi trabalhada no modelo flamelet Representativo Iterativo (em inglês, Representative Interactive Flamelet (RIF)) desenvolvido por Pitsch et al. [25] e constrói uma biblioteca dinâmica a cada passo de tempo durante a combustão no espaço de reação. Em cada passo de tempo, a taxa de dissipação escalar , para a região de combustão, é determinada com base na média volumétrica sobre estequiometria (média condicional). A equação flamelet é resolvida considerando a taxa de dissipação escalar e o efeito da turbulência na combustão. Este modelo foi aplicado para um n-heptano e verificou-se ser capaz de descrever a auto-ignição, após a neutralização da fase parcialmente pré-misturada, e a transição para a queima difusiva. Neste modelo RIF apenas um flamelet interativo foi considerado, representativo de todo o domínio, e a variação espacial da taxa de dissipação escalar foi ignorada. Barth et al. [26] estenderam o modelo RIF para vários flamelets que representaram a dependência espacial da taxa de dissipação de escalar.

O Modelo Flamelet de Partículas Eulerianas (em inglês, Eulerian Particle Flamelet Model (EPFM)) inclui partículas marcadoras numéricas, onde 
cada uma representa uma história flamelet que é introduzida no campo de escoamento turbulento. Uma equação de conveção-difusão não-estacionária é resolvida no código CFD para cada partícula traçadora, para encontrar a probabilidade de ocorrência local do Flamelet. A solução é então Flamelet ponderada com estas probabilidades locais para obter concentrações escalares. Este modelo foi aplicado a um spray diesel por Barths et al.[26] e Barths et al. [43]. Eles encontraram uma melhoria significativa na previsão de fase parcialmente pré-misturada de queima e formação de poluentes subsequente, $N O_{x}$ e de fuligem. O EPFM também tem sido aplicado 'a combustão não-pré-misturada turbulenta e estacionária numa câmara de combustão de uma turbina a gás por Barth et al.([44]). No modelo de Flamelet Lagrangiano, o tempo Flamelet é calculado por integração do inverso da velocidade na posição radial estequiométrica ao longo da direção do escoamento, o que limita a sua aplicação aos fluxos estritamente parabólicos.

Na literatura, a maioria dos estudos fazem uso de RANS $k-\epsilon$, e são muitas vezes baseadas em malhas axi-simétrica bidimensionais simplificadas ([45, 46]). Simulações de combustão em motores diesel com DNS não são viáveis por causa do alto custo computacional. Mas as simulações em LES de motores a Diesel é uma alternativa atraente em relação a simulações RANS. No entanto, este não é um problema simples para sprays Diesel, tendo em vista o escoamento multifásico e turbulento, sendo tema de diversos estudos.

Neste capítulo, serão apresentados os dois softwares integrantes da simulação do spray diesel. O primeiro é o FlameMaster, utilizado para a construção da biblioteca Flamelet. O segundo é o OpenFoam, que simula o spray propriamente dito.

\section{3}

\section{Softwares disponíveis para a simulação do spray Diesel}

\subsection{1}

\section{FlameMaster}

O software FlameMaster, desenvolvido por Pitsch [25], usa o método de Newton para resolver as equações flamelet, que são não lineares. Como o método de Newton necessita de uma solução inicial para garantir a convergência, o FlameMaster utiliza arquivos de soluções iniciais para cada combustível com condições iniciais distintas.

Além de possuir um solver para simulação de chamas difusivas estacionárias, o FlameMaster também possui um solver para simulação de chamas transientes, importantes para o estudo de parâmetros para a ignição. As so- 
luções químicas geradas com o FlameMaster são tabuladas onde a fração de massa para cada espécie química e a temperatura estão em função da fração de mistura $Z$ e da dissipação escalar $\chi$.

\subsection{2}

\section{OpenFoam}

O nome OpenFoam é um anacrônimo de Open source Field Operation and Manipulation. O software foi desenvolvido em $\mathrm{C}++$ e possui solvers para solução de problemas de mecânica do contínuo, incluindo CFD, com utilitários de pré e pós-processamento, como ilustrato na Fig. 2.1. Uma característica de destaque do OpenFOAM é sua sintaxe para operações com tensores e equações diferenciais parciais, baseados em elementos finitos e volumes finitos, que identificam em sua codificação de forma clara as equações a serem resolvidas [1]. Esta sintaxe, obtida mediante o uso de Programação Orientada a Objetos, que permite aos usuários criar solvers padronizados mais facilmente.

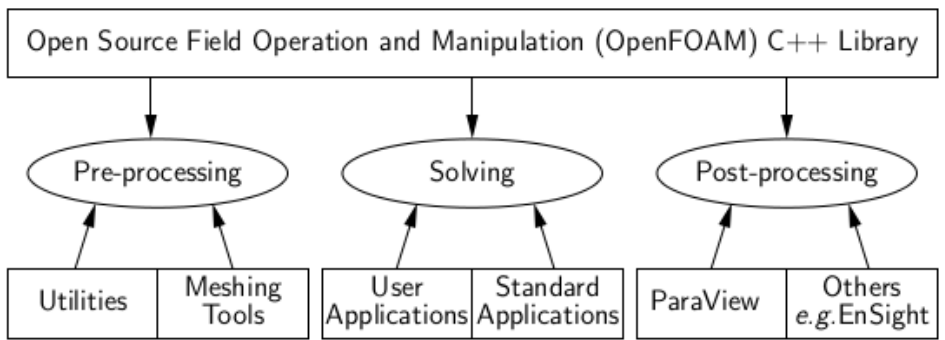

Figura 2.1: Estrutura do OpenFoam [1].

Como o OpenFoam é um software livre, ele permite diversas alterações nas estruturas de suas bibliotecas e dos seus solvers, permitindo assim, a otimização dos mesmos. O solver desenvolvido neste trabalho, o flameletsprayFoam, toma como base o solver sprayFoam integrante do pacote OpenFoam.

O sprayFoam é um solver transiente, com modelo de escoamento turbulento, compressível com o reator químico PasR. Ele pode ser utilizado para simular a combustão turbulenta com mudança de fase, pois possui bibliotecas eulerianas e lagrangianas, que fazem a interação entre a fase contínua e a fase discreta. O sprayFoam basea-se nas bibliotecas Cloud ( collection of Lagrangian particles), classe derivada do basicSprayCloud. Ele ainda possui dois diretórios característicos lagrangian e spray. Esses diretórios contém diferentes tipos de modelos de partículas.

FlameletFoam desenvolvido por H. Müller et al.[2] e é um solver trasiente de chamas não-pré-misturadas turbulentas. As bibliotecas Flamelets utilizadas no FlameletFoam são calculadas a partir do sóftware livre Cantera [47]. 
Uma vez que as soluções das equações Flamelet são conhecidas, para um determinado número de $\chi_{s t}$, os perfis de temperatura e de fração de massa das espécies podem ser tabulados $\left(T\left(Z, \chi_{s t}\right), Y_{k}\left(Z, \chi_{s t}\right)\right)$. A ligação entre as tabelas geradas no Cantera e o OpenFoam é feita através de um utilitário chamado canteraToFoam, onde $P\left(Z, \chi_{s t}\right)$ ver Eq.(4-7) gerados através do Cantera, são utilizados no cálculo de $\widetilde{Y}_{i}$ e $\widetilde{T}$ através da $\beta$-PDF, como descrito na seção anterior e na Fig.2.2.

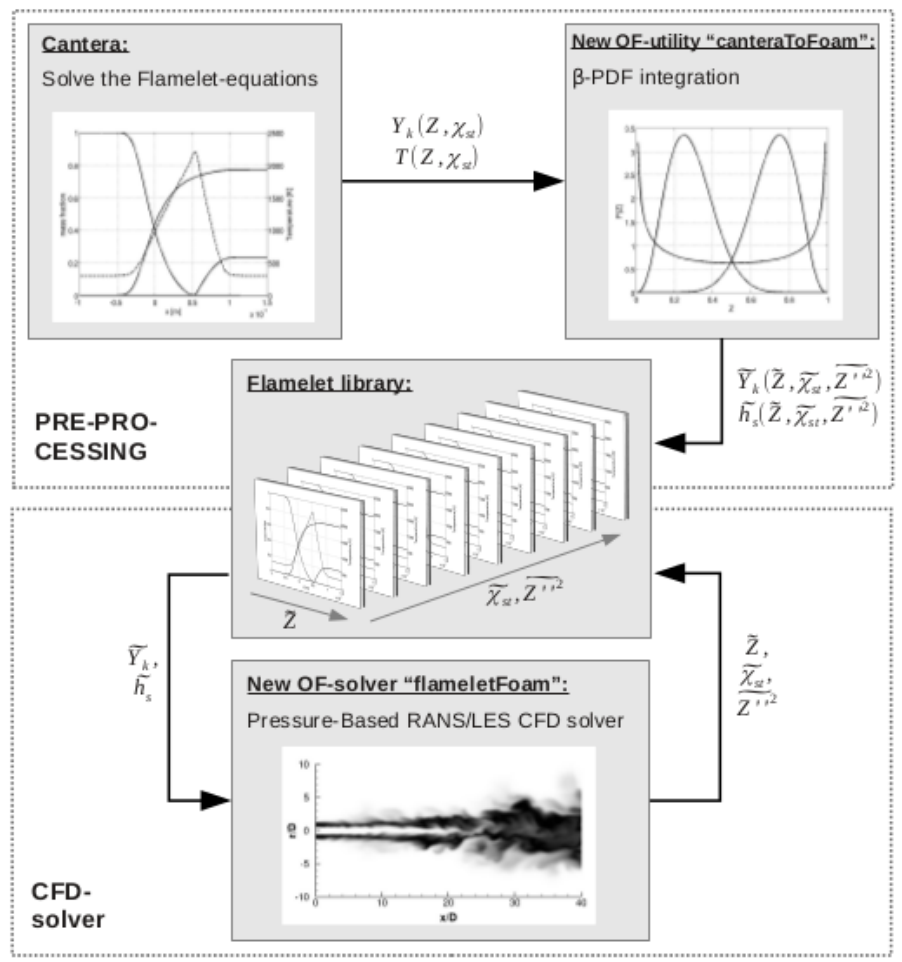

Figura 2.2: Esquema da implementação do flameletFoam [2]

\section{4}

\section{Descrição Experimental}

A Engine Combustion Network (ECN) e a the Turbulent Non-premixed Flame (TNF) é uma rede aberta para a colaboração internacional entre os grupos experimentais e de modelagem. No entanto, enquanto a TNF é focada em configurações de chamas difusivas, a ECN fornece medições experimentais para sprays turbulentos a alta pressão. Os objetivos da ECN [3] são:

- Estabelecer bibliotecas de medições experimentais bem documentadas para o modelo de validação e compreensão da combustão em condições específicas para motores; 
- Fornecer um quadro de comparação colaborativas de medidas e modelos;

- Identificar as prioridades para futuras pesquisas experimentais e computacionais.

A montagem experimental é composta por uma câmara à volume constante opticamente acessível em condições representativas das quiescentes condições de um motor diesel. A forma do recipiente de combustão é cúbica, e tem uma dimensão característica de $108 \mathrm{~mm}$. Cada um dos lados da câmara de combustão tem uma porta circular com um diâmetro de $105 \mathrm{~mm}$. A Fig. (2.3) mostra um esquema de um corte transversal do recipiente de combustão. O injetor de combustível está localizado em um lado da porta usando uma inserção de metal que forma a parede lateral à direita da câmara de combustão. Duas velas de ignição e uma ventoinha de mistura são montadas numa outra inserção de metal que forma a parede superior da câmara. Acesso ótico é fornecido por quatro janelas de safira com aberturas claras de $102 \mathrm{~mm}$ localizadas em outras quatro portas. A ventoinha de mistura montada no centro garante condições ambientes quase uniformes no início da injeção. Válvulas de admissão e de escape, ou instrumentos, tais como transdutores de pressão ou entradas de termopar, podem ser montados nos cantos da câmara de combustão em forma cúbica [3].

Entre os dados experimentais, o Sandia National Laboratories (SNL) realiza experimentos nas seguintes condições:

- As temperaturas dos gases ambientes variando entre $450 K$ e $1300 K$;

- As densidades dos gases ambientes variando entre $3 \mathrm{~kg} / \mathrm{m}^{3}$ e $60 \mathrm{~kg} / \mathrm{m}^{3}$;

- As concentrações molares do oxigênio variando entre $0 \%$ e $21 \%$;

A massa inicial e a composição do gás pré-misturado, juntamente com a pressão instantânea na câmara, determinam a temperatura do gás ambiente, a densidade e a composição no local de injeção 2.4 . 


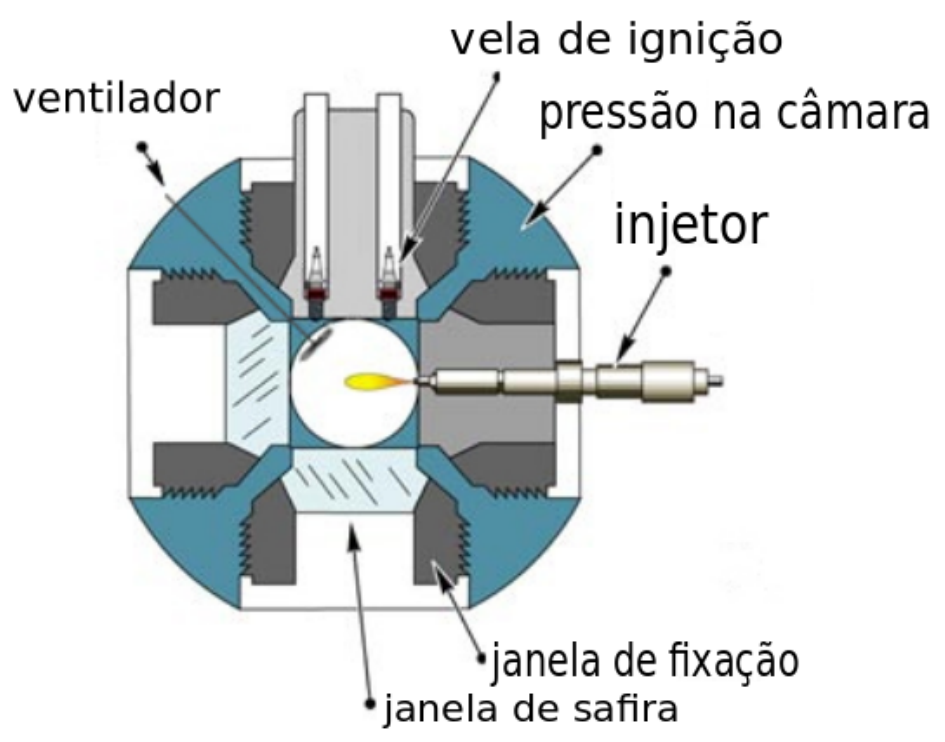

Figura 2.3: Esquema do corte transversal do SNL [3]

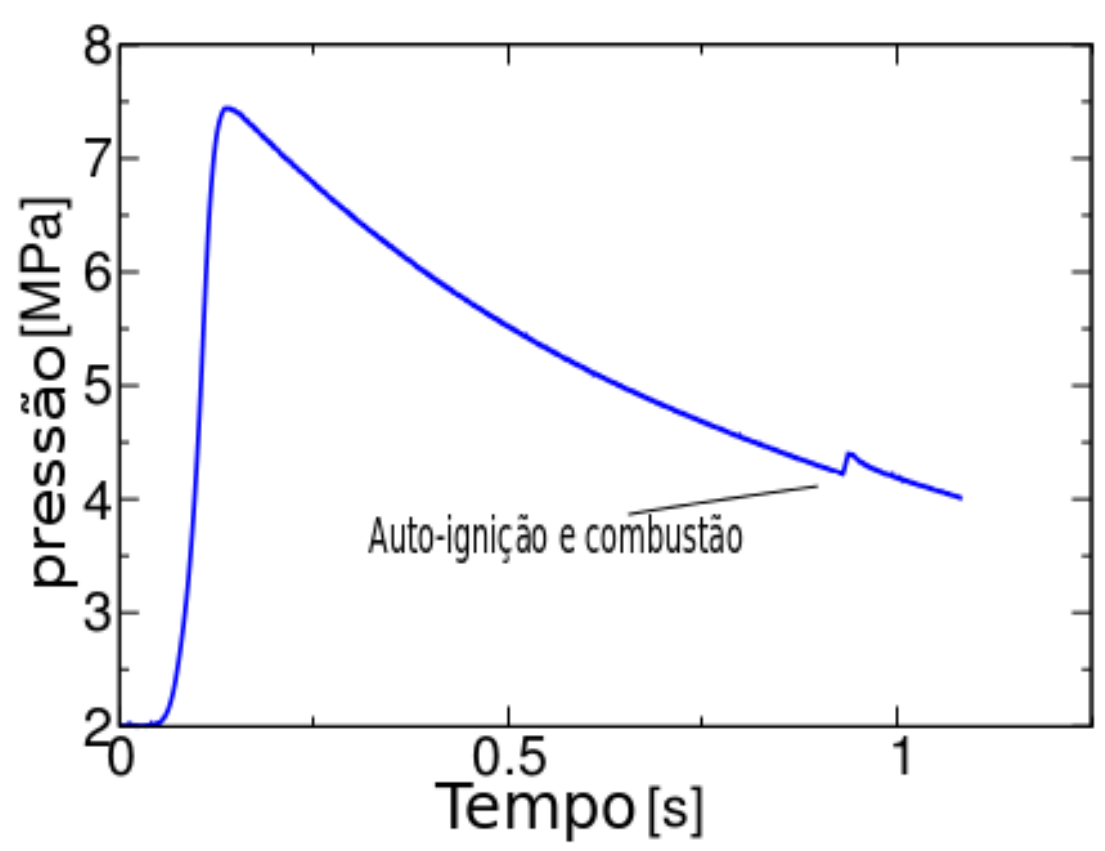

Figura 2.4: Simulação de combustão para o experimento SNL, com as seguintes condições: temperatura ambiente $T_{a}=1000 \mathrm{~K}$, densidade ambiente $\rho_{a}=$ $14.8 \mathrm{~kg} / \mathrm{m}^{3}$, fração molar de oxigênio de $21 \% \mathrm{O}_{2}$ [3]. 


\section{Fundamentos de Spray Líquido}

O processo físico de formação do spray e o processo de modelagem computacional é extremamente complexo. Consequentemente, a modelagem computacional também é altamente complexa. Além disso, a teoria do processo de caracterização e formação do spray líquido é muito ampla e ramificada e a compreensão de alguns dos seus aspectos físicos já é valiosa para a modelagem numérica. Neste capítulo, será apresentado os fundamentos do spray líquido, os regimes do spray, a formação de gotículas e os regimes de rompimento do spray.

\section{1}

\section{Regimes do Spray}

Geralmente os sprays Diesel possuem duas regiões particulares, uma densa e outra diluída, como pode ser visualizado na Fig.??. Isto define a profundidade óptica e a abordagem experimental que pode ser usada para o seu estudo. A região perto da saída do bocal, incluindo o núcleo líquido, é muito densa para ser estudada usando aparatos ópticos convencionais. Assim, muitos estudos relativos a esta região tem sido realizados utilizando técnicas de raios-X [48] ou imagiologia balístico [49]. No entanto, o estudo desta região continua a ser muito difícil e os resultados obtidos são, por vezes controversos [50]. A região diluída é normalmente referida como a área em que o processo de atomização termina. Nesta região, a espessura óptica do spray permite a aplicação de técnicas convencionais [51, 52]. Desta forma, caracteriza-se o spray, na saída do bocal como um núcleo líquido intacto. Alguns diâmetros mais ajusante do bocal, ocorre a formação de grandes gotas com tamanhos comparáveis ao diâmetro do bocal. Em seguida, o rompimento dos ligamentos em gotículas de dimensões menores, na zona de espessura em que o volume e a fração de massa da fase líquida é alta. Mais a jusante, ocorre uma divergência em relação ao ângulo característico do spray, assim surgem diversos regimes após a zona de rompimento [53].

A posição após a qual todas as gotículas líquidas já encontra-se evaporados é chamada de comprimento líquido. A partir de experiências automotivas, verificou-se que esse comprimento é aproximadamente constante depois de um curto tempo de desenvolvimento. A partir desse ponto o combustível evaporado continua a penetrar no gás circundante e é denotado como o comprimento de vapor. Em um intervalo de tempo de injeção Diesel normal (alguns milisse- 
gundos), o comprimento de vapor não atinge um estado estável [54].

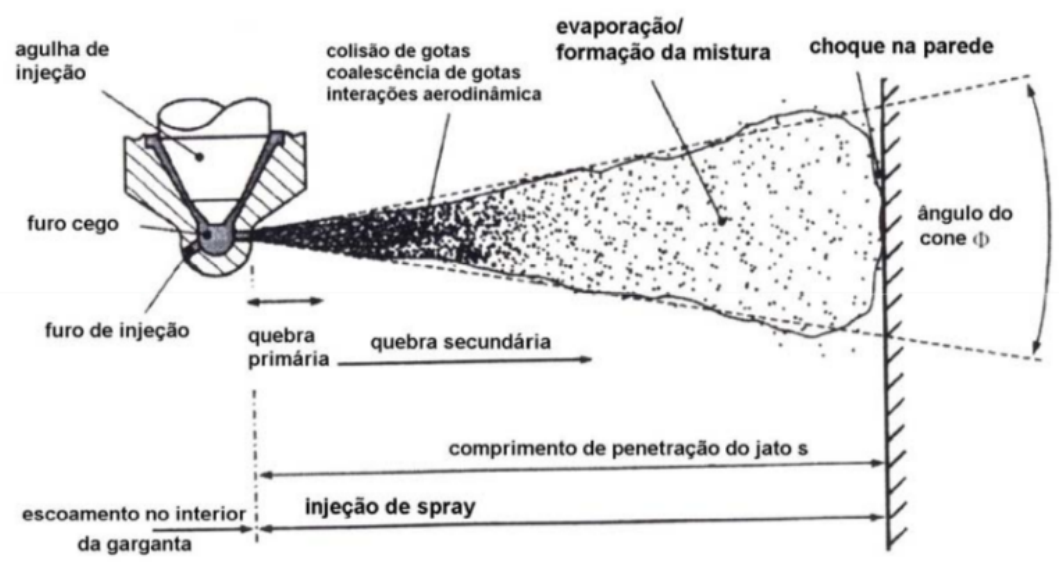

Figura 3.1: Estrutura do spray Diesel [4]

\section{2}

\section{Quebra de Jatos}

A quebra de gotas em sprays se divide em dois processos, o primeiro é a quebra de gotas primárias. Este mecanismo é caracterizado pelo tamanho das gotículas e pela ruptura do jato, que é definida como o comprimento do núcleo líquido intacto. Tanto o comprimento característico e o tamanho de gotas são propriedades dependentes da fase líquida e do gás circundante. Essas propriedades são tão importantes quanto a velocidade relativa entre a fase líquida e do gás circundante.

\subsection{1}

\section{Quebra de Jatos Primários}

O mecanismo de rompimento do jato pode ser dividido em quatro regimes. A fim de fazer uma classificação quantitativa dos regimes, o número Ohnesorge, Oh, que é uma razão entre as forças viscosas e forças de tensão superficial, é introduzido

$$
O h=\frac{\sqrt{W e_{l}}}{R e_{l}}
$$

onde o número de Weber $W e_{l}$ e o número de Reynolds $R e_{l}$ são definidos como

$$
\begin{aligned}
W e_{l} & =\frac{u^{2} D \rho_{l}}{\sigma} e \\
R e_{l} & =\frac{u D \rho_{l}}{\mu_{l}},
\end{aligned}
$$


onde $\rho$ é a densidade, $\sigma$ é a tensão superficial, $\mu$ é a viscosidade dinâmica, $u$ é a velocidade do jato e $D$ é o diâmetro do orifício e o subscrito $l$ refere-se a propriedade do líquido.

Desta forma, todas as propriedades relevantes do líquido são incorporadas de modo que os vários regimes podem ser classificados no espaço $O h$ em função da velocidade do jato, ou, alternativamente, do número de $R e_{l}$, como mostrado na Fig.3.2, chamado de diagrama de Ohnesorge. Nesta figura são indicados os quatro regimes e também as zonas relevantes para aplicações da injeção Diesel.

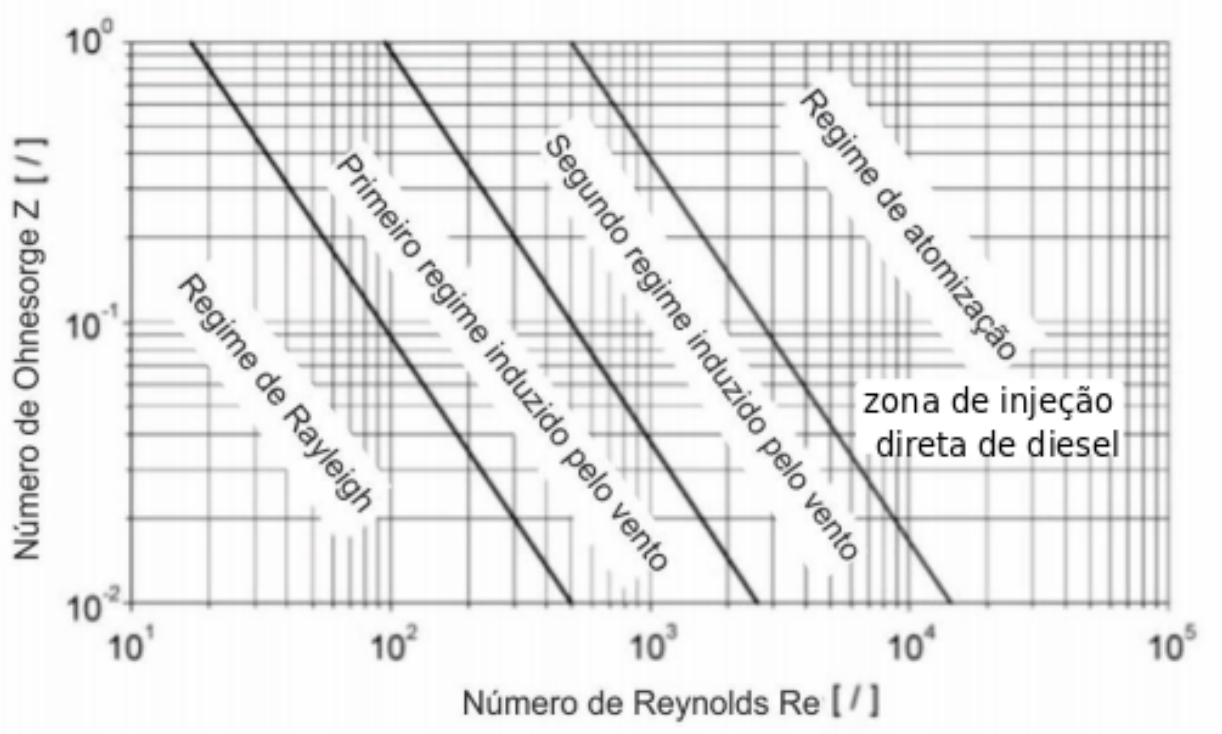

Figura 3.2: Diagrama de Ohnesorge (adaptado de [5])

De acordo com Reitz [55], classificamos a ruptura do jato em quatro regimes:

Rayleigh Causada pelo crescimento de oscilações axissimétricas na superfície do jato, induzidas pela tensão superficial

Primeiro regime induzido pelo vento Amplificação da tensão superficial e das forças de inércia da fase líquida. O efeito da tensão superficial é aumentado pela velocidade relativa entre o jato e o gás ambiente, que produz uma distribuição de pressão estática através do jato, acelerando o processo de ruptura do jato em gotas.

Segundo regime induzido pelo vento As gotas são produzidas pelo crescimento das ondas curtas instáveis na superfície sobre a superfície do jato, causadas pelo movimento relativo entre o jato e o gás ambiente. Este crescimento da onda é contrário à tensão superficial. 
Tabela 3.1: Tabela de valores do número de Weber para diferentes regimes de quebra de gota

\begin{tabular}{|l|l|l|}
\hline Regime & Expressão & Referência \\
\hline Rayleigh & $W e_{g}=1.2+3.41 O h^{0.9}$ & {$[56]$} \\
Primeiro vento induzido & $W e_{g}=13$ & {$[57]$} \\
Segundo vento induzido & $W e_{g}=40.3$ & {$[58]$} \\
Atomozação & $\frac{\rho_{g}}{\rho_{f}}=\frac{\sqrt{C}-1.15}{744}\left(\sqrt{3} / 6\left(1-e^{-10 T a}\right)\right)^{-2}$ & {$[55]$} \\
\hline
\end{tabular}

Atomização O jato rompe totalmente na saída do bocal e as gotas são formadas aleatoriamente.

Esses regimes podem ser classificados segundo a variação do número de Weber, como é mostrado na Tab. (3.2.1).
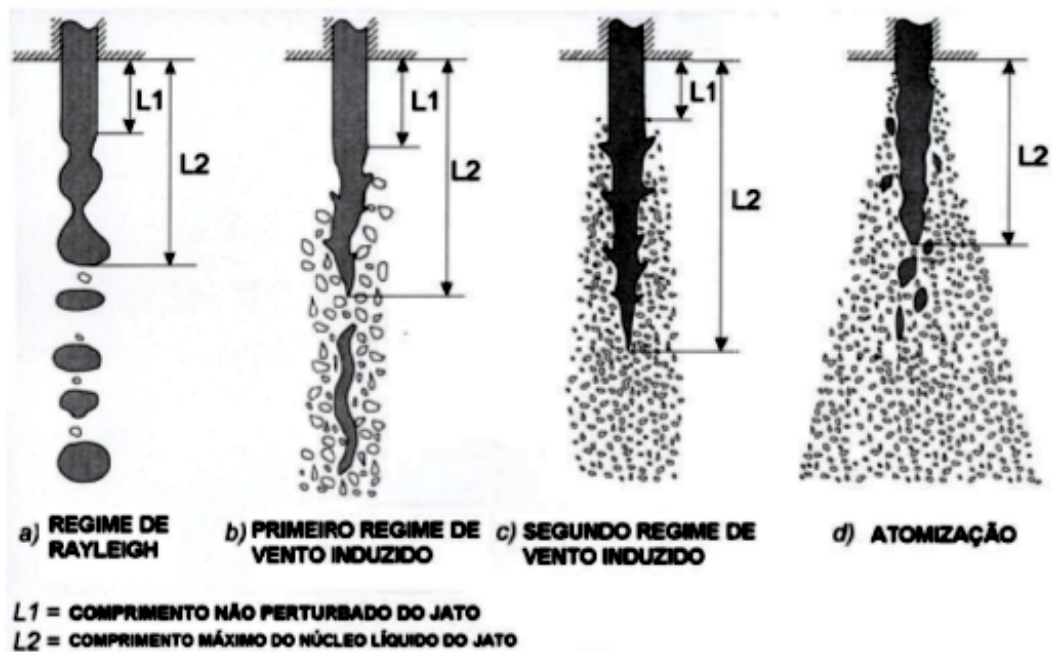

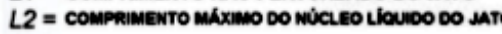

Figura 3.3: Esquema da ruptura de jatos e seus respectivos regimes $[6]$

\section{2 .2}

\section{Quebra de Jatos Secundários}

O mecanismo de separação secundário refere-se à separação de gotículas devido às forças aerodinâmicas, que são induzidas pela velocidade relativa entre as gotas e o gás circundante.

O número adimensional de Weber caracteriza o regime do processo, com a diferença de que o diâmetro do bocal $D$ na Eq.(3-2) é substituído pelo diâmetro das gotículas antes da ruptura $d$

$$
W e_{g}=\frac{u_{r e l}^{2} d \rho_{g}}{\sigma}
$$


Tabela 3.2: Tabela de valores do número de Weber para diferentes processos de quebra de gota.

\begin{tabular}{|l|l|l|}
\hline Regime & Wierzba [59] & Arcoumanis et al [60] \\
\hline Vibracional & $W e_{g} \approx 12$ & $12 \leq W e_{g} \leq 18$ \\
Bolsa & $W e_{g}<20$ & $W e_{g} \leq 45$ \\
Bolsa e pistão & $W e_{g}<50$ & $W e_{g} \leq 350$ \\
Folha e filhetes & $W e_{g}<100$ & $W e_{g} \leq 2670$ \\
Catastrófica & $W e_{g}>100$ & $W e_{g}>2670$ \\
\hline
\end{tabular}

Diminuindo o diâmetro das gotas $d$ aumenta-se a força da tensão superficial $\sigma$. Isto significa que a velocidade relativa de ruptura deve ser mais elevada. De acordo com Wierzba [59], cinco regimes diferentes podem ocorrer e são indicados na Tab. (3.2) e na Fig.3.4 de atomização secundárias. Para os números de Weber menores do que $W e_{g}=12$, as forças aerodinâmicas não são capazes de romper a gota, gerando apenas pequenas deformações na sua forma. No entanto, um pequeno incremento na velocidade relativa pode propiciar o primeiro regime, conhecido como vibração, em que a deformação da superfície cresce progressivamente até provocar a sua divisão. No segundo regime, o que corresponde ao número de Weber entre $12 \leq W e_{g} \leq 20$, o rompimento da gota inicia com uma deformação em forma de bolsa e termina com uma desintegração em pequenas gotículas. O Terceiro regime é semelhante, a única diferença é que a gota se quebra em gotas relativamente grandes. No quarto regime, para números Weber inferiores a $W e_{g}=100$, a gota é continuamente corroída na superfície e termina se desintegrando rapidamente resultando em pequenas gotas. O quinto e último regime, conhecido como rompimento catastrófico, ocorre para o número Weber maior do que $W e_{g}=1000$. A superfície das gotículas é ondulada por ondas de grande amplitude e longos comprimentos de onda que formam grandes fragmentos que, por sua vez dividem-se em partes menores.

Esses regimes também foram estudadas por Arcoumanis et al. [60], que também encontrou cinco regimes, mas não concordou com os limites entre eles, especialmente para números Weber elevados, como mostra a Tab. (3.2).

Perto do bico injetor o número Weber é alto, então a maioria das rupturas ocorrem na saída do bocal. Mais a jusante do bocal o número Weber é menor devido à diâmetros de gotículas menores e a velocidades inferiores. Portanto, a ruptura longe do bocal é muito menor. 


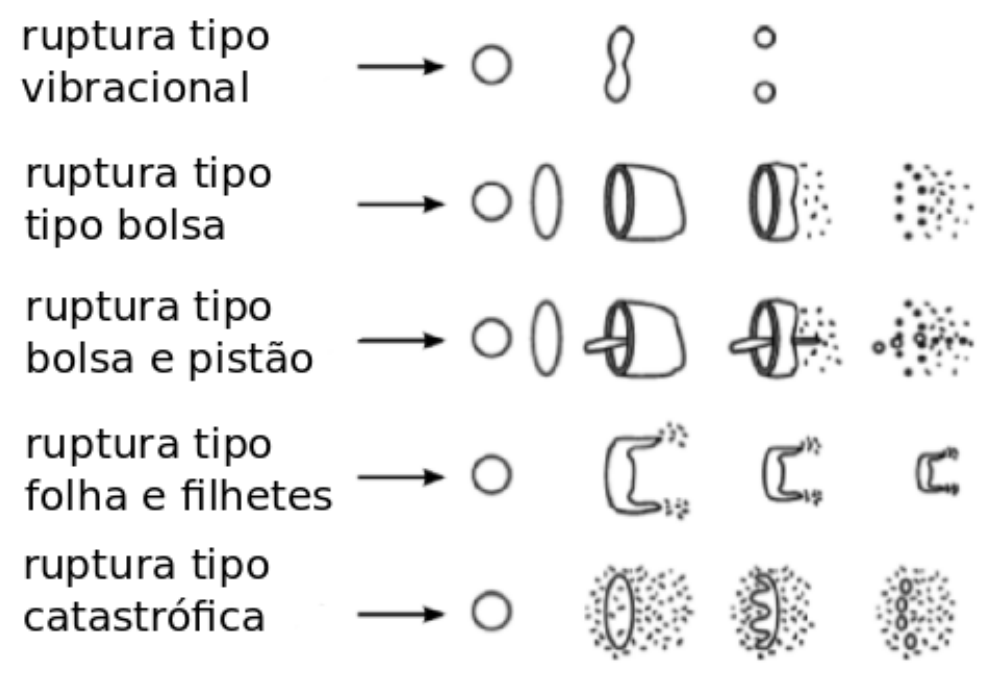

Figura 3.4: Esquema dos diferentes processos de quebra de jato

\section{3}

\section{Fundamentos da Combustão Diesel}

Nos motores Diesel, quando o pistão se aproxima do ponto morto superior (PMS) o combustível é injetado se desintegra e ocorre a mudança de fase para o vapor, iniciando o processo de combustão. A orientação do spray que sai do bico-injetor é fundamental na mistura inicial, podendo ser direta ou indireta. O processo lento de oxidação conduz a ligeiros incrementos na pressão interna, associada à produção de radicais. Paralela a essa atividade química, a mistura do combustível com gases quentes continua, formando o processo chamado de auto-ignição. A formação da fuligem incandescente, em um instante perto do máximo calor liberado (a radiação térmica da fuligem está presente em todo o processo da combustão), até atingir a estabilidade do frente de chama. Revelando a natureza transiente do processo, durante o período de difusão da combustão [61].

A estrutura do jato de combustão é conservada até o final da injeção, devido ao controle do fluxo de momento e da turbulência induzida pelo spray. A injeção de combustível tem, tipicamente, um tempo suficiente para a queima de grande parte do combustível, durante a combustão com mistura controlada. De modo que, o jato experimenta um período significativo "quase uniforme", quando a combustão e injeção acontecem ao mesmo tempo. A combustão é controlada pelos processos de difusão, onde a quantidade de libertação de energia pode ser gradual com o controle da injeção.

A Figura Fig. 3.5 representa o modelo conceitual com uma sequência temporal desde o início da injeção até a primeira parte da queima de uma mistura controlada. 

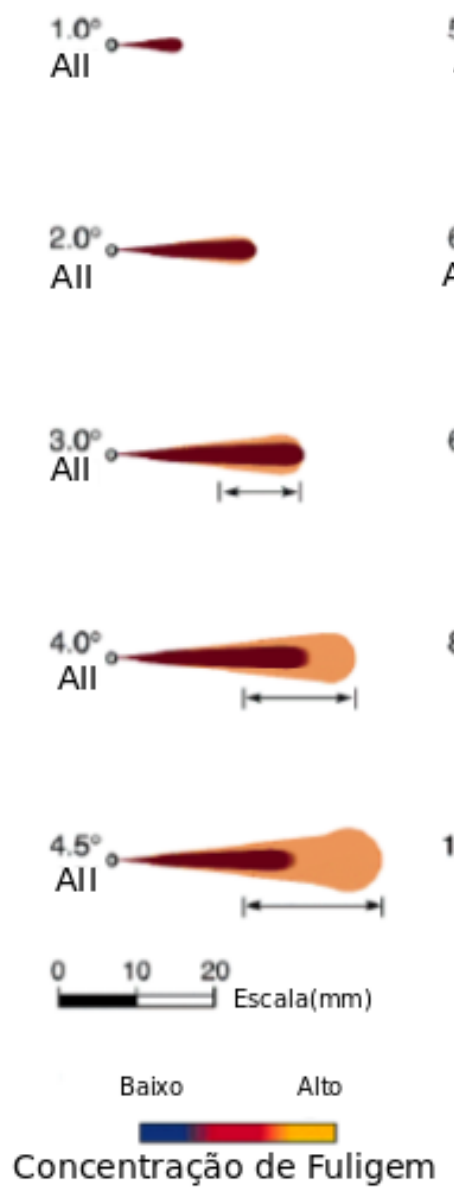
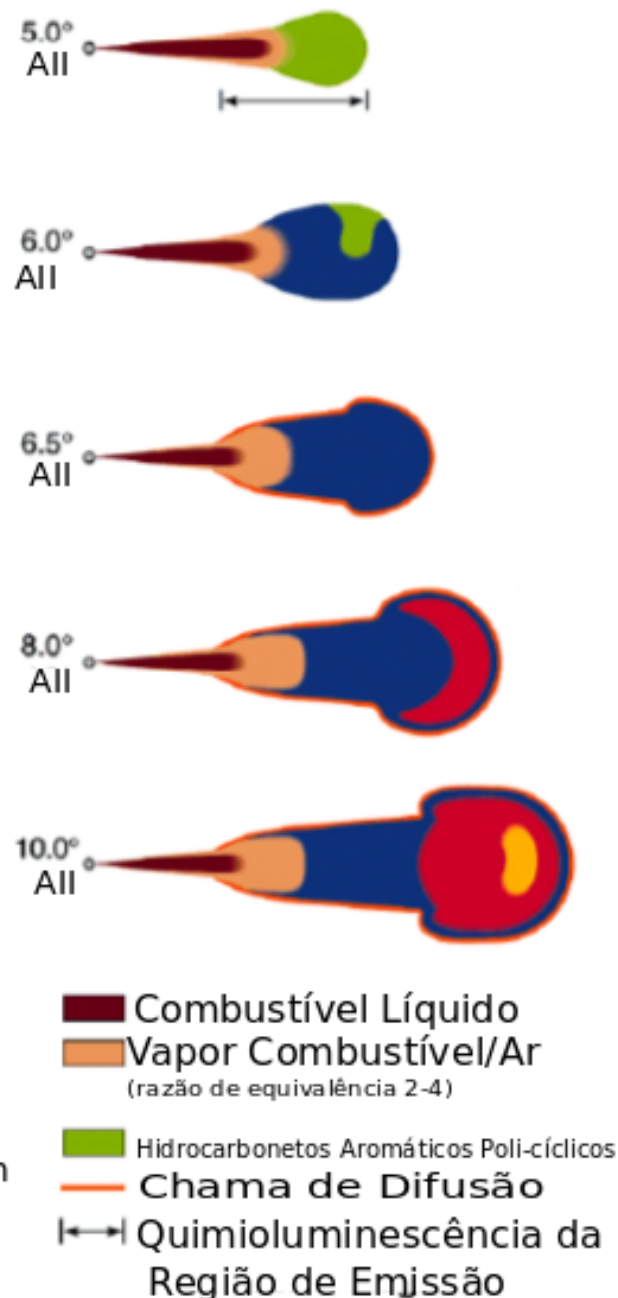

Combustível Líquido Vapor Combustível/Ar Hidrocarbonetos Aromáticos Poli-cíclicos Região de Emjssão

Figura 3.5: Esquema da sequência temporal da evolução da combustão do spray Diesel para uma queima controlada (reproduzida e adaptada a partir de [7]

A evolução da estrutura da chama é agora apresentado brevemente, com foco na evolução da fuligem. Nos motores Diesel MICID convencionais, o combustível é injetado a pressões elevadas (100MPa) e, devido aos processos de rompimento, as partículas do spray se difundem a partir de um orifício injetor.

A injeção começa próximo ao ponto morto superior, onde a pressão ambiente e a temperatura são elevadas. Depois, fase líquida e a fase vapor do combustível penetram e se misturam com o ar ambiente. Em algum instante de tempo, o primeiro estágio de acendimento ocorre na parte da cabeça do spray e logo em seguida, na segunda fase, a mistura rica em combustível se inflama. Em seguida, uma chama de difusão que envolve a maior parte do volume do spray se desenvolve. No entretanto, a injeção continua e o spray cresce mais a jusante. Porém, a posição da região de ignição e a estrutura da 
chama de difusão permanecem inalterados. Uma representação gráfica deste modelo conceitual, que tem sido proposto por Dec [7], é mostrado na Fig. 3.5 em uma sequência temporal.

Quando a combustão é rica, ela produz pequenas partículas de fuligem e o combustível deixa de ser consumido. Estes produtos ricos, da mistura com o ar circundante, geram uma chama fina de difusão (linha laranja na Fig. 3.5) na periferia do jato. Nessa região a mistura é quase estequiométrica e estende-se a montante a uma distância fixa a partir da saída do bocal. À medida que a chama de difusão é formada, as partículas maiores de fuligem são produzidas numa camada fina em torno da periferia do jato. Como a queima pré-misturada avança, a concentração de fuligem aumenta muito na ponta do jato, devido ao transporte turbulento de partículas produzidas pela chama de difusão. Os vórtices na cabeça das partículas são também maiores do que aqueles formados ao longo da chama de difusão. Com a transição para a queima de mistura controlada, quando o último ar pré-misturado é consumido, a estrutura do jato não se altera muito.

O processo de auto-ignição consiste de duas etapas, quando se olha desde o ponto de vista da constituição do combustível e as reações que são desenvolvidas. A primeira acontece a baixas temperaturas, que conduz à formação de radicais aldeídos e peróxido de hidrogênio que iniciam perto dos $700 \mathrm{~K}$, com liberação de calor, que aumenta a temperatura da mistura até que se atinge a segunda etapa a alta temperatura (900 K). Em resumo, a primeira etapa de auto-ignição libera calor e fornece as condições necessárias para ocorrer a segunda etapa, onde se dá a máxima quantidade de calor liberado, a qual controla o rendimento do motor. Se o pico de temperatura se atinge muito cedo na fase de compressão, a fase de combustão chega a ser muito adiantada, conduzindo a penalidades na eficiência, alto barulho, aumento da probabilidade de detonações com risco de dano do motor. Se o pico de temperatura é atingido muito tarde, tem uma alta probabilidade de apresentar falha de autoignição, o qual conduz à emissão de altas quantidades de $H C$ e redução do rendimento [61]. Dois fatores são especialmente importantes para assegurar a ignição por compressão e a determinação do início da mesma: a composição química da mistura e o ambiente térmico ao interior do cilindro, neste ponto o histórico da temperatura é crítico [62]. Os parâmetros que determinam as condições térmicas são principalmente a temperatura da carga de alimentação e a temperatura da parede. 


\section{4}

\section{Modelagem do Spray Diesel}

Neste capítulo serão apresentadas as equações que regem tanto a fase euleriana como a fase lagrangiana, que representam a fase gasosa e fase líquida, respectivamente. Devido ao acoplamento lagrangiano-euleriano as equações eulerianas possuem termos fontes para levar em conta a interação entre as fases.

\section{1}

\section{Fase Gasosa}

Em mecânica dos fluidos, os fenômenos podem ser descritos através de três equações de conservação:

- equação de continuidade: que representam a conservação de massa;

- equação de quantidade de movimento: que representam a conservação do momento;

- equação de energia: que representam a conservação de energia.

- equação de espécies: que representam a conservação de espécies químicas.

\subsection{1}

\section{Equação de Continuidade}

A equação de continuidade é referenciada como a conservação de massa para a fase gasosa. A equação de continuidade é

$$
\frac{\partial(\rho}{\partial t}+\frac{\partial\left(\rho u_{i}\right)}{\partial x_{i}}=\rho \dot{S}
$$

onde $i$ é uma direção espacial genérica e $\dot{S}$ é um termo fonte referente a fase líquida.

\subsection{2}

\section{Equação de Quantidade de Movimento}

A equação de momento refere-se à segunda lei de Newton para um fluido em movimento. Nesta equação vários termos fonte aparecem, bem como um tensor, que descreve a deformação do fluido devido às forças internas, $\rho g$ representa à aceleração da gravidade e um termo de origem, devido à interação entre a fase líquida e a fase gasosa. Assim, temos a equação

$$
\frac{\partial \rho u_{j}}{\partial t}+\frac{\partial \rho u_{i} u_{j}}{\partial x_{i}}=-\frac{\partial p}{\partial x_{j}}+\frac{\partial \tau_{i j}}{\partial x_{i}}+\rho g_{j}+f_{j}^{s}
$$


onde $p$ é a pressão isotrópica, $\tau_{i j}$ é o tensor simétrico e $f_{j}^{s}$ é a taxa de momento devido a interação entre a fase líquida e gasosa.

Assumindo o fluido newtoniano, $\tau_{i j}$ têm-se

$$
\tau_{i j}=\mu\left[\left(\frac{\partial u_{j}}{\partial x_{i}}+\frac{\partial u_{i}}{\partial x_{j}}\right)-\frac{2}{3}(\vec{\nabla} \cdot \vec{u}) \delta_{i j}\right],
$$

onde $\mu$ é a viscosidade dinâmica e $\delta_{i j}$ é o delta de Kronecker.

\subsection{3}

\section{Equação de Energia}

Considerando a primeira lei da termodinâmica, o transporte do fluxo de energia pode ser escrito como uma equação em termos da entalpia da forma

$$
\frac{\partial \rho h}{\partial t}+\frac{\partial \rho u_{i} h}{\partial x_{i}}=\frac{D p}{D t}-\frac{\partial j_{i}^{q}}{\partial x_{i}}+\dot{q}_{s}+\dot{q}_{r}
$$

onde o transporte diffusivo é representado em termos de $j_{i}^{q}$ dado por

$$
j_{i}^{q}=-\lambda \frac{\partial T}{\partial x_{i}}+\sum_{k=1}^{n s} j_{i, k} h_{k} .
$$

A primeira parte de $j_{i}^{q}$ se refere a difusividade térmica de fluido e a segunda parcela está relacionada ao transporte de entalpia devida a difusão de espécies.

Os outros termos, referentes a transferência de calor na presença do spray líquido e a perda de calor por radiação, são desprezados nesse trabalho. Porém, a influência desses termos podem ser acrescidas no programa desenvolvido e em trabalhos futuros.

\subsection{4}

\section{Modelagem da Turbulência}

No escoamento turbulento, ocorrem flutuações continuamente nas propriedades. E esse comportamento está associado às forças inércia, que dominam o escoamento em relação as forças viscosas. Sendo assim, podemos caracterizar o escoamento turbulento, pode-se definir a velocidade instantânea como a soma de um valor médio mais uma flutuação, descrito por Tennekes et al. [63]

$$
u=\bar{u}+u^{\prime}
$$

onde o valor médio é obtido por

sendo $\overline{u^{\prime}}=0$.

$$
\bar{u}=\frac{1}{\Delta t} \int_{\Delta t} u d t
$$




\subsubsection{1}

\section{Modelo $k-\epsilon$}

Modelo que possui relevância a partir dos trabalhos de Launder e Spaldin [64]. Neste modelo o comprimento característico é obtido a partir da função da dissipação $\left(l=k^{3 / 2} / \epsilon\right)$. A viscosidade turbulenta é dada por

$$
\begin{gathered}
\mu_{t}=\frac{c_{\mu} \rho k^{2}}{\epsilon} . \\
\rho \frac{\partial k}{\partial t}+\rho \frac{\partial}{\partial x_{j}}\left(\bar{u}_{j} k\right)=P_{k}+\frac{\partial}{\partial x_{j}}\left[\left(\mu+\frac{\mu_{t}}{\sigma_{k}}\right) \frac{\partial k}{\partial x_{j}}\right]-\rho \epsilon, \\
\rho \frac{\partial \rho \epsilon}{\partial t}+\rho \frac{\partial}{\partial x_{j}}\left(\rho \bar{u}_{j} \epsilon\right)=\frac{\partial}{\partial x_{j}}\left[\left(\mu+\frac{\mu_{t}}{\sigma_{k}}\right) \frac{\partial \epsilon}{\partial x_{j}}\right]+\left[c_{1 \epsilon} P_{k}-c_{2 \epsilon} \rho \epsilon\right] \frac{\epsilon}{k},
\end{gathered}
$$

sendo

$$
\begin{gathered}
P_{k}=\mu_{t}\left(\frac{\partial \bar{u}_{i}}{\partial x_{j}}+\frac{\partial \bar{u}_{j}}{\partial x_{i}}\right) \frac{\partial \bar{u}_{i}}{\partial x_{j}}, \\
\mu_{t}=c_{\mu} \rho \frac{k^{2}}{\epsilon}
\end{gathered}
$$

onde as constantes empíricas utilizadas durante a simulação estão na tabela Tab. 6.1.

O modelo $k-\epsilon$ é robusto, econômico e tem razoável precisão, razão pela qual é muito usado industrialmente para simular escoamentos.

\subsection{5}

\section{Modelagem Flamelet}

Neste capítulo serão discutidos alguns conceitos teóricos úteis para estudar chamas de difusão: o conceito flamelet, onde a fração de mistura e da taxa de dissipação de escalar são partes integrantes desse conceito.

As equações genéricas de conservação que governam o escoamento newtoniano, já foram apresentadas no capítulo anterior. No entanto, a rigidez destas equações as tornam úteis para resolver sistemas de combustão práticos. A chamada teoria flamelet foi introduzido por Peters [23] para fornecer uma alternativa à estrutura chama local. Esta abordagem separa os processos químicos, a partir do campo do fluxo (mistura), que forma a base para muitos métodos de modelagem química.

\subsubsection{1}

\section{Fração de Mistura}

A mistura é frequentemente descrita através da introdução de uma fração mistura $Z$ que é uma definição para a composição de mistura local [22]. A definição fração mistura é adotada como 


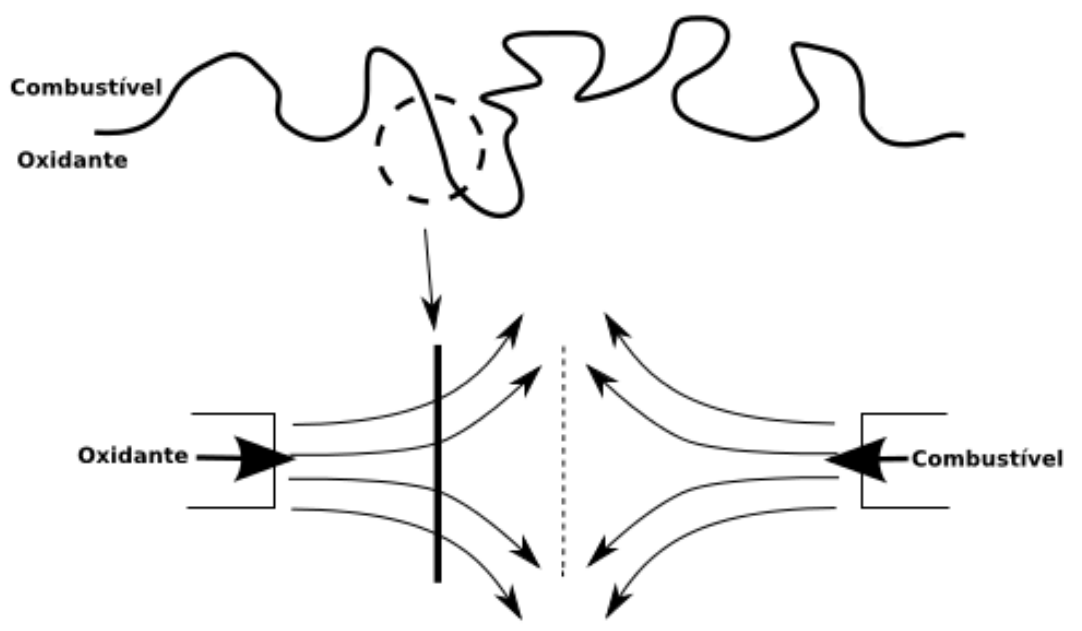

Figura 4.1: Configuração contra-corrente

$$
Z=\frac{2 \frac{Z_{C}-Z_{C, 2}}{M_{C}}+\frac{1}{2} \frac{Z_{H}-Z_{H, 2}}{M_{H}}-\frac{Z_{O}-Z_{O, 2}}{M_{O}}}{2 \frac{Z_{C, 1}-Z_{C, 2}}{M_{C}}+\frac{1}{2} \frac{Z_{H, 1}-Z_{H, 2}}{M_{H}}-\frac{Z_{O, 1}-Z_{O, 2}}{M_{O}}},
$$

onde $Z_{i}$ é a fração de massa do elemento e $M_{i}$ é a massa molar do carbono do elemento $(C)$, o hidrogênio $(\mathrm{H})$ e o oxigênio $(O)$. Os subscritos 1 e 2 referemse à fração de massa constante no combustível e no oxidante definido no escoamento, respectivamente. $Z$ é um escalar conservado que varia no espaço e no tempo, apenas devido à mistura. Definiu-se de tal forma que $Z=0$ no fluxo de oxidante e $\mathrm{Z}=1$ no fluxo do combustível, e aumenta monotonicamente no meio Fig. 4.1. Estas propriedades fazem de $Z$ uma variável adequada para parametrizar o processo de mistura em combustão.

Assim, considerando uma reação genérica, da seguinte forma:

$$
\nu_{F} F+\nu_{O} O \longleftrightarrow \nu_{P} P
$$

onde os subscritos $O, F$ e $P$ indicam oxidante, combustível e produtos, respectivamente.

Antes de escrever uma equação de conservação para a fração de mistura, consideram-se as equações diferenciais para conservação de massa e de temperatura na forma

$$
\begin{gathered}
\frac{\partial \rho Y_{F}}{\partial t}+\frac{\partial \rho u_{i} Y_{F}}{\partial x_{i}}=\frac{\partial}{\partial x_{i}}\left(\rho D \frac{\partial \rho Y_{F}}{\partial x_{i}}\right)+\dot{\omega}_{F}, \\
\frac{\partial \rho Y_{O}}{\partial t}+\frac{\partial \rho u_{i} Y_{O}}{\partial x_{i}}=\frac{\partial}{\partial x_{i}}\left(\rho D \frac{\partial \rho Y_{O}}{\partial x_{i}}\right)+s \dot{\omega}_{F}, \\
\frac{\partial \rho T}{\partial t}+\frac{\partial \rho u_{i} T}{\partial x_{i}}=\frac{\partial}{\partial x_{i}}\left(\frac{\lambda}{C_{p}} \frac{\partial \rho Y_{F}}{\partial x_{i}}\right)-\frac{Q}{C_{p}} \dot{\omega}_{F},
\end{gathered}
$$

onde $D$ é o coeficiente de difusão, $C_{p}$ é o calor específico, $\dot{\omega}_{F}$ é a taxa de reação do combustível, $s$ é a razão estequiométrica de massa e $Q$ é a libertação de calor por unidade de massa na reação. O número de Lewis é definido como 


$$
L e=\frac{\lambda}{\rho C_{p} D} .
$$

Definindo três escalares passivos $z_{1}, z_{2}$ e $z_{3}$ como

$$
\begin{gathered}
z_{1}=s Y_{F}-Y_{O}, \\
z_{2}=\frac{C_{p} T}{Q}+Y_{F}, \\
z_{3}=s \frac{C_{p} T}{Q}+Y_{O},
\end{gathered}
$$

assume-se que a equação de balanço para fração de mistura é da forma

$$
\frac{\partial \rho z_{j}}{\partial t}+\frac{\partial \rho u_{i} z_{j}}{\partial x_{i}}=\frac{\partial}{\partial x_{i}}\left(\rho D \frac{\partial \rho z_{j}}{\partial x_{i}}\right)
$$

com $j=1,2,3$. Além de satisfazerem as condições de contorno, os escalares passivos podem ser normalizados em 1 para o contorno do combustível e 0 para o contorno do oxidante

$$
Z=\frac{z_{1}-z_{1}^{O}}{z_{1}^{F}-z_{1}^{O}}=\frac{z_{2}-z_{2}^{O}}{z_{2}^{F}-z_{2}^{O}}=\frac{z_{3}-z_{3}^{O}}{z_{3}^{F}-z_{3}^{O}} .
$$

Assim, estes escalares normalizados são iguais e, podem ser modelados por uma única equação de balanço,

$$
\frac{\partial \rho Z}{\partial t}+\frac{\partial \rho u_{i} Z}{\partial x_{i}}=\frac{\partial}{\partial x_{i}}\left(\rho D_{Z} \frac{\partial \rho Z}{\partial x_{i}}\right)+\rho \dot{S}
$$

onde $\rho \dot{S}$ é o termo fonte da evaporação do spray, que faz com que $Z$ seja um não conservativo escalar.

A equação média de Eq. (4-24) é dada por

$$
\frac{\partial \bar{\rho} \widetilde{Z}}{\partial t}+\frac{\partial \bar{\rho} \widetilde{u_{i}} \widetilde{Z}}{\partial x_{i}}=\frac{\partial}{\partial x_{i}}\left(D_{t} \frac{\partial \widetilde{Z}}{\partial x_{i}}\right)+\tilde{\bar{\rho}} \tilde{S}
$$

onde $D_{t}$ é a difusividade turbulenta expressa como $D_{t}=\frac{\mu_{e f f}}{S c_{t}}, S c_{t}$ é o número de Schmidt turbulento, $\mu_{\text {eff }}$ é a viscosidade efetiva composta pela viscosidade laminar mais a viscosidade turbulenta $\left(\mu_{e f f}=\mu+\mu_{t}\right)$. O acoplamento da equação Eq. (4-25) faz-se necessário uma equação adicional para a variância da fração de mistura $\widetilde{Z^{\prime \prime 2}}$, dada por

$$
\frac{\partial \bar{\rho} \widetilde{Z}^{\prime \prime 2}}{\partial t}+\frac{\partial \bar{\rho} \widetilde{u_{i}} \widetilde{Z^{\prime \prime 2}}}{\partial x_{i}}=\left(D_{t} \frac{\partial \widetilde{Z}^{\prime \prime 2}}{\partial x_{i}}\right)-2 D_{t}\left(\frac{\partial \widetilde{Z^{\prime \prime}}}{\partial x_{i}}\right)^{2}-\bar{\rho} \widetilde{\chi}
$$

\subsubsection{2}

\section{Taxa de Dissipação Escalar}

As medidas das taxas de dissipação escalares do gradiente de $Z$ e os fluxos de espécies na direção da chama são definidos por 


$$
\tilde{\chi}=2 D_{t}\left(\frac{\partial \widetilde{Z}}{\partial x_{i}}\right)^{2}
$$

Pode-se observar que as médias escalares da taxa de dissipação de $Z$ possui o mesmo papel de epsilon para a energia cinética turbulenta. Portanto, esta analogia é usada para modelar $\chi$ como uma relação que expressa a proporcionalidade entre a taxa de dissipação de escalar e tempo de dissipação turbulenta:

$$
\tilde{\chi}=C_{\chi} \frac{\epsilon}{k} \widetilde{Z}^{\prime \prime 2}
$$

onde $C_{\chi}$ é uma constante que assume, usualmente, o valor 2 descrito por Janicka e Peters [65].

Como $\chi$ é uma função de $Z$, a partir da modelagem de uma chama laminar difusiva com densidade e coeficientes difusivos constantes, Peters [23] modelou a taxa de dissipação escalar como

$$
\chi(Z)=\frac{a_{s}}{\pi} \operatorname{Exp}\left\{-2\left[e r f c^{-1}(2 Z)\right]^{2}\right\}
$$

onde $a_{s}$ é a taxa de estiramento e $e r f c^{-1}$ é o inverso do complementar da função erro.

Eliminando a representação do espaço físico, o que possibilita a diminuição do custo computacional, a taxa de dissipação escalar pode ser reescrita como

$$
\chi(Z)=\chi_{s t} \frac{\operatorname{Exp}\left\{-2\left[\operatorname{erf} c^{-1}(2 Z)\right]^{2}\right\}}{\operatorname{Exp}\left\{-2\left[\operatorname{erfc}^{-1}\left(2 Z_{s t}\right)\right]^{2}\right\}}
$$

onde $\chi_{s t}$ e $Z_{s t}$ são a taxa de dissipação escalar estequiométrica e a fração de mistura estequiométrica, respectivamente.

\subsection{6}

\section{Chamas difusivas no espaço da fração de mistura}

Em chamas não pré-misturadas ou difusivas os reagentes não são prémisturados, mas se misturam e reagem simultaneamente. Dois estados de fronteira ocorrerem: o oxidante puro e o combustível puro. Na zona de mistura destes dois estados, as reações químicas ocorrem. A zona de reação está dentro de uma gama limitada ao redor da mistura estequiométrica que ocorre entre o fluxo de combustível e oxidante, devido a uma certa distância de cada lado da superfície estequiométrica, a mistura é ou muito pobre ou muito rica para a reação.

A zona de reação deve ser continuamente alimentada por um combustível, caso contrário, a velocidade da reação diminui com o tempo. Ao contrário da chama pré-misturada, uma chama não pré-misturada não tem uma velocidade 
de propagação característica ou espessura, porque estas propriedades são controladas pelo processo de mistura e, por conseguinte, as propriedades do escoamento.

Em chamas não pré-misturados a velocidade da reação é controlada pelo processo de mistura em vez da química, que pode ser considerado como infinitamente rápida. A grande vantagem da introdução da fração de mistura $Z$ é a possibilidade de reduzir o número de variáveis e assim, reduzir o custo computacional. Desta forma, a estrutura da chama depende unicamente da fração de mistura $Z$ e do tempo $t$ [66], assim

$$
\left(x_{1}, x_{2}, x_{3}, t\right) \Longrightarrow\left(Z, y_{2}, z_{3}, t\right) \Longrightarrow(Z, t)
$$

onde, $y_{2}$ e $y_{3}$ são neglicenciados desde que, seus gradientes sejam menores do que fluxo na direção de $Z$. Assim, a estrutura da chama fica unicamente em função de $Z$ e do tempo. Assim, tomando como base a simplificação da chama difusiva para o espaço da fração de mistura, Peters derivou e simplificou as equações para fração de massa das espécies e para temperatura,

$$
\begin{gathered}
Y_{k}=Y_{k}(Z, t), \\
T=T(Z, t),
\end{gathered}
$$

gerando as seguintes equações flamelet

$$
\begin{gathered}
\rho \frac{\partial Y_{i}}{\partial t}-\rho \frac{\chi}{2} \frac{\partial^{2} Y_{i}}{\partial Z^{2}}=\dot{m}_{i} \\
\rho \frac{\partial T}{\partial t}-\rho \frac{\chi}{2} \frac{\partial^{2} T}{\partial Z^{2}}-\rho \frac{\chi}{2 c_{p}}\left[\sum_{i=1}^{n s} c_{p_{i}} \frac{\partial Y_{i}}{\partial Z}+\frac{\partial c_{p}}{\partial Z}\right] \frac{\partial T}{\partial Z}= \\
=\frac{1}{c_{p}}\left(\frac{\partial p}{\partial t}-\sum_{i=1}^{n s} \dot{m}_{i} h_{i}\right),
\end{gathered}
$$

onde $\dot{m}_{i}$ é taxa de reação química para a espécie genérica $i$.

\section{2}

\section{$\beta$-PDF presumida}

Uma abordagem baseada no modelo flamelet define a evolução temporal de toda a reação como uma função da composição média de $Z$. A média de Favre no domínio físico, pode ser avaliada a partir da sua composição na direção $Z$ no espaço por meio de uma função de densidade de probabilidade da fração de mistura. A FDP pode ser uma solução de uma equação de transporte ou presumida, assumindo que sua estrutura é aleatória no campo de escoamento. A $\beta$-PDF presumida é utilizada, a qual é calculada conforme a expressão 


$$
\widetilde{P}(Z)=\frac{Z^{\beta_{1}-1}(1-Z)^{\beta_{2}-1}}{\int_{0}^{1} Z^{\beta_{1}-1}(1-Z)^{\beta_{2}-1} d Z}
$$

onde $\beta_{1}$ e $\beta_{2}$ são parâmetros dependentes de $\widetilde{Z}$ e da sua variância $\widetilde{Z}^{\prime \prime 2}$, definidos como

$$
\begin{gathered}
\beta_{1}=\widetilde{Z}\left(\frac{\widetilde{Z}(1-\widetilde{Z})}{\widetilde{Z^{\prime \prime 2}}}-1\right), e \\
\beta_{1}=(1-\widetilde{Z})\left(\frac{\widetilde{Z}(1-\widetilde{Z})}{\widetilde{Z^{\prime \prime 2}}}-1\right),
\end{gathered}
$$

sendo que a Eq. (4-36) pode ser reescrita usando funções gama como

$$
\widetilde{P}(Z)=\frac{\Gamma\left(\beta_{1}+\beta_{2}\right)}{\Gamma\left(\beta_{1}\right) \Gamma\left(\beta_{2}\right)} Z^{\beta_{1}-1}(1-Z)^{\beta_{2}-1},
$$

onde $\Gamma(\beta)$ são definidos como

$$
\Gamma(\beta)=\int_{0}^{\infty} x^{\beta-1} e^{-x} d x
$$

Assim, a solução média para a fração de massa $\widetilde{Y}_{i}\left(Z, \chi_{s t}\right)$ e da temperatura $\widetilde{T}\left(Z, \chi_{s t}\right)$ são calculadas a partir da integração das soluções flamelet $Y_{i}\left(Z, \chi_{s t}\right)$ e $T\left(Z, \chi_{s t}\right)$, utilizando a $\beta$ - PDF, tal que

$$
\begin{aligned}
& \widetilde{Y}_{i}=\int_{0}^{\infty} \int_{0}^{1} Y_{i}\left(Z, \chi_{s t}\right) P\left(Z, \chi_{s t}\right) d Z d \chi_{s t}, \\
& \widetilde{T}=\int_{0}^{\infty} \int_{0}^{1} T\left(Z, \chi_{s t}\right) P\left(Z, \chi_{s t}\right) d Z d \chi_{s t},
\end{aligned}
$$

onde o $\operatorname{FDP} P\left(Z, \chi_{s t}\right)$ é decomposto assumindo a independência estatística como

$$
P\left(Z, \chi_{s t}\right)=P(Z) P\left(\chi_{s t}\right)
$$

\section{3}

\section{Modelos de spray}

Nesta seção serão apresentadas as equações que modelam a fase discreta, com modelos de quebra de jatos, evaporação, força de arraste e transferência de energia.

\subsection{1}

\section{Características da Injeção}

A forma mais comum para analisar o escoamento interno consiste em parâmetros médios no orifício de saída e de coeficientes adimensionais, como o coeficiente de descarga $C_{d}$ [67]. Este coeficiente é definido como a relação entre o fluxo mássico real e o fluxo de mássico teórico ideal. Teoricamente, o fluxo de 
massa através do orifício de saída pode ser calculada pela equação Eq. (4-44), quando são conhecidos os perfis de densidade e de velocidade

$$
\dot{m}_{f}=\int_{A} \rho(U \cdot n) d A
$$

Considerando a componente de velocidade perpendicular a área de saída do orifício, à Eq. (4-44) pode ser simplificada e obtendo o fluxo de massa teórico, dado por

$$
\dot{m}_{f, t h}=\rho u_{t} A_{0},
$$

onde, $u_{t}$ é a velocidade teórica obtida através da equação de Bernoulli Eq. $(4-45)$

$$
u_{t}=\sqrt{\frac{2\left(p_{i n j}-p_{a}\right)}{\rho_{f}}},
$$

onde $p_{a}$ é a pressão ambiente e $p_{i n j}$ é a pressão injeção. Experimentalmente o injetor utilizado é um Bosch de segunda geração common rail, tipo axial, com o diâmetro de $100 \mu m$ [3].

Assim, o fluxo de massa teórico pode ser obtido pelo coeficiente de descarga é dado por

$$
C_{d}=\frac{\dot{m}_{f}}{\dot{m}_{f, t h}}=\frac{\dot{m}_{f}}{A_{0} \sqrt{2\left(p_{i n j}-p_{a}\right) \rho_{f}}}=0,8 .
$$

A relação entre o coeficiente de descarga $C_{d}$ e o coeficiente de contração $C_{a}$ para o injetor, de acordo com os valores do ECN [3], é dado por

$$
C_{a}=\frac{C_{d}}{C_{v}}=0,86
$$

onde $C_{v}$ é o coeficiente de velocidade. O gráfico da taxa de fluxo de massa de líquido injetado é representado na figura Fig. (4.2)

\subsection{2}

\section{Modelo de quebra de jatos}

Assume-se que o combustível é introduzido na câmara de combustão, como grandes gotas esféricas com um tamanho uniforme, igual ao diâmetro do bocal, e o número de gotas injetadas por unidade de tempo é determinada a partir da vazão mássica. Assim, considera-se o modelo Kelvin-HelmholtzRayleigh-Taylor (KH-RT) [68, 69] para quebra de gotas primárias e secundárias [70, 71] como uma combinação do modelo de Kelvin-Helmholtz (KH) [55] e do modelo de Rayleigh-Taylor (RT) [55]. 


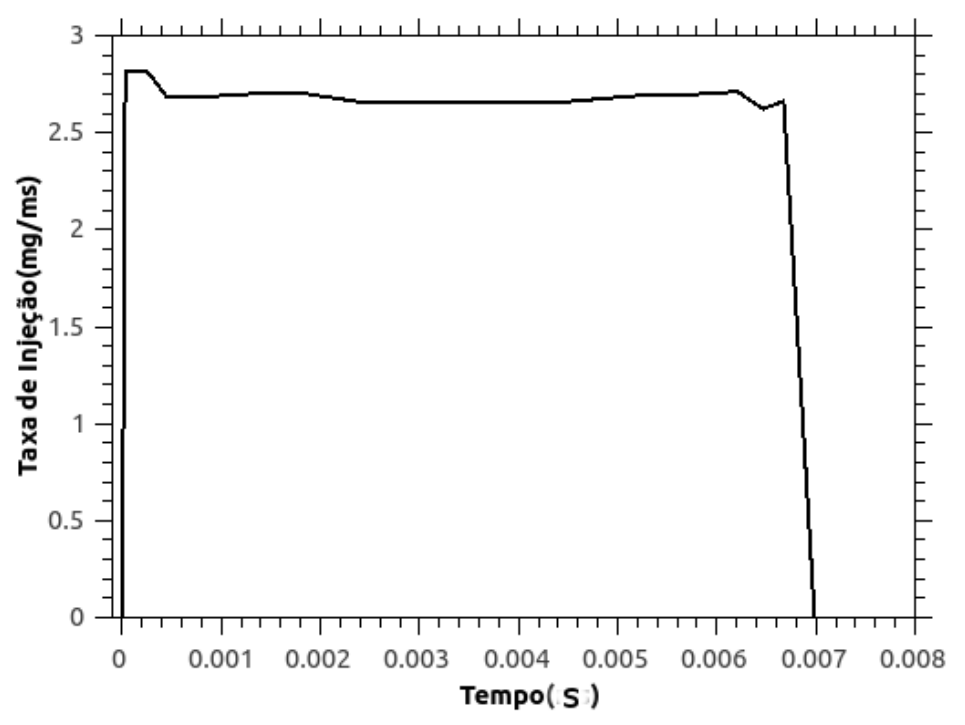

Figura 4.2: Taxa de injeção para o experimento SNL [3], onde a temperatura ambiente $T_{a}=1000 \mathrm{~K}$, densidade ambiente $\rho_{a}=14.8 \mathrm{~kg} / \mathrm{m}^{3}$ e fração molar de oxigênio de $21 \% \mathrm{O}_{2}[3]$

\subsubsection{1}

\section{Modelo Kelvin-Helmholtz}

Com base na análise de primeira ordem linear a instabilidade de KelvinHelmholtz é crescente sobre a superfície de um jato líquido e cilíndrico. Tais instabilidades começam a crescer na superfície das gotas e também nas gotículas subsequentemente geradas. O crescimento da onda é mais rápido com a taxa de crescimento $\Omega_{K H}$ e comprimento de onda $\Lambda_{K H}$. Estes dependem do raio $r$ das gotas geradoras, da velocidade relativa, das densidades na fase líquida e na fase gasosa, da tensão superficial e da viscosidade cinemática do líquido, agrupados em vários números adimensionais responsáveis pelo descolamento de novas gotas com raio $r_{\text {new }}$. Definidos por

$$
\begin{gathered}
\Omega_{K H}=\frac{0.34+0.38 W e^{1.5}}{(1+O h)\left(1+T^{0.6}\right)} \sqrt{\frac{\sigma}{\rho d r^{3}}}, \\
\Lambda_{K H}=9.02 r \frac{(1+0.45 \sqrt{O h})\left(1+0.4 T^{0.7}\right)}{\left(1+0.865 W e^{1.67}\right)^{0.6}},
\end{gathered}
$$

onde foram expressas e estudadas por R. D. Reitz [55]. O tamanho das novas gotículas é proporcional ao comprimento de onda $\Lambda_{K H}$

$$
r_{\text {new }}=B_{0} \cdot \Lambda_{K H},
$$

onde $B_{0}$ é constante. Um produto contendo nova parcela de gotas de raio $r_{n e w}$ é criado e adicionado computacionalmente. Assim, a perda de massa e a velocidade com que seu tamanho reduz é dado por 
sendo,

$$
\frac{d r}{d t}=\frac{r-r_{n e w}}{\tau_{K H}}
$$

$$
\tau_{K H}=3,788 B_{1} \frac{r}{\Lambda_{K H} \Omega_{K H}},
$$

onde $\tau_{K H}$ é a característica da quebra de gota em função do tempo e $B_{1}$ é a constante de ajuste experimental (tem valores propostos na literatura entre 1.73 e $60[55])$.

\subsubsection{2}

\section{Modelo Rayleigh-Taylor}

Sabe-se que as gotas de um spray líquido Diesel têm velocidades iniciais muito altas e desaceleram rapidamente devido a forças de arrasto. Neste caso, às instabilidades de Rayleigh-Taylor também podem desempenhar um papel importante nos mecanismos de rompimento de gotas adicionado as instabilidades de Kelvin-Helmholtz [72]. Isto porque o rompimento da gota é induzida pela inércia do líquido e pela ação das forças de resistência aerodinâmica, gerando ondas instáveis que crescem atrás da gota. As expressões para a taxa de crescimento $\Omega_{R T}$ e para número de onda $K_{R T}$ da onda são derivadas a partir das expressões da força de arrasto e a aceleração da interface gás-líquido. O comprimento de onda $\Lambda_{R T}$ é obtido pela expressão

$$
\Lambda_{R T}=\frac{2 \pi C_{R T}}{K_{R T}} .
$$

Se $\Lambda_{R T}<r$, assume-se que as ondas de RT começaram a crescer na sua superfície. Assim, RT excede um tempo característico $\tau_{R T}$, a quebra de gota ocorre e pequenas gotas de raio $r_{n e w}$ se formam, onde

$$
\begin{gathered}
r_{\text {new }}=\frac{\pi C_{R T}}{K_{R T}}, \\
\tau_{R T}=\frac{C_{\tau}}{\Omega_{R T}},
\end{gathered}
$$

onde $C_{\tau}$ e $C_{R T}$ são constantes ajustadas experimentalmente.

\subsubsection{3}

\section{Modelo $\mathrm{KH}-\mathrm{RT}$}

No caso do modelo de KH-RT, ambos os modelos KH e RT são utilizados. Enquanto o modelo RT prediz a ruptura no passo de tempo real, o modelo de KH irá gerar pequenas gotas e reduzir o diâmetro das gotas geradoras. Uma vez que a taxa de redução do tamanho das gotas pelo modelo RT é demasiada alta, quando este é aplicado às gotas que saem do orifício do bico. Este é desligado, 
dentro do assim chamado de comprimento de ruptura $L_{b u}$, onde apenas KH é utilizado e a Fig. (4.3) ilustra como são aplicados os dois modelos no espaço.

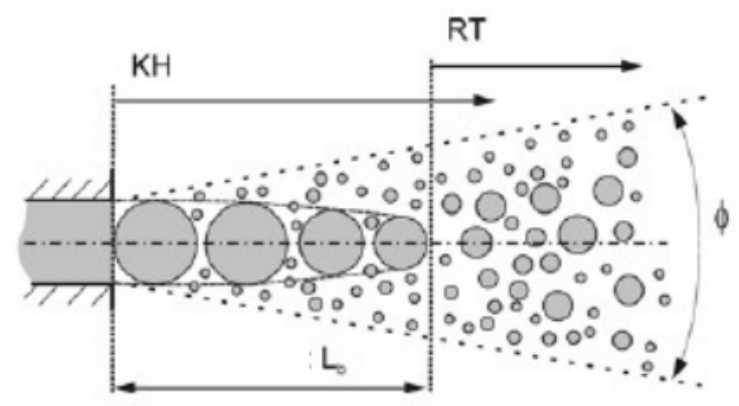

Figura 4.3: Esquema do modelo KH-RT de quebra de gotas [4]

A expressão para o comprimento de ruptura é dado por

$$
L_{b}=C_{b u} \cdot \sqrt{\frac{\rho_{l}}{\rho_{s}}} \cdot d_{n o z}
$$

Em comparação com a utilização de um único modelo, a utilização do modelo

KH-RT permite um melhor ajuste com o modelo experimental, assim como um ajuste melhor para a modelagem para grandes gotas, e um aumento da evaporação. Na Tab.(4.1), encontram-se os valores de referência para as constantes utilizadas no modelo de quebra de gotas.

Tabela 4.1: Tabela com as constantes do modelo KHRT

\begin{tabular}{|l|l|}
\hline Parâmetros do Modelo & Valor Numérico \\
\hline$B_{0}$ & 0,61 \\
$B_{1}$ & 40,0 \\
$C_{\tau}$ & 1,0 \\
$C_{R T}$ & 0,1 \\
$m_{s, \text { limite }}$ & 0,4 \\
$W e_{\text {limite }}$ & 6 \\
\hline
\end{tabular}

\subsection{3}

\section{Modelo de Arraste}

Em 1983, Sirignano [48] modelou a vaporização avaliando apenas a viscosidade na camada limite da gotícula no cálculo do número de Reynolds

$$
R e=\frac{\rho_{c}\left|u-u_{c}\right| d}{\mu_{\text {ref }}} .
$$

Existem diversos modelos na literatura para o coeficiente de arraste $[73,74]$. O OpenFOAM também oferece a possibilidade de contabilizar as 
alterações no arrasto devido a oscilações da superfície da gotícula, isto é, as ondas de instabilidade, eventualmente, resultando em separação de gotículas. Se este modelo é usado, o modelo separador [75] será utilizado para calcular as oscilações e o arraste resultante será adicionado ao arrasto, descrito por

$$
C_{D}=\left\{\begin{array}{l}
\frac{24}{R e_{d}}\left(1+\frac{R e_{d}^{\frac{2}{3}}}{6}\right) \quad R e_{d}<1000 \\
0,44 \quad R e_{d}>1000
\end{array}\right.
$$

O OpenFOAM também oferece a possibilidade de contabilizar as alterações do arrasto devido à oscilações na superfície da gotícula, isto é, as ondas de instabilidade, eventualmente, resultando em separação das gotas. O modelo separador [76] irá ser utilizado para calcular as oscilações e o arrasto resultante

$$
C_{D}=C_{D, m}\left(1+C_{D, d} \min \left(y_{l i m}, y\right)\right),
$$

onde $C_{D, m}, C_{D, d}$ e $y_{l i m}$ são constantes definidas pelo modelo, e $y$ é o desvio relativo da borda da gota, onde o valor de $y_{\text {lim }}$ é geralmente definido como 1, 0 .

\subsection{4}

\section{Modelo de Evaporação}

Ao modelar a evaporação de uma gota, o parâmetro chave é o tempo de evaporação da gota. A derivação deste intervalo de tempo se dá através da variação da massa da gotícula em função do tempo

$$
\frac{d m_{d}}{d t}=-A_{d} K_{g} p_{t} \ln \left(\frac{p_{t}-p_{v, \infty}}{p-p_{v, s}}\right)
$$

onde $p_{t}, p_{v, s}$ e $p_{v, \infty}$ são as pressões total do gás, do vapor na superfície da gota e no ambiente, respectivamente. O coeficiente de transferência de massa $K_{g}$ é dado pela seguinte relação

$$
K_{g}=\frac{S h D_{m}}{R_{m} T_{m} D_{d}}
$$

em que, $T_{m}$ é a temperatura média do filme. O número de Sherwood $S h$, é uma função do número de Reynolds $R e_{d}$ e do número de Schmidt $S c$ segundo [57], tal que

$$
S h=2\left(1+0.3 R e_{d}^{1 / 2} S c^{1 / 3}\right)
$$

\subsection{5}

\section{Modelo de Transferência de Energia}

O balanço de energia da gota correlaciona a variação da energia interna da gotícula, a transferência de calor na superfície bem como a evaporação dada 
por

$$
m_{d} c_{p, d} \frac{d T_{d}}{d t}=-A_{d} q_{d}^{\prime \prime}+h_{f g} \frac{d m_{d}}{d t}
$$

onde $c_{p, d}$ é o calor específico da gota, $h_{f g}$ é o calor latente do combustível à temperatura $T_{d}, A_{d}$ é a superfície de transferência de calor entre as duas fases. $q_{d}^{\prime \prime}$, é proporcional a diferença de temperatura de acordo com o fluxo de calor

$$
q_{d}^{\prime \prime}=h\left(T_{d}-T_{g}\right)
$$

onde $h$ é o coeficiente de transferência de calor entre as fases, calculado por

$$
h=\frac{k_{g} N u Z}{\left(e^{Z}-1\right) D_{d}},
$$

onde, $N u$ é o número de Nusselt expresso por

$$
N u=2\left(1+0.3 \operatorname{Re}_{d}^{1 / 2} \operatorname{Pr}^{1 / 3}\right)
$$

sendo que $\operatorname{Pr}$ é o número de Prandtl e o fator de correção $\mathbf{Z}$ é definido por

$$
\mathbf{Z}=\frac{-c_{p}\left(d m_{d} / d t\right)}{\pi D_{d} K_{g} N u}
$$




\section{5 \\ Metodologia}

Como o escoamento base em sprays Diesel é turbulento, faz-se necessário a utilização de um tratamento a escala de tempo químico e a escala de tempo de turbulento.

\section{1}

\section{Modelo PaSR}

O termo fonte da equação de conservação espécies químicas $\dot{\omega}_{F}$ na Eq. (4-15) e na Eq. (4-16) é desconhecido e requer um modelo de fechamento para resolver o termo. O modelo de combustão utiliza geralmente a escala de tempo turbulenta e a escala de tempo química para explicar a taxa de reação, uma vez que, a taxa de mistura determina a cinética química no caso de química rápida. As velocidades de reação são uma função da temperatura local e da variação da taxa de reação e é dada pela equação da lei da taxa de Arrhenius

$$
k=A T^{n} \exp \frac{-E_{a}}{R T},
$$

onde $A$ é um fator exponencial, $T$ a temperatura, $n$ o expoente empírico, $E_{a}$ a energia de ativação para a reação química e $R$ a constante dos gases.

Vários modelos de combustão estão disponíveis para fechar os termos de origem associados à entalpia e à massa de massa das espécies. No solver sprayFoam do software OpenFoam, a interação entre a turbulência e a química é modelada por meio de um Modelo de Reator Parcialmente Agitado (em inglês, Partially Stirred Reactor (PaSR)).

No modelo PaSR desenvolvido por Karlsson [42], uma célula computacional é dividida em duas zonas diferentes, onde em uma das zonas ocorrem todas as reações químicas, e na outra, não ocorrem reações químicas. Assim, a composição muda devido à troca de massa com a zona de reação. Além disso, a zona de reação é tratada como um reator perfeitamente agitado (em inglês, perfectly stirred reator (PSR)), na qual a composição é homogênea (todas as espécies são consideradas perfeitamente misturadas umas com as outras). Isso nos permite desconsiderar quaisquer flutuações no cálculo dos termos de origem química. 
Para o modelo PaSR a fração de massa reativa é definida à medida que o cálculo é avançado, de $c_{0}$ até $c_{1}$. Primeiro, o modelo distingue três concentrações molares:

$c_{0}$ é a concentração média na alimentação da célula e pode ser considerada como a concentração média inicial na célula.

$c$ é a concentração desconhecida na zona de reação num nível de submalha na fração reativa desconhecida do material celular.

$c_{1}$ é o tempo de concentração de saída do reator. Esta é também a concentração média na célula.

Tendo estabelecido isso, a concentração de saída do reator pode ser obtida, a partir de conservações em massa, olhando, como

$$
c_{1}=k^{*} c+\left(1-k^{*}\right) c_{0}
$$

onde $k^{*}$ é a fração de massa da mistura que reage.

Todo o processo pode ser dividido em dois sub-passos, procedendo em paralelo:

1. A concentração inicial na zona de reação muda de $c_{0}$ para $c$ à medida que reage,

2. A mistura reativa, $c$, é misturada com a mistura não reativa, $c_{0}$, por turbulência, resultando na concentração média $c_{1}$

Como $c_{1}$ é o valor inicial para o próximo passo de tempo, o tempo entre $c_{0}$ e $c_{1}$ deve ser o passo de integração, $\tau$. E como a mistura turbulenta de $c$ com $c_{0}$, a diferença de tempo entre $c$ e $c_{1}$ deve ser o tempo característico para a turbulência, $\tau_{m i x}$. O tempo de reação total para o caminho 1, pode, assim, ser considerado como a razão do tempo químico, $\tau$ pela soma $\tau+\tau_{\text {mix }}$.

O tempo químico $\tau \propto \frac{1}{k}$ e tempo característico para a turbulência $\tau_{m i x}$ é calculado por

$$
\tau_{\text {mix }}=C_{\text {mix }} \sqrt{\frac{\mu_{e f f}}{\rho \epsilon}}
$$

onde $C_{\text {mix }}$ é uma constante empírica com o valor de 0,03 e $\epsilon$ é a taxa de dissipação da energia cinética turbulenta.

Pode-se obter as seguintes relações, assumindo uma taxa de reação na zona de reação, $c$

$$
\frac{c_{1}-c_{0}}{\tau}=\frac{c-c_{1}}{\tau_{\text {mix }}}=f_{m}(c),
$$

que podem ser reescritos como

$$
c_{1}=k^{*} c+\left(1-k^{*}\right) c_{0}, \quad k^{*}=\frac{\tau}{\tau+\tau_{\operatorname{mix}}} .
$$


Tradicionalmente, o OpenFoam utiliza o reator PaSR para simular spray e a desvantagem do PaSR está no custo associado na resolução da equação de conservação de espécies químicas para cada espécie química $Y_{i}$. Desta forma, a modelagem flamelet, com a cinética química tabulada, torna-se uma ferramenta poderosa no auxílio da minimização do custo computacional relacionado a interação entre a parte química e a parte turbulenta.

\section{2}

\section{Modelo Flamelet}

O conceito de flamelet baseia-se no pressuposto de que a escala de tempo químico $\tau$ é muito mais rápida do que a escala de tempo de turbulento $\tau_{m i x}$. A chama é, portanto, tratada usando uma abordagem laminar, onde a turbulência e a química foram desacopladas.

Grandes parte do cálculo termodinâmico no OpenFOAM é baseado na entalpia sensível $h_{s}$, o sprayFoam calcula o seu valor a partir da equação de entalpia Eq. (4-5), partindo do princípio de que temperatura e outras quantidades termodinâmicas são derivadas. Assim, para ser consistente com o padrão OpenFOAM e ser flexível em termos de modelagem termodinâmica, o solver proposto nesse trabalho, o flameletsprayFoam, utiliza o flameMaster para calcular a entalpia a partir da temperatura dada. O conjunto completo de modelos termodinâmicos do OpenFOAM está disponível para esta etapa.

Os valores para a fração de massa para cada espécie $Y_{k}$ é calculado dentro da Eq. (4-34) com o termo fonte $\dot{m}_{i}$, utilizando o FlameMaster, em função da fração de mistura $Z$ e não mais na Eq. (4-15) e na Eq. (4-16), como é feito no reator PaSR. Após a integração da PDF, os valores médios da fração de massa da espécies $\widetilde{Y}_{k}$ e da entalpia $\widetilde{h}_{s}$ são gerados e armazenados na "biblioteca de chamas"(flamelet) em função dos valores médios da fração de mistura $\widetilde{Z}$, da variância da fração de mistura $\widetilde{Z^{\prime \prime 2}}$ e da taxa de dissipação escalar na mistura estequiométrica $\widetilde{\chi_{s t}}$. Estas três quantidades, proporcionadas pelo préprocessamento do código CFD (FMFoam) no OpenFoam, são utilizadas pelo solver CFD no OpenFoam que atualiza a biblioteca flamelet com os valores médios da fração de mistura $\widetilde{Z}$, da variância da fração de mistura $\widetilde{Z^{\prime \prime 2}}$ e da taxa de dissipação escalar na mistura estequiométrica $\widetilde{\chi_{s t}}$ como é mostrado na Fig. (5.1).

As chamas na biblioteca são caracterizadas por $\chi_{s t}$, enquanto que o valor incondicional pode ser calculado apenas com as Eq. (4-34) e a Eq. (4-34). Pitsch et al. [25] demonstraram que o modelo que faz uso da forma de PDF presumida pode ser utilizado para conectar a taxa de dissipação escalar $\chi$ a seu valor no ponto de estequiometria $\chi_{s t}$. No entanto, na prática a 


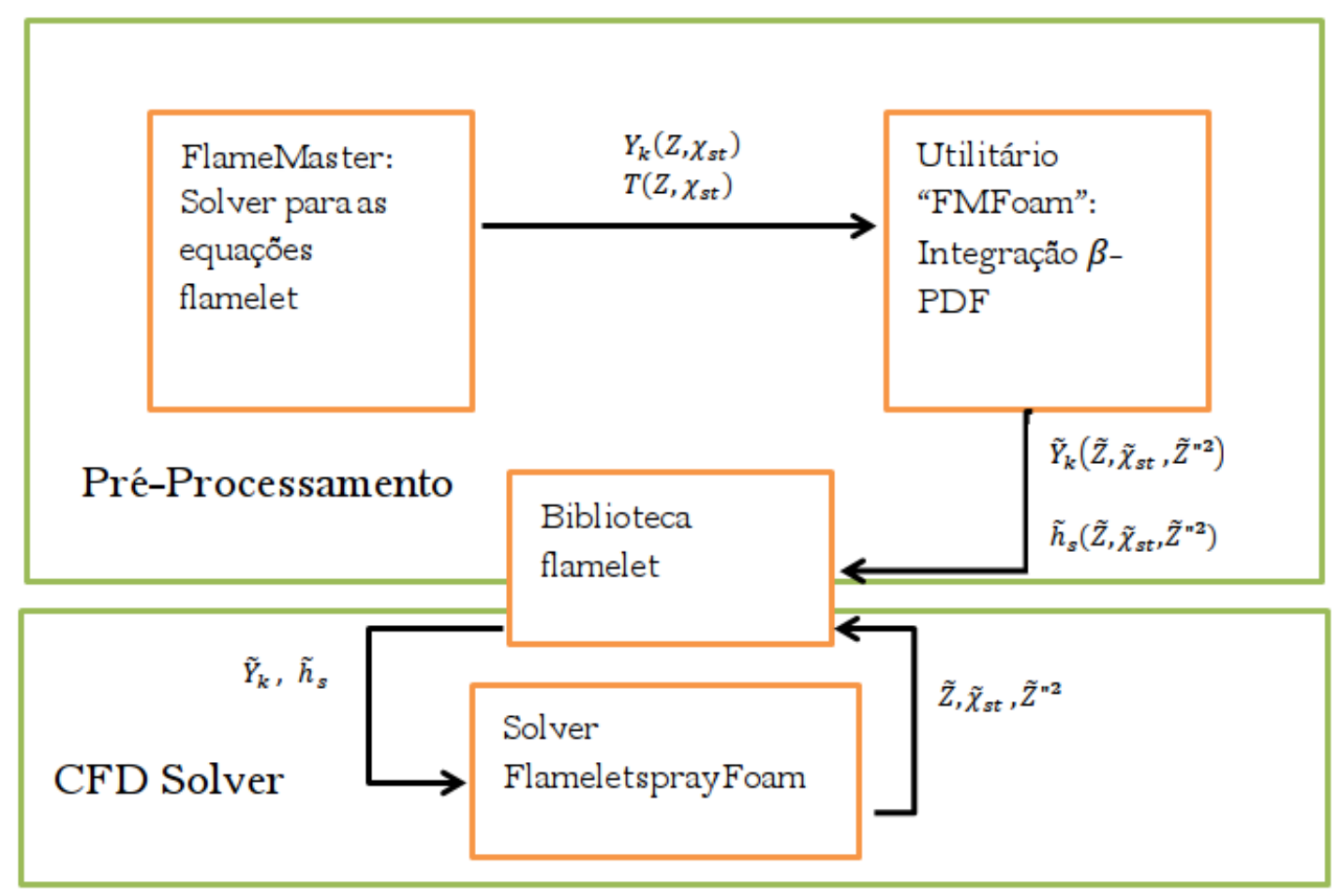

Figura 5.1: Esquema de construção das bibliotecas flamelet

aproximação $\chi=\chi_{\text {st }}$ é aceitável, uma vez que o seu erro é pequeno em torno da mistura estequiométrica, que é o foco de interesse. Além disso, modelar a taxa de dissipação escalar condicionada introduz incertezas adicionais. Por essa razão, a taxa de dissipação escalar incondicionada é utilizada na presente implementação para extrair as fracções de massa de espécies e a entalpia sensível nos flamelets.

Desta forma, a construção da tabela flamelets visa capturar todos os ramos importantes para a construção da chama difusiva, acompanhado dos pontos críticos, para a ignição e o início da fase estável. As diversas flamelets não pré-misturadas que estão representados na Fig. (5.2) formam uma zona de reação difusiva fina caracterizando-se por um elevado gradiente de temperatura em torno da fração mistura estequiométrica $Z_{s t}$. À medida que o alongamento do flamelets aumenta, o pico de temperatura cai devido ao maior grau de perda de calor para as regiões exteriores da zona de reação em comparação com a quantidade de calor libertado. O flamelets finalmente extingue quando a taxa de dissipação atinge seu limite $\chi_{s t}=\chi_{s t, q}$, resultando em uma mistura dos reagentes inerte. Os perfis flamelets dos reagentes são mostrados na Fig. (5.3). 


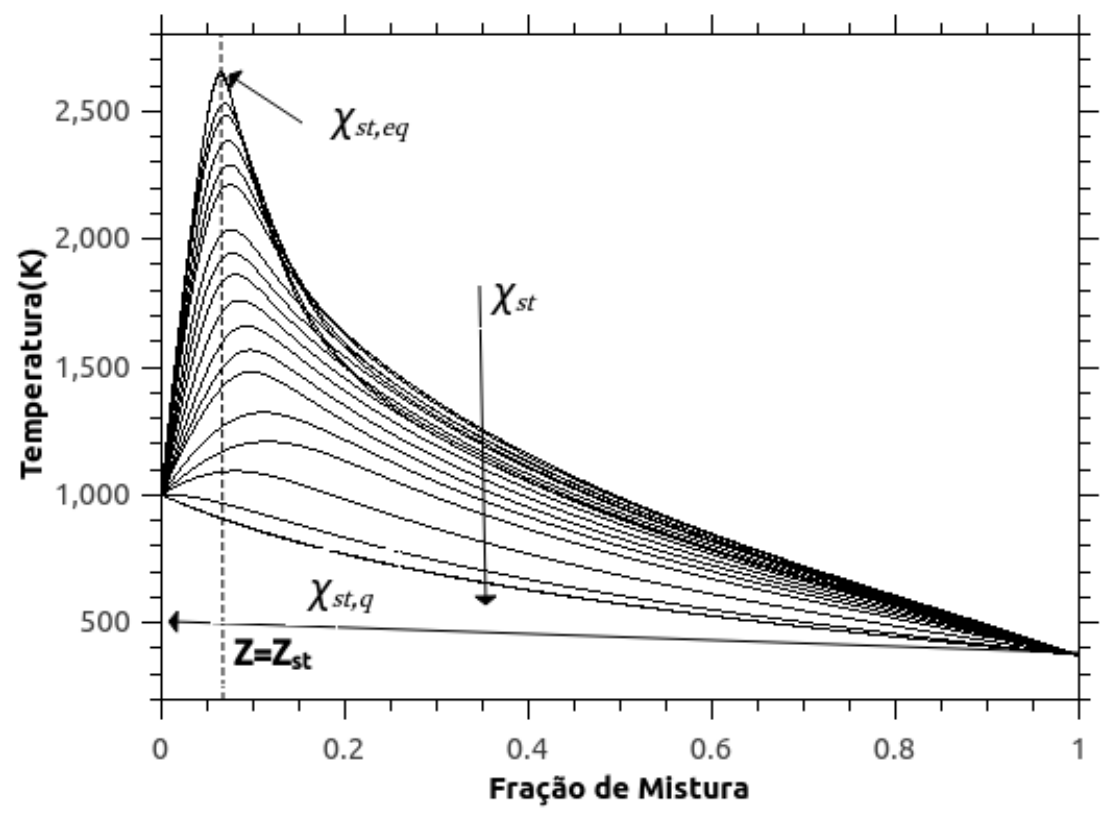

Figura 5.2: Curvas de perfis de temperatura em função da fração de mistura para $T_{a}=1000 \mathrm{~K}, T_{f}=373 \mathrm{~K}$.

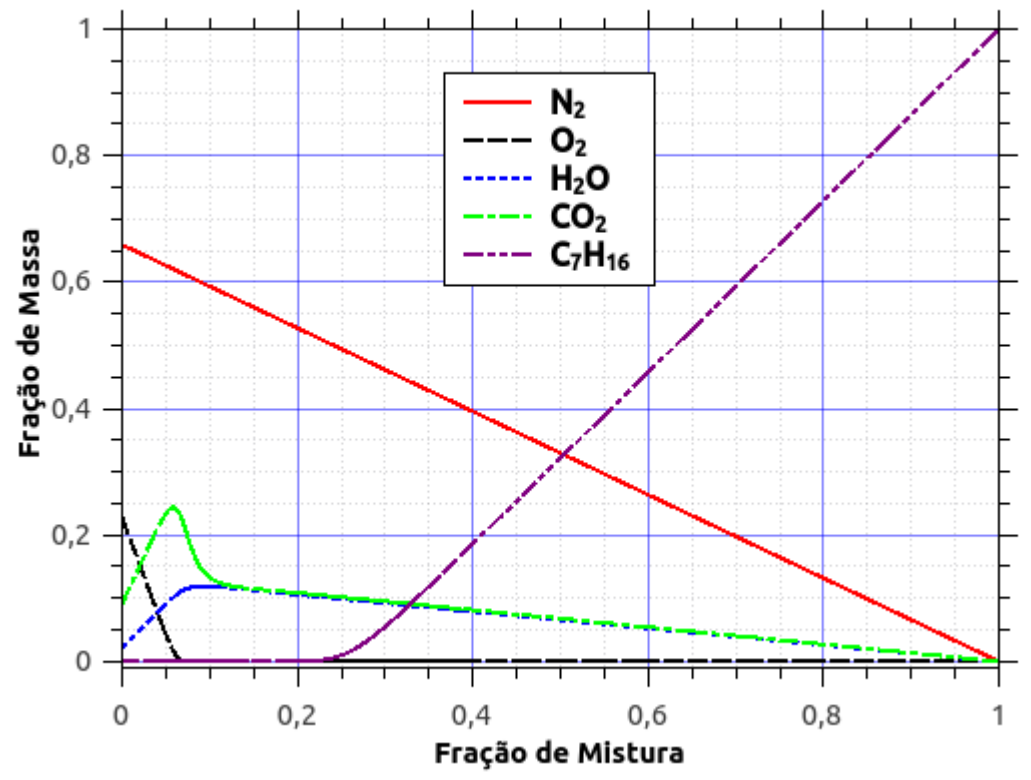

Figura 5.3: Curvas de fração de massa dos reagentes em função da fração de mistura para $T_{a}=1000 \mathrm{~K}, T_{f}=373 \mathrm{~K}$ e e $21 O_{2} \%$.

Para mapear as regiões importantes para a construção da tabela, desde a ignição até a extinção, faz-se necessário a utilização de um gráfico que cubra todos os pontos críticos em função $\chi_{s t}$. Assim, define-se a curva-S mostrada na Fig. (5.4) , onde os ramos superiores indicam o local aonde as chamas são 
estáveis, o ramo do meio indica as chamas instáveis e o ramo de mistura é indicado pelo ramo inferior.

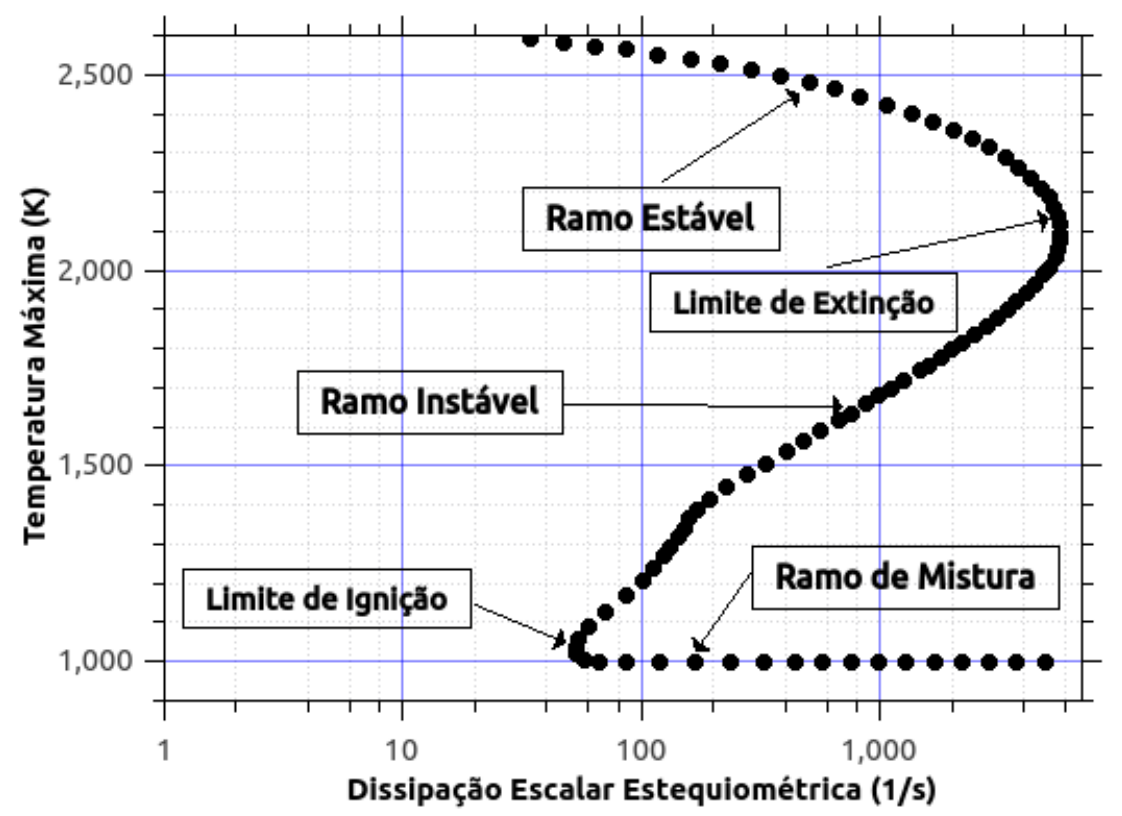

Figura 5.4: Curva-S para $T_{a}=1000 K, T_{f}=373 K$

O solver flameletsprayFoam foi desenvolvido com base no flameletFoam desenvolvido por Muller [2], porém com o acréscimo das bibliotecas para a fase líquida e alterando o software de cinética química laminar, do Cantera para o FlameMaster, devido a sua estabilidade e credibilidade para utilização de mecanismos de cinética química complexos, como o n-heptano, dentro do espaço da fração de mistura. Além disso, exigiu-se um acréscimo do termo fonte de evaporação $\rho \dot{S}$ dentro da equação de conservação da fração de mistura (Eq. (4-24)). Uma vez que, o flameletFoam foi desenvolvido para simular chamas difusivas turbulentas monofásicas. 
Tabela 5.1: Tabela de condições iniciais e condições de contorno para o sprayFoam

\begin{tabular}{|l|l|l|}
\hline Variável/Propriedade & Condição Inicial & Contorno na Parede \\
\hline alphat & Uniform value $=0$ & Zero gradient \\
$\mathrm{k}$ & Uniform value $=1$ & Compressible wall function \\
$\mathrm{mut}$ & Uniform value $=0.00036$ & Uniform value $=0.00036$ \\
$\mathrm{p}$ & & Zero gradient \\
$\mathrm{T}$ & & Zero gradient \\
$\mathrm{Ux}$ & Unifor value $=0$ & Unifor value $=0$ \\
$\mathrm{Uz}$ & Uniform value $=0$ & Unifor value $=0$ \\
Ydefault & Uniform value $=0$ & Unifor value $=0$ \\
\hline
\end{tabular}

Tabela 5.2: Tabela de condições iniciais e condições de contorno para o flameletsprayFoam

\begin{tabular}{|c|c|c|}
\hline Variável/Propriedade & Condição Inicial & Contorno na Parede \\
\hline alphat & Uniform value $=0$ & Zero gradient \\
\hline & Uniform value $=1$ & Compressible wall function \\
\hline mut & Uniform value $=0.00036$ & Uniform value $=0.00036$ \\
\hline $\mathrm{p}$ & & Zero gradient \\
\hline $\mathrm{T}$ & & Zero gradient \\
\hline Ux & Unifor value $=0$ & Unifor value $=0$ \\
\hline Uy & Uniform value $=0$ & Unifor value $=0$ \\
\hline $\mathrm{Uz}$ & Uniform value $=0$ & Unifor value $=0$ \\
\hline chi & Uniform value $=0$ & Zero gradient \\
\hline varZ & Uniform value $=0$ & Zero gradient \\
\hline $\mathrm{Z}$ & Uniform value $=0$ & Zero gradient \\
\hline
\end{tabular}

\section{3}

\section{Condições de Contorno e Propriedades Físicas}

As condições iniciais e de contorno devem ser estabelecidas quando se resolve um conjunto de equações diferenciais para um dado caso. Estas condições são necessárias para que cada variável seja resolvida dentro do domínio. Na Tab. (5.1) será apresentado as condições para o sprayFoam e na Tab. (5.2) as condições utilizadas para o flameletsprayFoam: 
Os valores para pressão ambiente e temperatura estão em branco pois variam de acordo com o caso selecionado.

\section{4}

\section{Volumes Finitos e Algoritmos de solução}

O OpenFoam usa o método de Volumes Finitos para discretizar problemas de mecânica do contínuo. De acordo com [77], há três termos que podem ser discretizados: espaço, tempo e equações diferenciais.

No método de volumes finitos, a discretização espacial é obtida dividindo o domínio da solução em um número definido, mas muitas vezes não fixo, de volumes de controle, também chamados de células. Essas células e o conjunto de seus vértices compõe a chamada malha.

As células são delimitadas por um conjunto arbitrário de faces planas, que podem ser orientadas sem qualquer restrição no seu alinhamento.

Cada célula possui um ponto de referência P que é o seu centroide, onde as variáveis dependentes, como as propriedades do escoamento, são definidas. No entanto, eles também podem estar em faces ou vértices.

O tempo é discretizado dividindo o domínio do tempo em um número finito de intervalos de tempo, cuja duração pode variar durante a simulação. Neste trabalho a duração do passo de tempo é fixa e igual a $1 X 10^{-6} s$ : este valor assegura uma melhor convergência do solver de spray.

A discretização das equações consiste em gerar um sistema de equações algébricas com base nas equações diferenciais parciais, que descrevem o problema físico e relacionadas a quantidades discretas definidas em locais específicos no domínio.

Cada categoria de termos matemáticos que compõe uma equação diferencial parcial pode ser discretizada com vários métodos. As técnicas de discretização utilizadas neste trabalho são agora apresentadas na Tab. (5.3).

O termo laplaciano é integrado ao longo de um volume de controle (célula) e, através do teorema de Gauss (que permite alternar de integrais de volume para integrais de superfície e vice-versa), é discretizado como

$$
\int_{V} \vec{\nabla} \cdot(\Gamma \vec{\nabla} \phi) d V=\int_{S} \overrightarrow{d S} \cdot(\Gamma \vec{\nabla} \phi)=\sum_{f} \Gamma_{f} \vec{S}_{f} \cdot(\vec{\nabla} \phi)_{f},
$$

onde $\Gamma_{f}$ é o coeficiente Laplaciano calculado através da Interpolação dos valores nos centróides das duas células vizinhas $P$ e $N$.

Os termos divergentes são discretizados como

$$
\int_{V} \vec{\nabla} \cdot(\rho \phi \vec{u}) d V=\int_{S} \overrightarrow{d S} \cdot(\rho \phi \vec{u})=\sum_{f} \vec{S}_{f} \cdot(\rho \vec{u})_{f} \phi_{f},
$$

onde $\phi_{f}$ é calculado através da interpolação linear. 
Vários solvers estão disponíveis no OpenFoam para resolver os conjuntos de equações lineares discretizadas. Devido às enormes dimensões das matrizes envolvidas na computação, um solver iterativo deve ser escolhido.

Neste estudo, um solver baseado no algoritmo 'Gradiente Conjugado'. Para conseguir uma convergência rápida, o processo de resolução é precedido por pré-condicionamento.

O solver de gradiente conjugado pré-condicionado (em inglês, Preconditioned Conjugate Gradient solver (PPG)) funciona somente em matrizes simétricas, portanto, é usado apenas para resolver a equação de continuidade e a equação de pressão no loop PISO. O pré-condicionador para este solver é baseado no algoritmo de Cholesky com Diagonal Incompleta (em inglês, Diagonal incomplete Cholesky (DIC)).

Como os termos de divergência geram matrizes assimétricas, a equação de quantidade de movimento, a equação energia, a equação $\mathrm{k}-\epsilon$, a equação para a fração de mistura e para a variância não podem ser resolvidas com o algoritmo PCG. Gradiente pré-condicionado bi-conjugado (em inglês, Pre-conditioned bi-Conjugate Gradient (PBiCG)), uma evolução do algoritmo de Gradiente Conjugado que pode gerenciar matrizes assimétricas, é usado juntamente com um pré-condicionador LU com Diagonal Incompleta (em inglês, Diagonal Incomplete LU (DILU)). 


\subsection{1}

\section{Esquemas de discretização}

Os esquemas de discretização que foram utilizados para os diferentes termos estão resumidos na Tab. (5.3) para o sprayFoam e para o flameletsprayFoam. 
Tabela 5.3: Tabela com os Esquemas de discretização para o sprayFoam e flameletsprayFoam

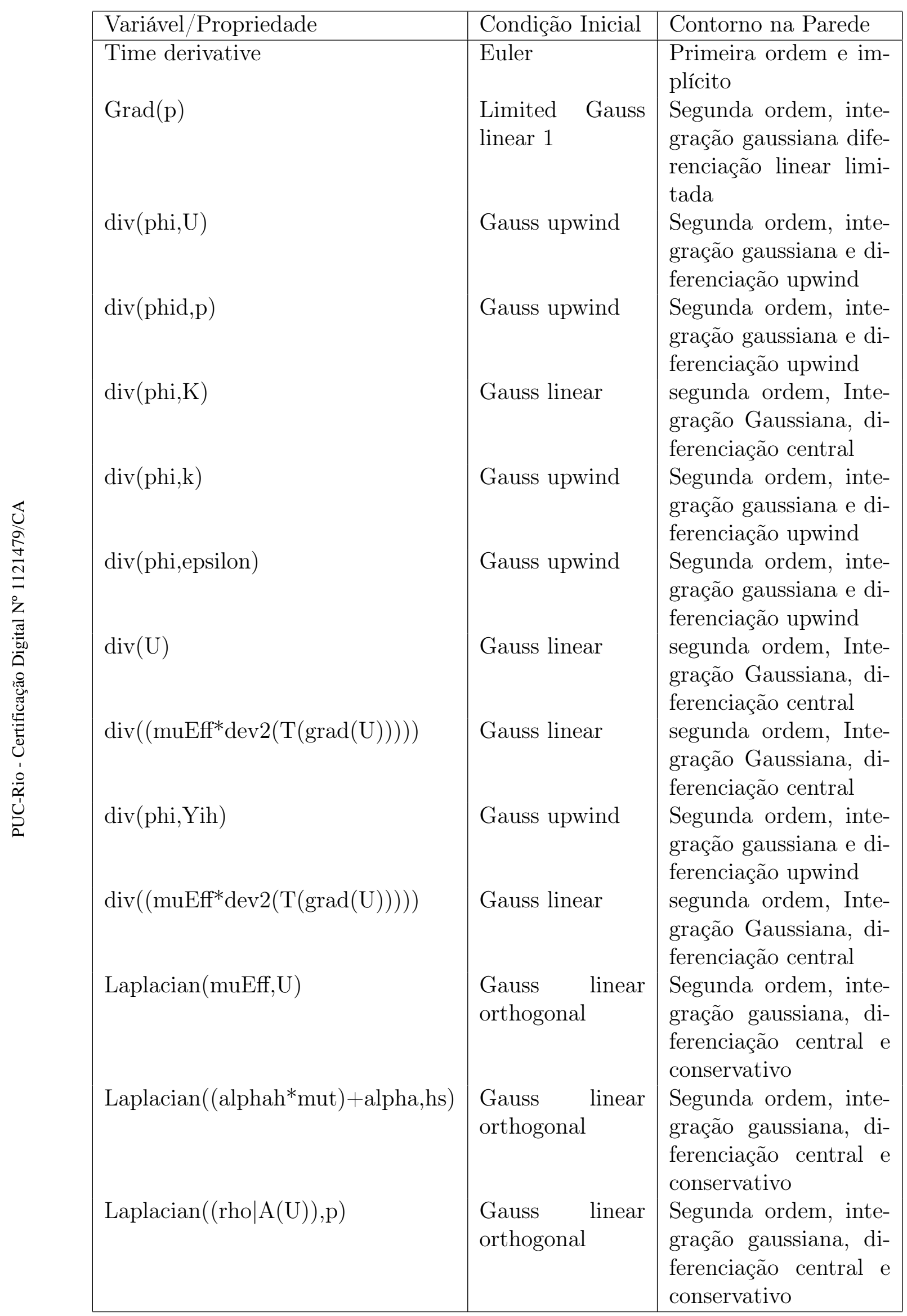




\section{5}

\section{Configuração da Malha}

A malha do domínio físico é representada na Fig. (5.5) e na seção transversal Fig. (5.6) com o spray . Esta malha foi gerada no software gmsh e reproduz a câmara de combustão do SNL, que é modelada como um cubo de dimensão $108 \mathrm{~mm}$ x $108 \mathrm{~mm}$ x $108 \mathrm{~mm}$. Onde o número de pontos em cada aresta para a simulação 3-D foi variado com o objetivo de variar a influência da malha na simulação, como será mostrado no capítulo de resultados.

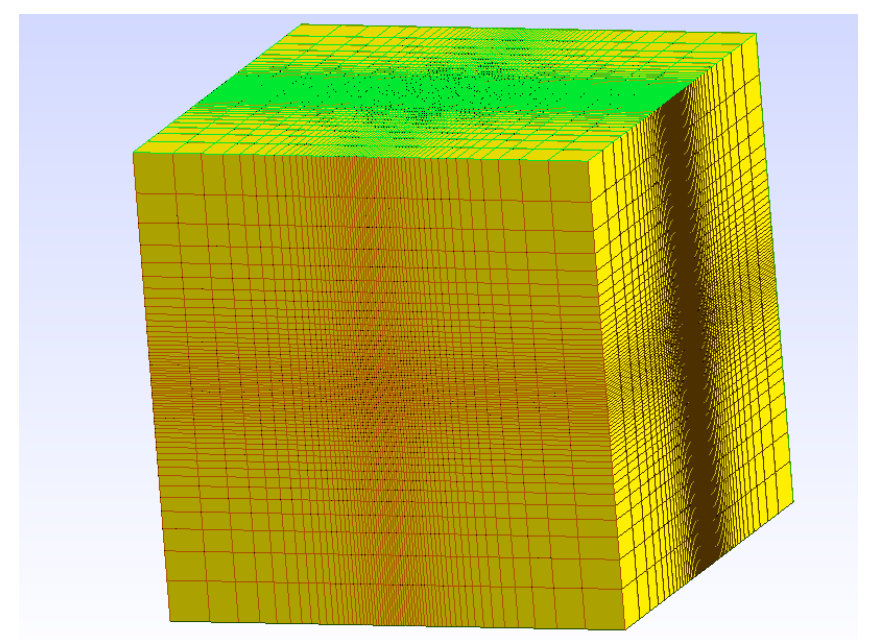

Figura 5.5: Geometria da câmara de combustão

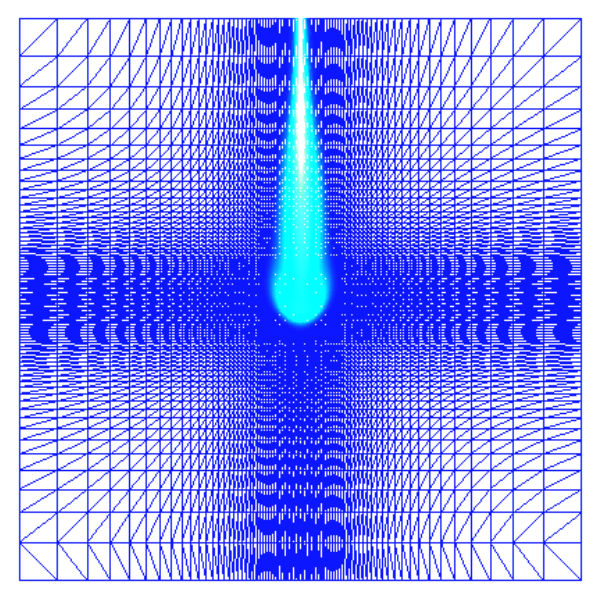

Figura 5.6: Seção transversal do domínio de malha 


\section{6 \\ Resultados}

Antes de estudar spray propriamente dito, necessitou-se avaliar o mecanismo de cinética química de modo que, fosse capaz de reproduzir os dados experimentais com uma maior precisão. Sendo assim, inicialmente estudou-se a autoignição na configuração de contrafluxo em uma chama difusiva laminar na Fig. (6.1), nas condições de contorno estabelecidas por Seiser et al [8] 15\% de n-Heptano pré-vaporizado e diluído com $85 \% N_{2}$ a uma temperatura de $572 \mathrm{~K}$ e ar $\left(N_{2}=79 \%\right.$ e $\left.O_{2}=21 \%\right)$ a uma temperatura de $827 \mathrm{~K}$. A pressão é fixada a $40 \mathrm{~atm}$. A temperatura de $572 \mathrm{~K}$ corresponde a temperatura de ebulição do n-heptano a 40 atm e $827 \mathrm{~K}$ é obtido a partir da compressão adiabática do ar a $300 \mathrm{~K}$ de $1 \mathrm{~atm}$ até $40 \mathrm{~atm}[9]$.

\section{Ar + Nitrogênio}

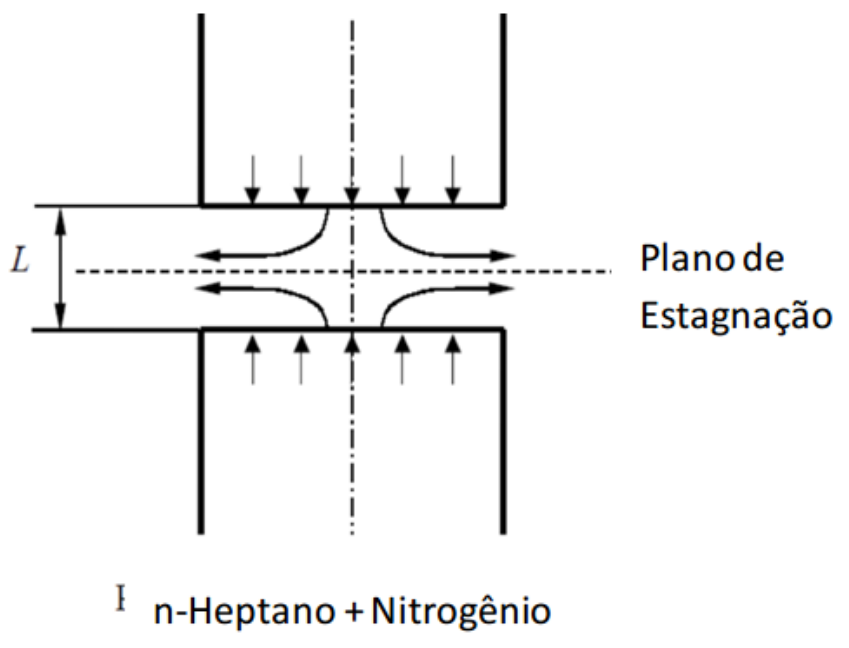

Figura 6.1: Configuração do Contrafluxo [8]

Para o estudo do spray, seis casos experimentais foram selecionados para a análise. Estes casos e as suas condições estão listadas na Tab.(6.1). A seleção desses casos foi feita da seguinte forma: o caso $3\left(\mathrm{O}_{2}=0 \%\right)$ serve como uma validação do modelo de vaporização e caracterização da penetração dos combustíveis nas fases gasosas e líquidas. Todos os outros casos contém $21 \% O_{2}$ no gás ambiente e entram em combustão. O objetivo é obter um estudo abrangente sobre o efeito da variação da temperatura ambiente no atraso de ignição e no comprimento de ancoramento da chama. 
Tabela 6.1: Tabela com os casos e condições experimentais utilizados para a validação

\begin{tabular}{|c|c|c|c|}
\hline Caso & $\mathrm{O}_{2} \%$ & $T_{a} K$ & Condições \\
\hline 1 & 21 & 800 & \multirow{6}{*}{$\begin{array}{l}\text { combustível }=\text { n-heptano } \\
d_{\text {bocal }}=100 \mu \mathrm{m} \\
p_{\text {inj }}=150 \mathrm{MPa} \\
\rho=14.8 \mathrm{Kg} / \mathrm{m}^{3} \\
T_{f}=373 \mathrm{~K}\end{array}$} \\
\hline 2 & 21 & 900 & \\
\hline 3 & 0 & 1000 & \\
\hline 4 & 21 & 1000 & \\
\hline 5 & 21 & 1100 & \\
\hline 6 & 21 & 1200 & \\
\hline
\end{tabular}

6.1

\section{Avaliação do Mecanismo de Cinética Química Através do Contrafluxo}

Os casos analisados neste estudo foram resolvidas o software FlameMaster [25], utilizando as equações flamelet Eq.(4-34) e Eq.(4-35). Com o objetivo de analisar os mecanismo de cinética química para n-heptano com 43 espécies e 185 reações de Liu et al. [9], o mecanismo esquelético com 188 espécies [78] e o mecanismo esquelético com 68 espécies [79], ambos baseados no mecanismo de cinética química detalhada da LLNL com 561 espécies e 2539 reações.

Para o estudo da evolução da ignição temporal do mecanismo de cinética química com 43 espécies, considerou-se diversas taxas de dissipação escalares. Para as taxas de dissipação menores do que $\chi_{s t}=75,301 / \mathrm{s}$ as chamas encontra-se estáveis e o tempo de ignição é menor, conforme na Fig. (6.2). Portanto, para taxas de dissipação mais elevadas ocorre a extinção e a reignição da chama.

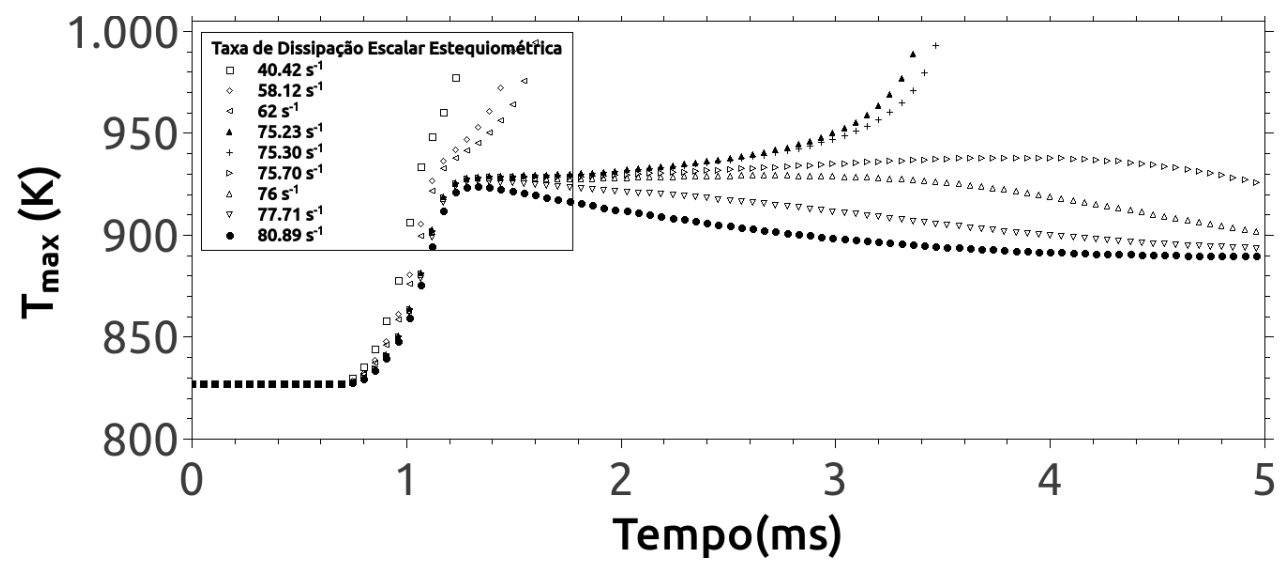

Figura 6.2: Evolução temporal da Temperatura para diversos valores de $\chi$ para a cinética química com 43 espécies [9]

De acordo com Kim [80] e Liu et al. [9], a taxa de dissipação do local varia em função da estequiometria e também com o aumento da temperatura 
de acordo com o coeficiente de difusão da temperatura. O aumento da taxa de dissipação escalar leva a um aumento no atraso da ignição e, se a taxa de dissipação de escalar é suficientemente grande, leva à inibição da ignição. A primeira fase da ignição, associada à baixa temperatura, é pouco sensível às variações na taxa de dissipação estequiométrica. $\mathrm{O}$ valor $\chi_{s t}=75,301 / \mathrm{s}$ representa um limite de ignição, pois para altas taxas de dissipação escalar o atraso de ignição indica que as reações químicas são lentas e que ocorre uma alta perda de calor.

No entanto, as cinéticas químicas com 68 espécies e 188 espécies não reproduzem o limite de ignição Fig. (6.3) e Fig. (6.4). De acordo com Liu et al. [9], as pressões elevadas favorecem o aumento das taxas de reação em conformidade com aceleração do processo de ignição. Onde, os gradientes induzidos por deformações retardam a ignição porque reduzem a espessura da zona de reação e aumentam as perdas de calor e os radicais produzidos durante o processo de ignição.

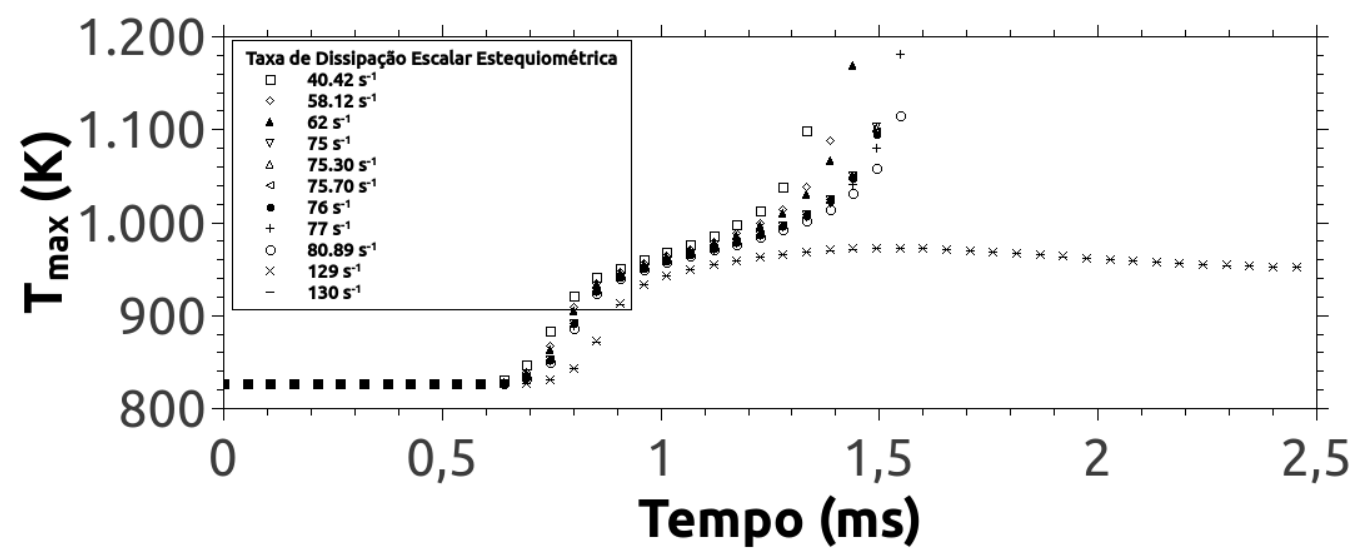

Figura 6.3: Evolução temporal da Temperatura para diversos valores de $\chi_{s t}$ para a cinética química com 68 espécies [9] 


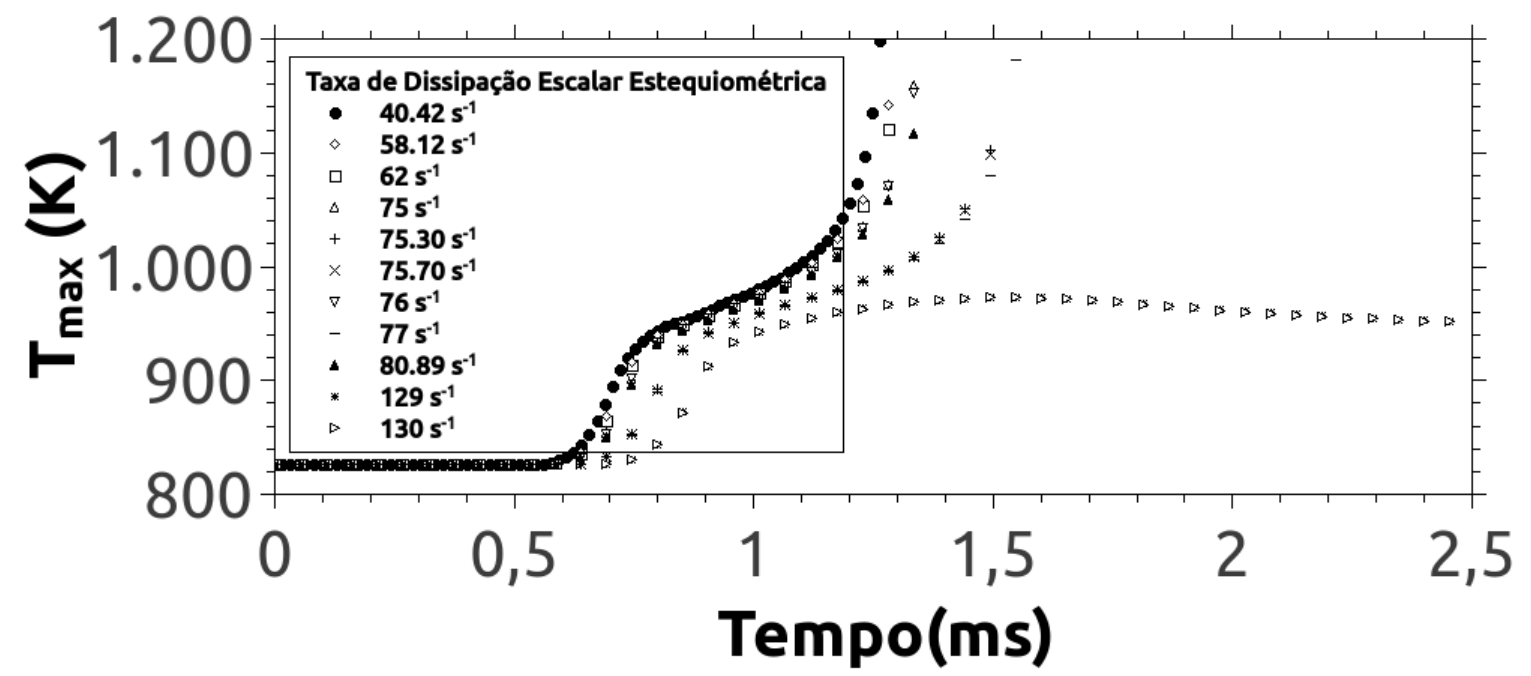

Figura 6.4: Evolução temporal da Temperatura para diversos valores de $\chi_{s t}$ para a cinética química com 188 espécies [9]

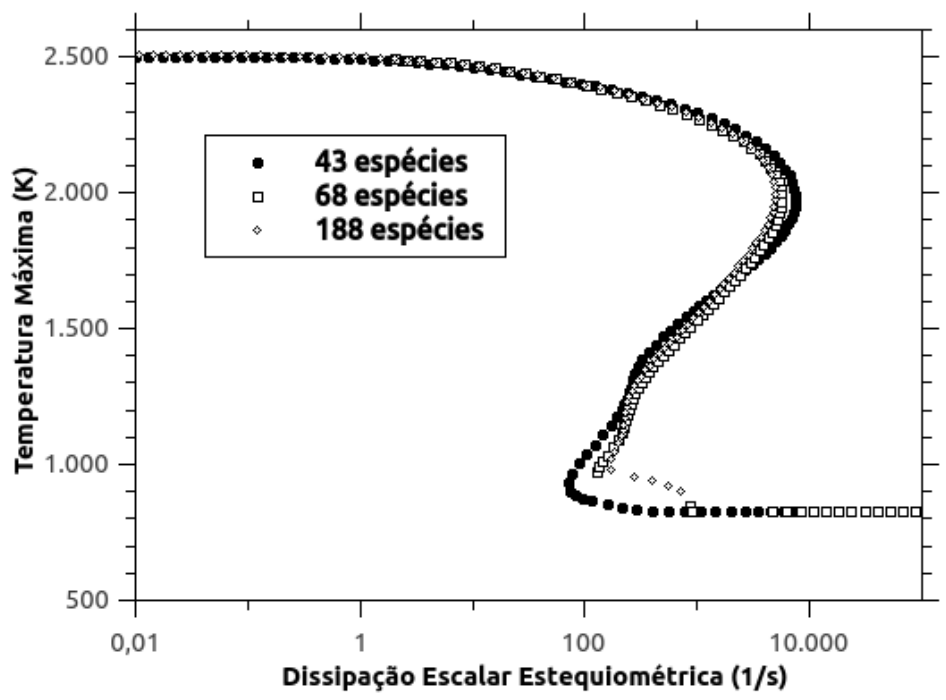

Figura 6.5: Curva-S para diversos mecanismos de cinética química

Ao comparar os mecanismos de cinética química, através da curva-S, na Fig. (6.5) com as Fig. (6.2), Fig. (6.3) e Fig. (6.4), percebe-se que o mecanismo com 43 espécies de Liu at al. [9] é o único capaz de reproduzir com precisão os tempos de ignição com o mínimo de espécies dependentes. De modo que, os passos de reação críticos fundamentais no processo de ignição possa ser identificado. Mecanismos de reação química são preditivos sobre uma ampla gama de condições como condição importante para o sucesso da aplicação dos 
modelos de combustão. Cinéticas químicas reduzidas visam reduzir os custos computacionais. Assim, a precisão de um método de tabulação está ligada pela precisão do mecanismo, que é utilizado para construir a tabela.

\section{2}

\section{Validação para o spray não reativo}

Para avaliar a capacidade do modelo de reproduzir corretamente tanto a auto-ignição como as fases da combustão na mistura controlada, não só a penetrações da fase vapor deve ser considerada, uma vez que estes dados não são totalmente representativos do processo de mistura ar-combustível, devese considerar também a variação radial da fração de mistura para diferentes distâncias do injetor [81]. Sendo assim, a modelagem proposta foi comparada com os dados experimentais, onde a concentração de oxigênio é igual a 0 e a temperatura ambiente e a densidade são, respectivamente, iguais a $1000 \mathrm{~K}$ e $14,8 \mathrm{~kg} / \mathrm{m}^{3}$, como descrito na Tab. (6.1).

Para estudar o escoamento não reativo, utilizou-se os seguintes parâmetros de interesse, a penetrabilidade do spray na fase líquida e na fase vapor e a variação radial da fração de mistura. Onde define-se a penetrabilidade na fase líquida e na fase vapor como:

Penetração da fase Líquida Distância axial abrangendo $95 \%$ da massa de combustível líquido injetado.

Penetração da fase Vapor A distância máxima, a partir do injetor, em que a fração de massa do combustível é de $0,1 \%$.

Para o estudo da variação da fração de mistura, considerou-se as distâncias de $20 \mathrm{~mm}$ e $40 \mathrm{~mm}$, a partir do ponto de injeção, nos instantes $0.7 \mathrm{~ms}$ e $1.15 \mathrm{~ms}$.

\subsection{1}

\section{Verificação das constantes do modelo de turbulência do modelo $k-\epsilon$}

O estudo da validação do código flameletsprayFoam, começou com a avaliação das constantes empíricas de turbulência do modelo $k-\epsilon$ na Tab. (6.2), divididos em dois casos A e B, onde variou-se os valores das constantes empíricas. Essa variação tem como intuito verificar a influência do modelo $k-\epsilon$ na penetrabilidade da fase vapor. Na Fig. (6.6) evidencia-se uma sensível influência da constante $c_{1 \epsilon}$ sobre a penetrabilidade na fase vapor, não alterando os valores de penetrabilidade da fase líquida. Verifica-se ainda que os valores de B ajustam-se melhor aos valores experimentais. Isso se deve a integrações 
Tabela 6.2: Constantes empíricas do modelo de turbulência $k-\epsilon$

\begin{tabular}{|c|c|c|c|c|c|}
\hline Modelos & $c_{\mu}$ & $c_{1 \epsilon}$ & $c_{2 \epsilon}$ & $\sigma_{k}$ & $\sigma_{\epsilon}$ \\
\hline $\mathrm{A}$ & 0.09 & 1.44 & 1.92 & 1.0 & 1.3 \\
\hline $\mathrm{B}$ & 0.09 & 1.55 & 1.92 & 1.0 & 1.4 \\
\hline
\end{tabular}

do modelo do turbulência e o modelo proposto para a equação de fração de mistura [82].

Essa diferença fica mais evidente quando fixa-se uma distância de $20 \mathrm{~mm}$ Fig. (6.7) do ponto de injeção em $t=0,7 \mathrm{~ms}$. Verifica-se que A possui $Z_{\text {max }}=0,05$ enquanto que, em B, em coerência com os dados experimentais [3], possui o valor de $Z_{\max }=0,18$. E com a evolução temporal, de $t=1.15 \mathrm{~ms}$ Fig. (6.8), essa diferença cai de $Z_{\max }=0,19 \mathrm{em} \mathrm{B}$ e $Z_{\max }=0,13 \mathrm{em} \mathrm{A}$, porém as constantes em $\mathrm{B}$ ainda representam melhor os dados experimentais para o escoamento não reativo. No entanto, quando evoluímos no tempo, em $t=1.15 \mathrm{~ms}$ e avançando $40 \mathrm{~mm}$ do bocal Fig. (6.9), tem-se o valor $Z_{\max }=0,15$ em B e $Z_{\max }=0,06$ em A, enquanto o valor experimental é de $Z_{\max }=0,09$. Isso mostra que, com o avanço espacial e temporal, torna-se difícil a validação radial para esse modelo [82].

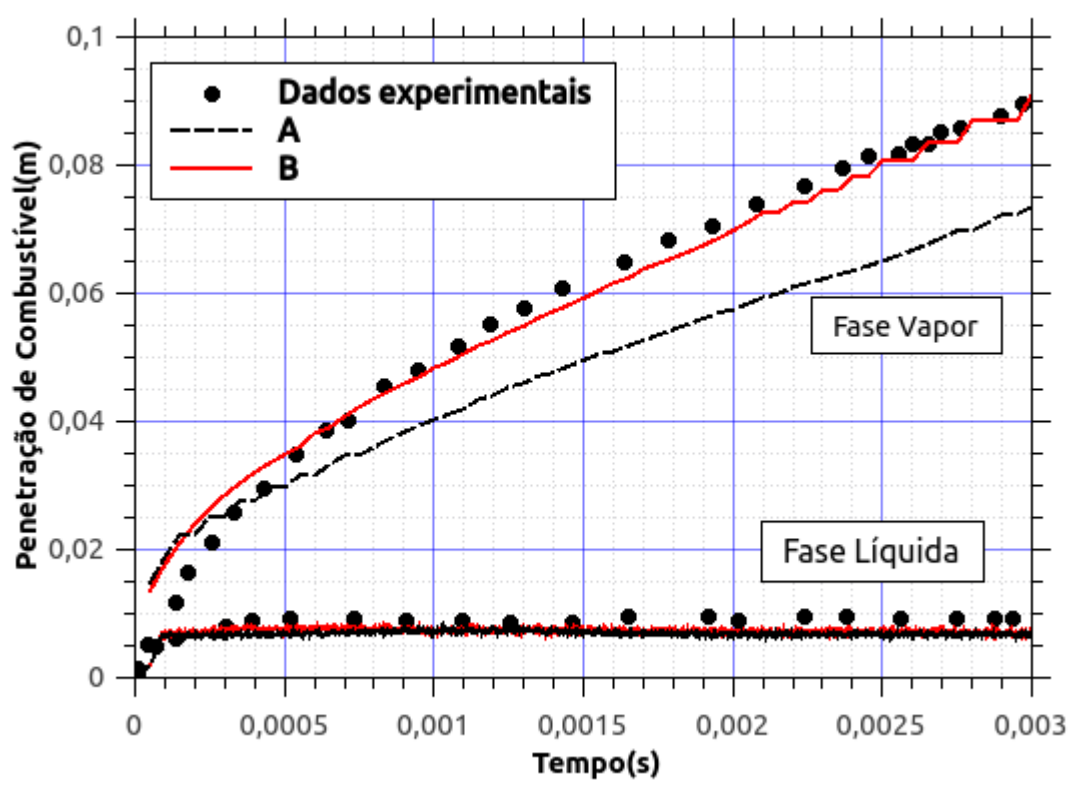

Figura 6.6: Evolução da fase líquida e da fase vapor comparando com dados experimentais [3] para diferentes valores de constantes de turbulência do modelo $k-\epsilon$ 


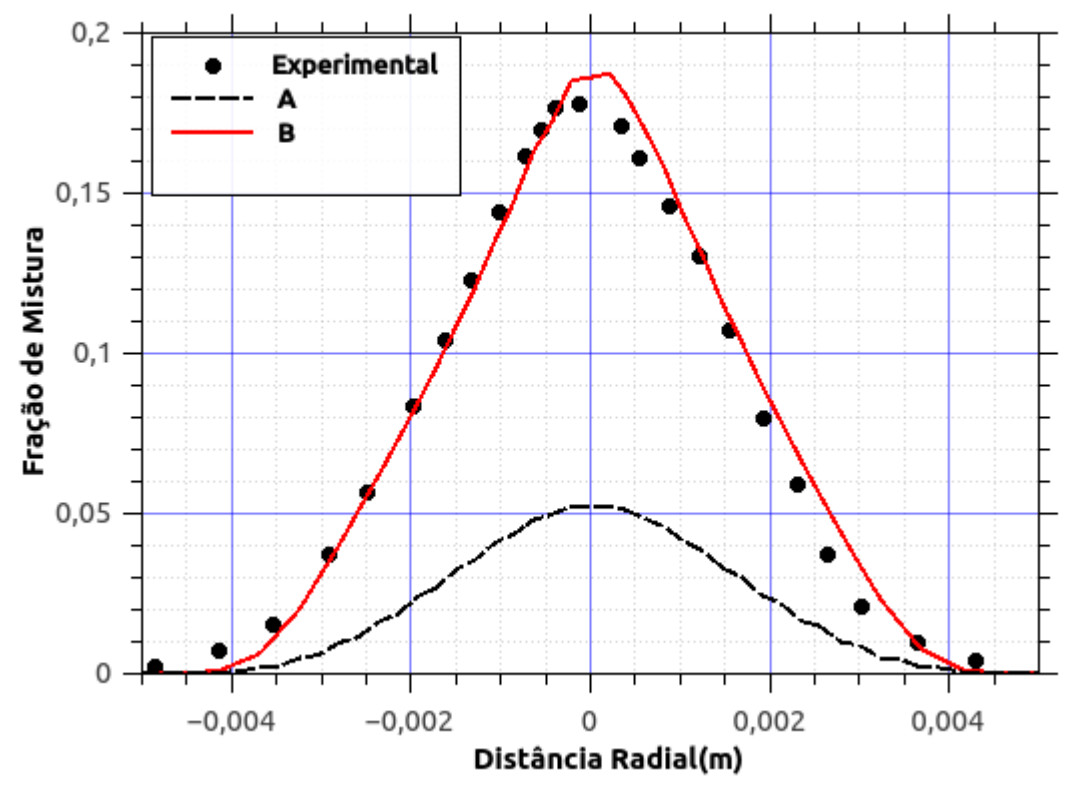

Figura 6.7: Evolução da fração de mistura comparando com dados experimentais [3] para diferentes valores de constantes de turbulência do modelo $k-\epsilon$ a $20 \mathrm{~mm}$ do ponto de injeção em $t=0,7 \mathrm{~ms}$

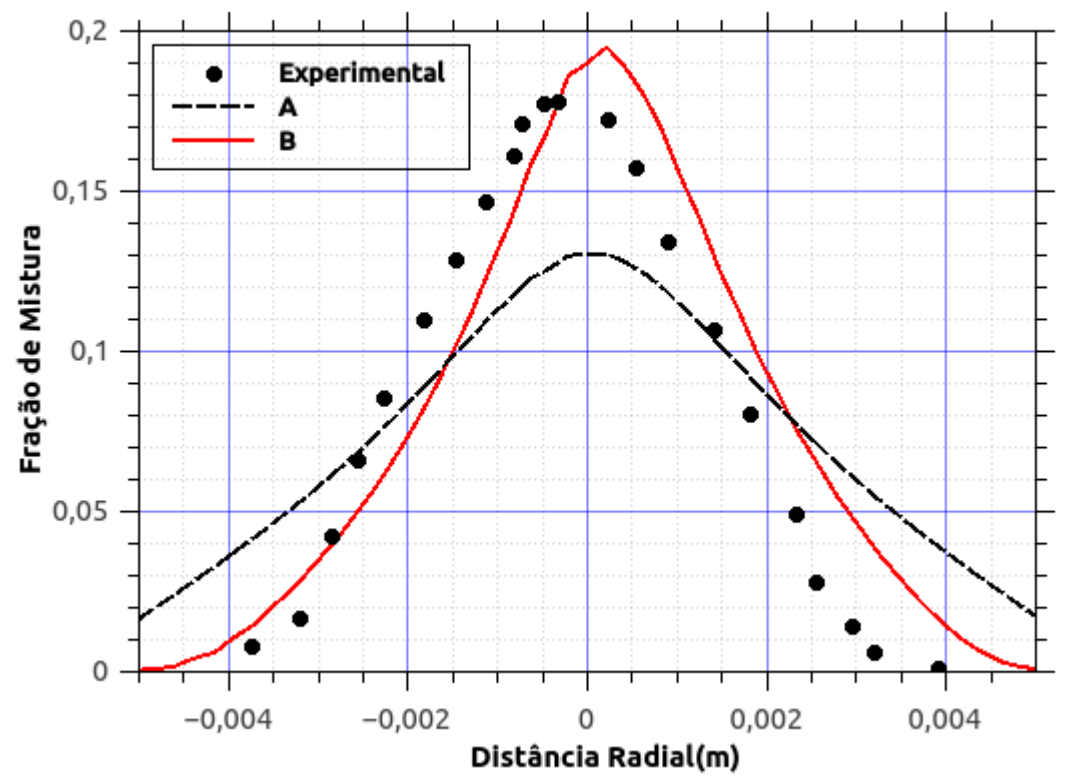

Figura 6.8: Evolução da fração de mistura comparando com dados experimentais [3] para diferentes valores de constantes de turbulência do modelo $k-\epsilon$ a $20 \mathrm{~mm}$ do ponto de injeção em $t=1,15 \mathrm{~ms}$ 


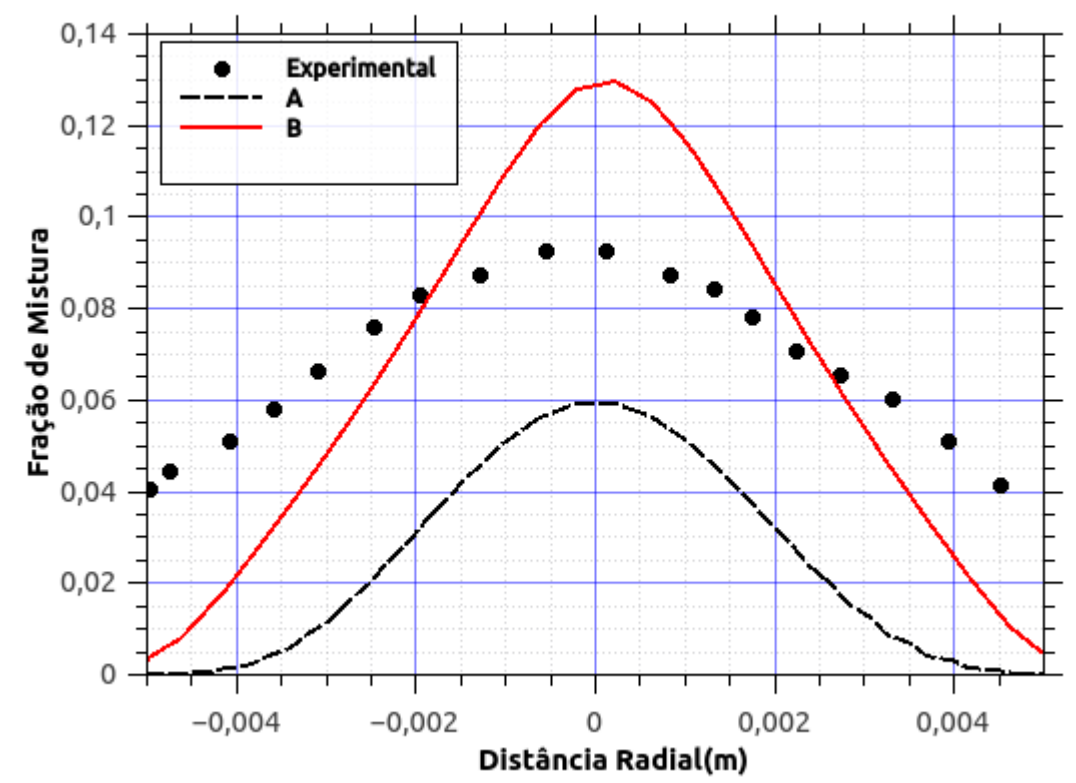

Figura 6.9: Evolução da fração de mistura comparando com dados experimentais [3] para diferentes valores de constantes de turbulência do modelo $k-\epsilon$ a $40 \mathrm{~mm}$ do ponto de injeção em $t=1,15 \mathrm{~ms}$

\section{2 .2}

\section{Teste de malha}

Após a avaliação das contantes de turbulência para o modelo $k-\epsilon$, avaliou-se a influência temporal e espacial da malha sobre a fase líquida, sobre a fase vapor e para a fração de mistura. Para isso, variou-se com 40 pontos, 60 pontos e 80 pontos em cada direção da malha. A malha é hexaédrica com o número de células variando de 59319 células até 493039 células.

Comparando a variação do número de pontos com os dados experimentais na penetrabilidade da fase vapor na Fig. (6.10), percebe-se que a principal diferença entre os perfis está após $2.5 \mathrm{~ms}$. Porém, essa diferença não se mostra significativa, devido ao fato de que a ignição do Diesel ocorre antes de $2.5 \mathrm{~ms}$, para todos os casos reativos citados nesse trabalho, na Tab. (6.1). Como foi dito anteriormente, o estudo da penetrabilidade da fase vapor e a variação radial da fração de mistura influem diretamente na autoignição do Diesel e na combustão [81]. Desta forma, optou-se pela escolha de 80 pontos em cada direção devido à sua melhor aproximação dos dados experimentais, observados tanto na Fig. (6.10) como na Fig. (6.11). 


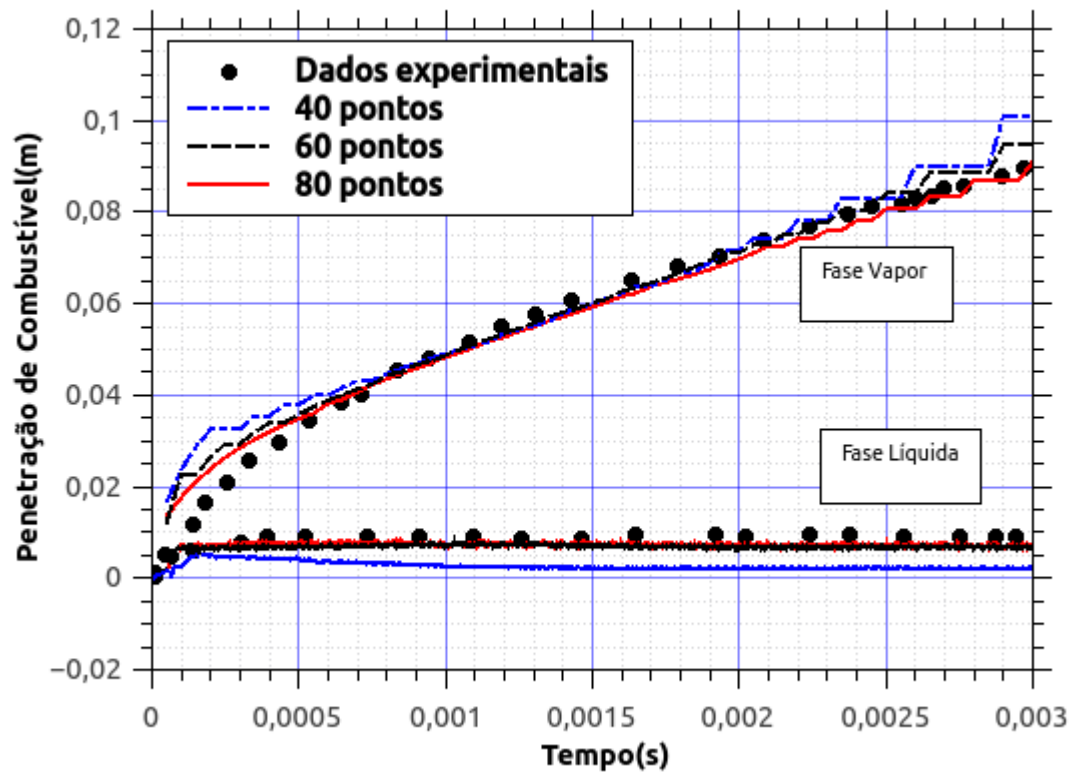

Figura 6.10: Convergência de malha variando o número de pontos e comparando com dados experimentais [3] para a fase líquida e fase vapor

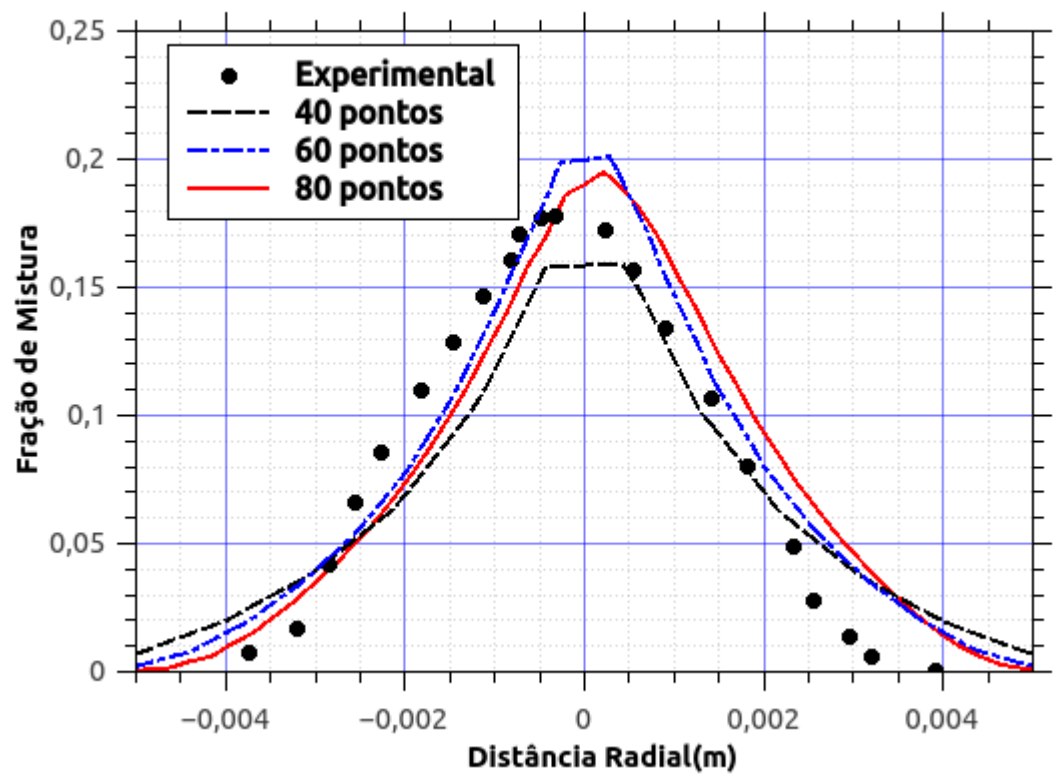

Figura 6.11: Convergência de malha variando o número de pontos e comparando com dados experimentais [3] para a fase líquida e fase vapor

\subsection{3}

\section{Variação do número de Courant}

Como a simulação do spray é transiente, o OpenFoam possui algumas opções adicionais que controlam o passo de tempo. A opção é utilizar um 
passo de tempo ajustável, onde OpenFOAM define automaticamente o passo de tempo com base no número Courant. O número Courant representa a velocidade de propagação de informação numérica por uma velocidade característica da propagação física.

$$
C o=\frac{\bar{v} \Delta t}{\delta x}
$$

onde $C o$ é o número Courant, $\bar{v}$ é a velocidade característica média na célula. $\delta x$ é a dimensão característica da célula e $\Delta t$ é o passo de tempo. Com o passo de tempo $\Delta t=1 \mu \mathrm{s}$ isso assegura $C o<1 \mathrm{em}$ todos os casos de validação. Assim como nos casos de validação para a variação do número de pontos (Fig. $6.10,6.11)$, a influência temporal sobre a variação do número de Courant fica evidente após o instante 2,5 ms na Fig. (6.12), descartando o $C o=0,05$, que é menos representativo em relação aos dados experimentais, comparado aos resultados para $C o=0,1$, sendo assim utilizado nas demais simulações.

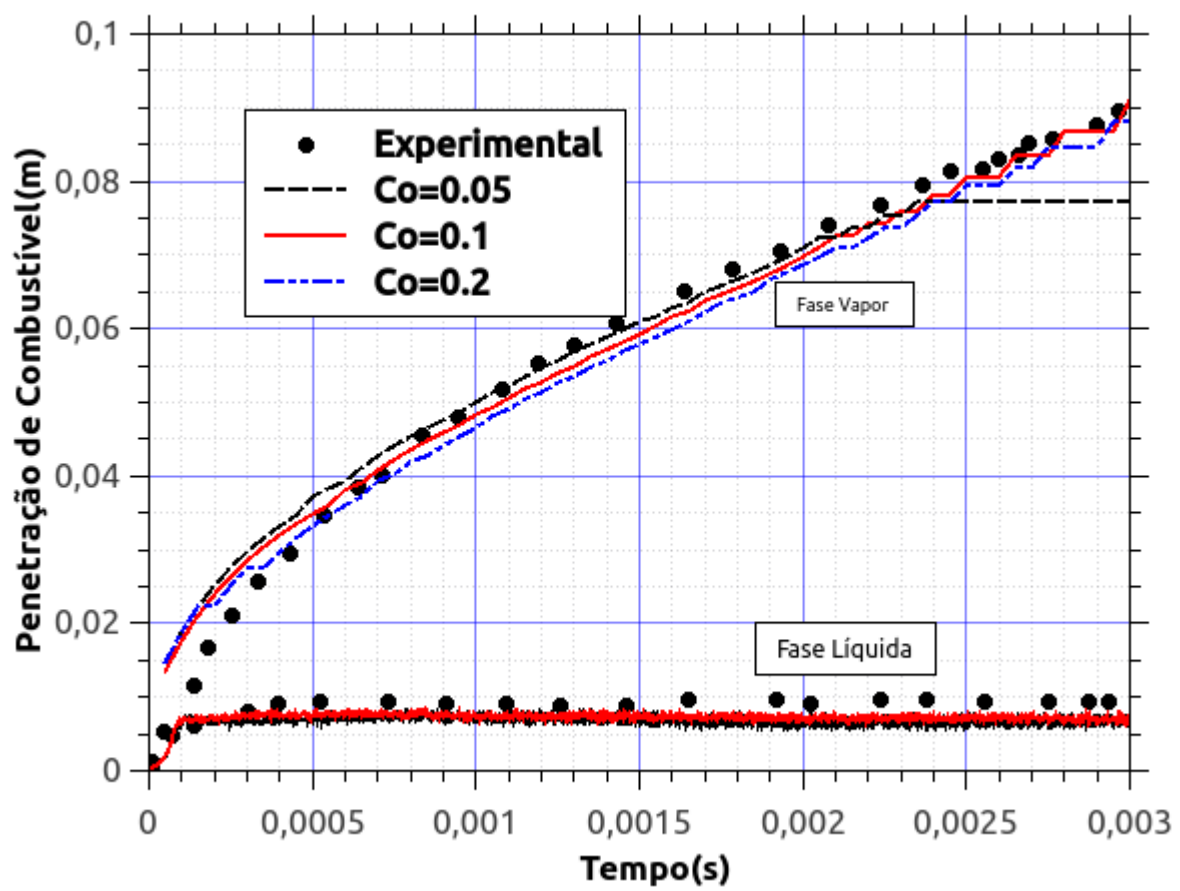

Figura 6.12: Evolução da fase líquida e da fase vapor comparando com dados experimentais [3] para diferentes valores do número de Courant

\section{2 .4}

\section{Comparação entre sprayFoam e flameletsprayFoam}

Para completar a simulação não reativa, comparou-se o sprayFoam e o flameletsprayFoam com as mesmas condições iniciais e os mesmos parâmetros lagrangianos. Como resultado na Fig. (6.13), verifica-se que sprayFoam tem 
uma penetrabilidade maior, tanto para a fase vapor como para a fase líquida, em relação ao flameletsprayFoam, devido à utilização das constantes de turbulência B. Porém, a diferença mais relevante, entre ambos os códigos, está no tempo de execução apresentado na Fig. (6.14). Pode-se mostrar que o sprayFoam leva em torno de $10 \mathrm{~h}$ para executar $3 \mathrm{~ms}$ de simulação computacional, enquanto o flameletsprayFoam leva em torno de $3 \mathrm{~h}$ os mesmos $3 \mathrm{~ms}$.

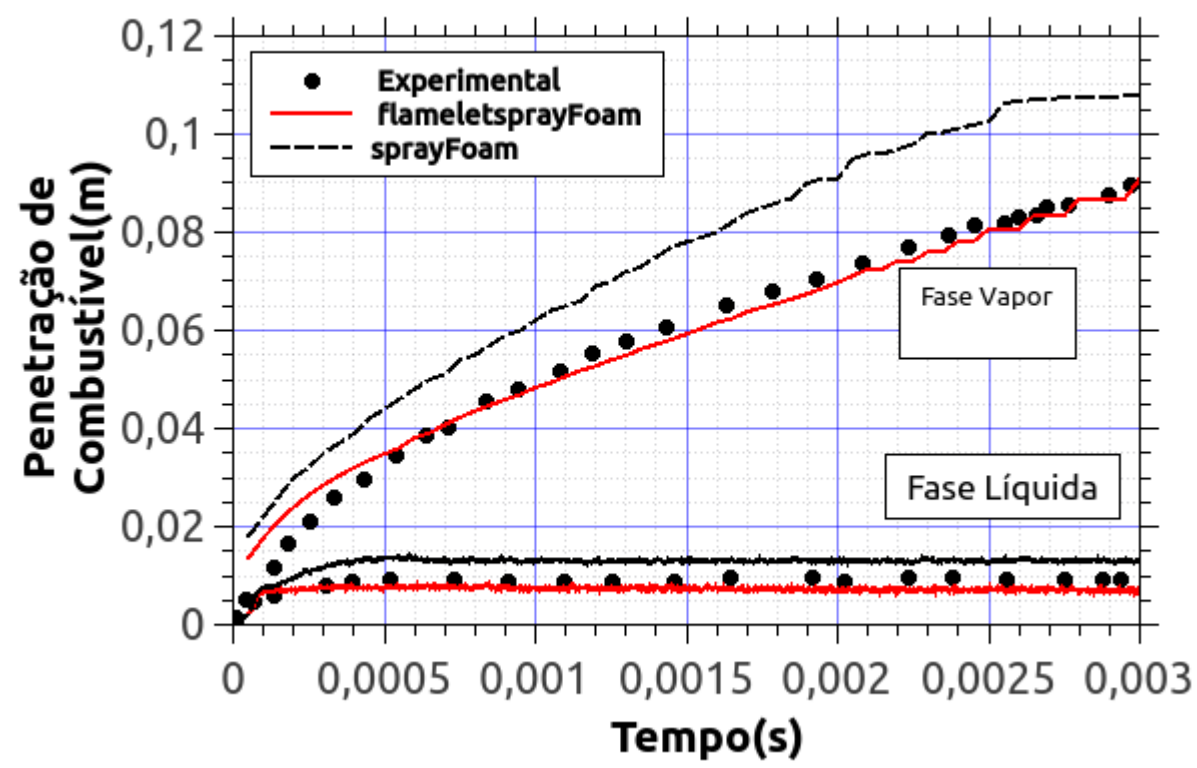

Figura 6.13: Evolução da fase líquida e da fase vapor comparando sprayFoam e flameletsprayFoam

\section{3}

\section{Validação para o escoamento reativo}

Nesta seção serão apresentados os parâmetros de interesse para o escoamento reativo relacionado ao spray. Desta forma, inicialmente será apresentado a construção das tabelas flamelet através do FlameMaster. Em seguida será comparado o custo computacional entre o flameletsprayFoam e o sprayFoam. E, fechando, será apresentado o estudo de ignição e o CAC para a variação da temperatura ambiente do spray.

\subsection{1}

\section{Comparação entre sprayFoam e flameletsprayFoam}

Ao comparar o sprayFoam e o flameletFoam reativos para $T_{a}=1000 \mathrm{~K}$, $T_{f}=373 \mathrm{~K}$ e $21 O_{2} \%$, na Fig. (6.15), percebe-se que o tempo computacional de execução do sprayFoam cresce exponencialmente em relação ao flamelets- 


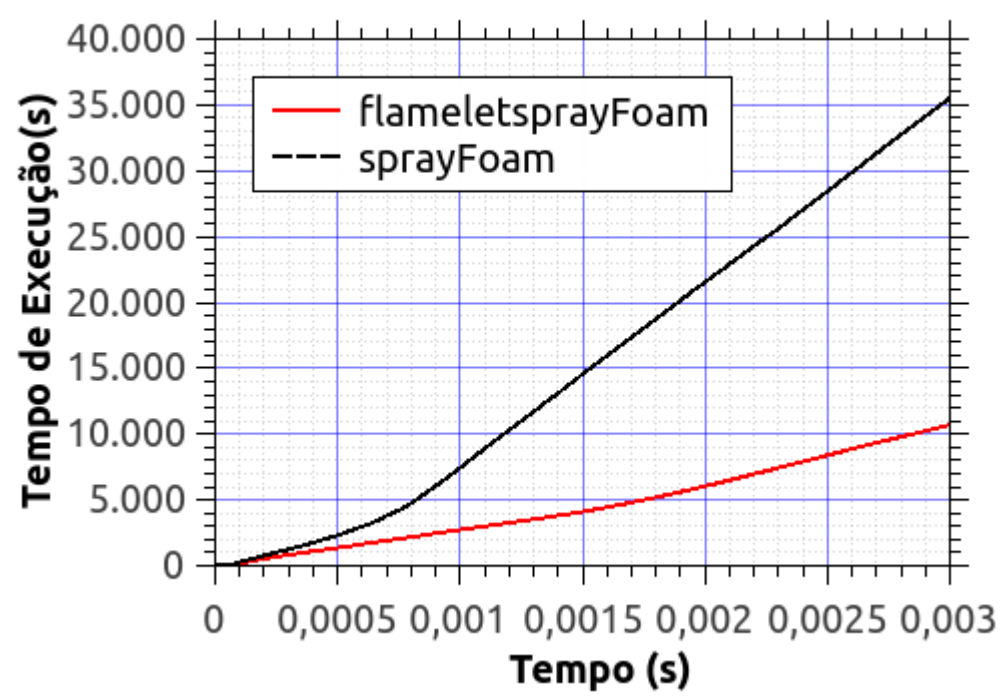

Figura 6.14: Evolução da fase líquida e da fase vapor comparando o tempo computacional entre o sprayFoam e flameletsprayFoam

prayFoam, acarretando em um custo computacional maior para o sprayFoam. As Fig. (6.16), Fig. (6.17) e Fig. (6.18) mostram que o flameletsprayFoam tem uma difusão maior que o sprayFoam, concentrando uma temperatura maior na ponta do spray para o sprayFoam. E, em concordância com os resultados não reativos, o flameletsprayFoam tem uma penetrabilidade maior do que o sprayFoam, em concordância com o resultado experimental. 


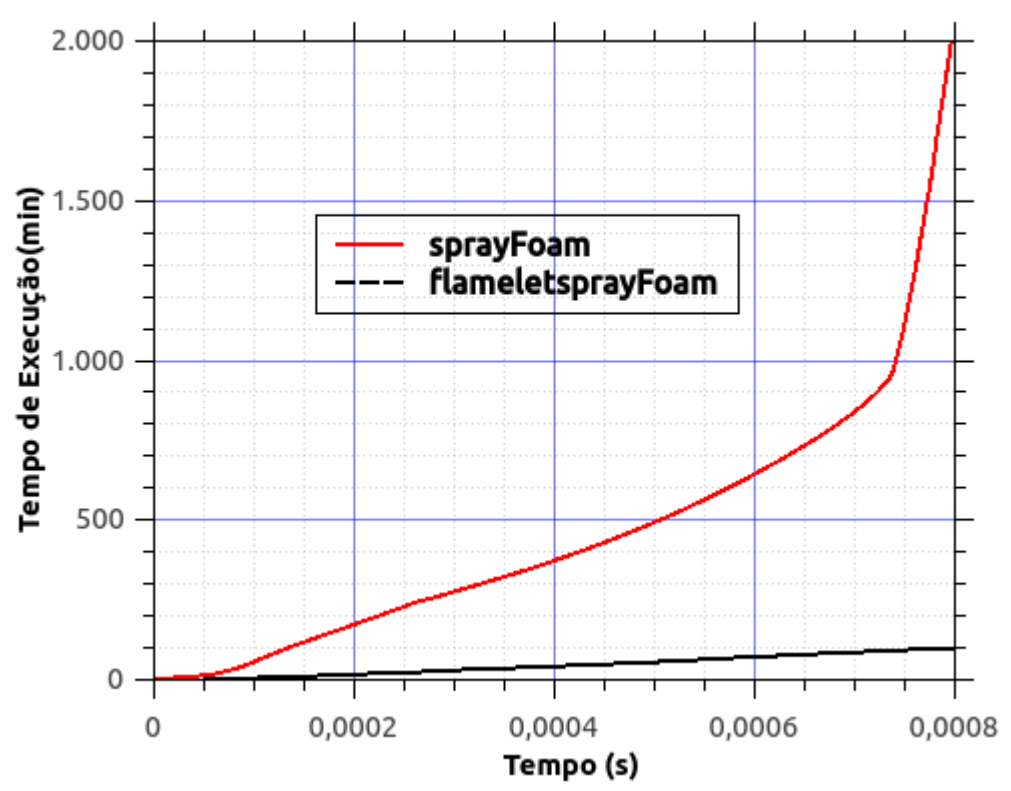

Figura 6.15: Tempo de execução para sprayFoam e flameletsprayFoam com $T_{a}=1000 K, T_{f}=373 \mathrm{~K}$ e $21 O_{2} \%$.

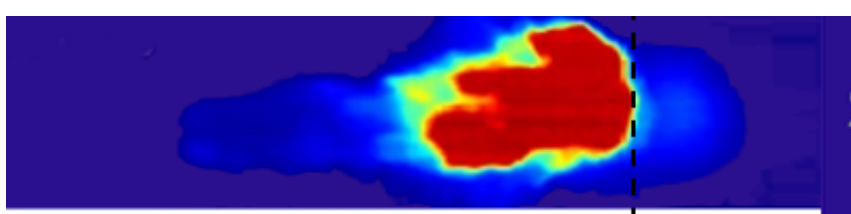

\section{$2.5 e+03$}

$\mathrm{T}$
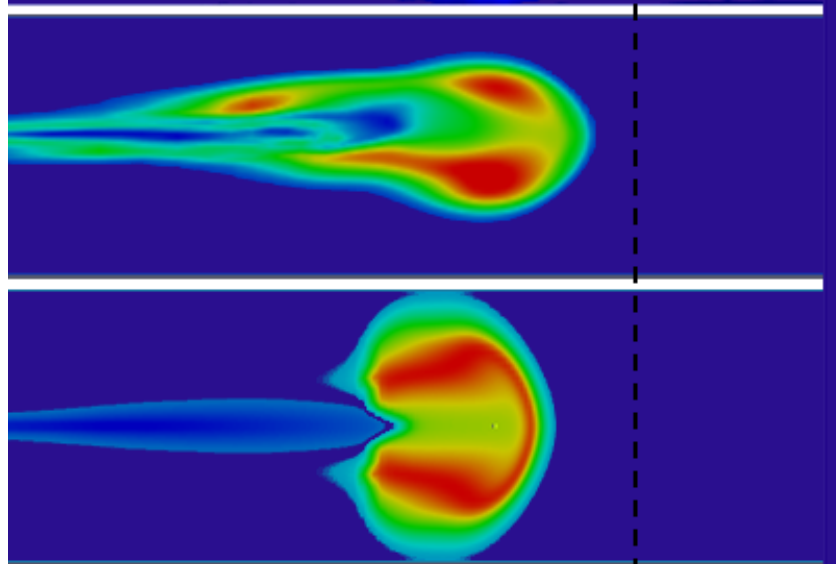

900

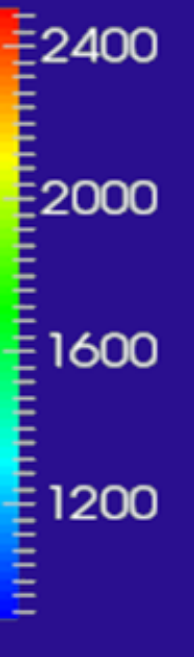

Figura 6.16: Spray Experimental(topo), flameletsprayFoam(meio) e sprayFoam(baixo) no instante de $1 \mathrm{~ms} T_{a}=1000 \mathrm{~K}, T_{f}=373 \mathrm{~K}$ e $21 \mathrm{O}_{2} \%$, com a marcação (pontilhado) a $54 \mathrm{~mm}$ do injetor. 


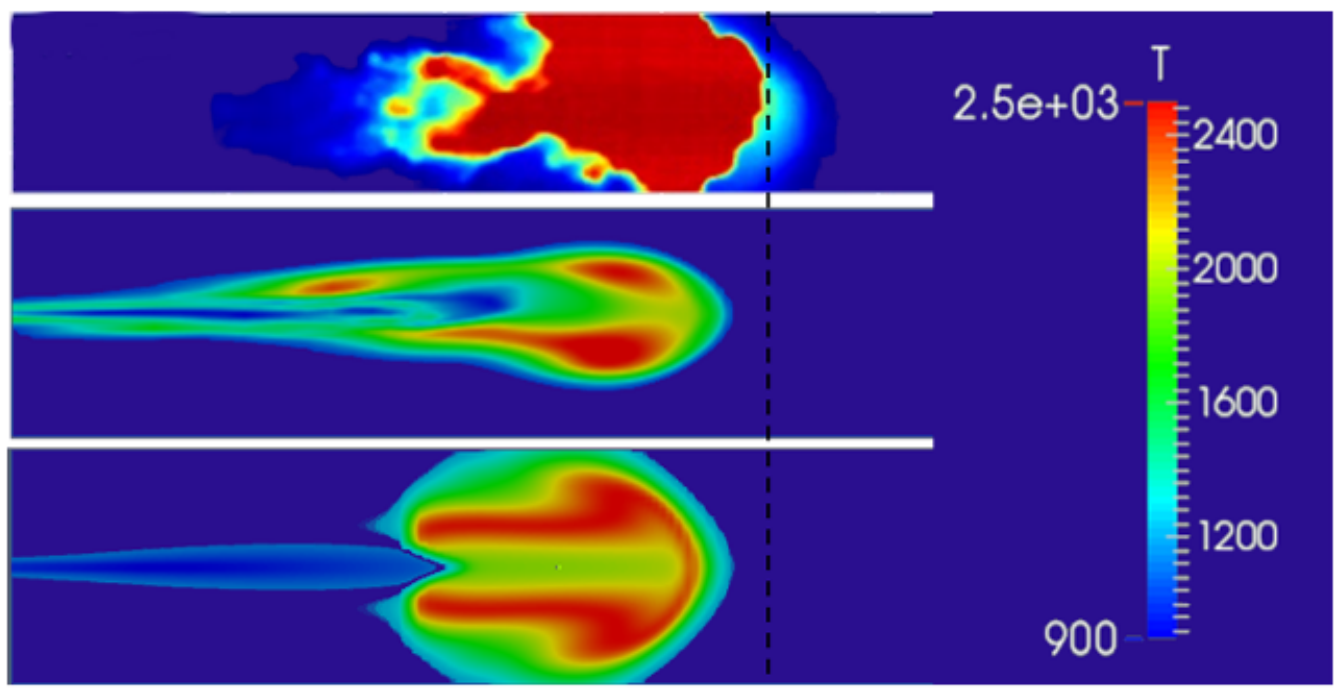

Figura 6.17: Spray Experimental(topo), flameletsprayFoam(meio) e sprayFoam(baixo) no instante de $1,5 \mathrm{~ms} T_{a}=1000 \mathrm{~K}, T_{f}=373 \mathrm{~K}$ e $21 \mathrm{O}_{2} \%$, com a marcação (pontilhado) a $69 \mathrm{~mm}$ do injetor.

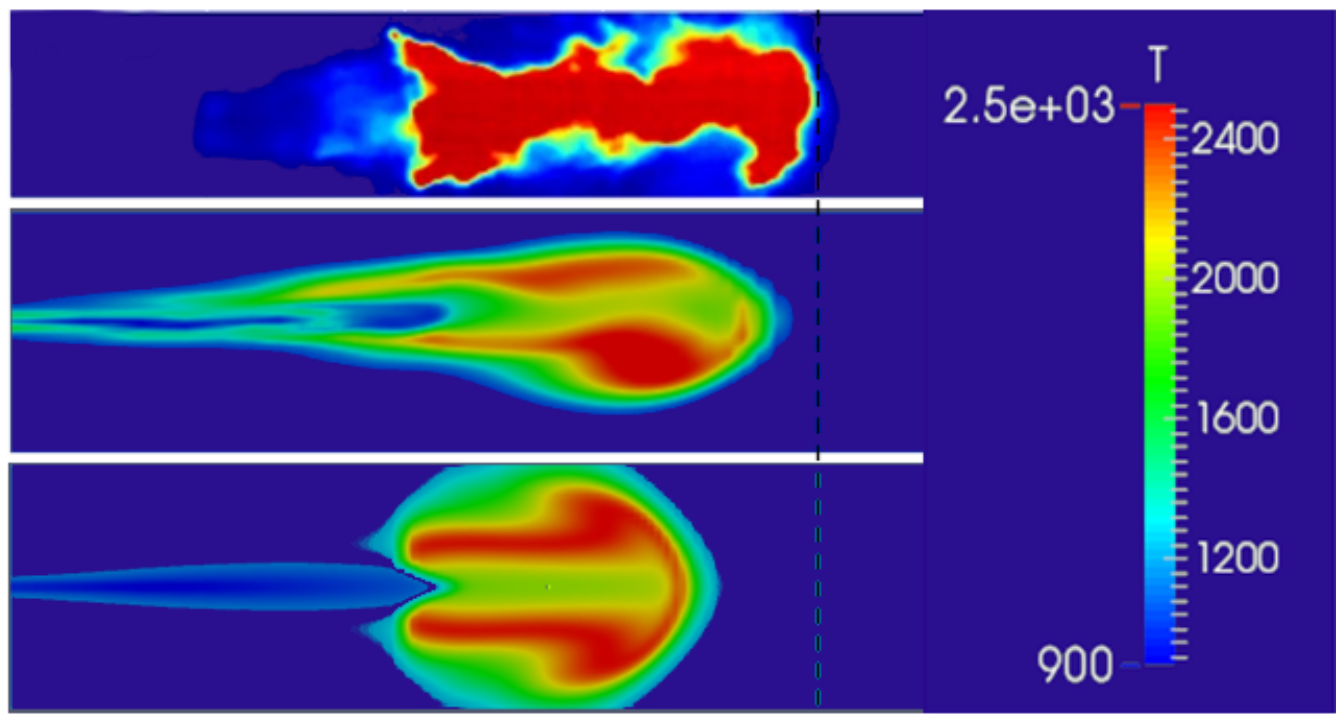

Figura 6.18: Spray Experimental(topo), flameletsprayFoam(meio) e sprayFoam(baixo) no instante de $2 \mathrm{~ms} T_{a}=1000 \mathrm{~K}, T_{f}=373 \mathrm{~K}$ e $21 \mathrm{O}_{2} \%$, com a marcação (pontilhado) a $80 \mathrm{~mm}$ do injetor.

\subsection{2}

\section{Atraso de Ignição}

Nesta seção serão apresentados os tempos de atraso de ignição para os casos citados na Tab. (6.1), com variação da temperatura ambiente. Estes 
dados são comparados com o atraso da ignição obtido experimentalmente, que são baseados em medições para o aumento da pressão. No entanto, a definição experimental, com embasamento na pressão, pode não ser adequada para simulações baseadas na geometria da câmara real. Sendo assim, várias definições, relacionadas à variação de temperatura, são utilizadas para o estudo do atraso de ignição [83]. Portanto, no presente estudo, foram utilizadas duas definições para o atraso da ignição, de modo a haver um consenso com os dados experimentais. A primeira é definida como o ponto no tempo quando a temperatura máxima no domínio atinge metade do aumento de temperatura total no domínio, ou seja, $T_{i g}=\left(T_{a}+T_{\max }\right) / 2[45,54]$. E a segunda é o momento em que a temperatura média é superior a $1600 K$ dentro do domínio [84].

Na Fig. (6.19), vê-se o comportamento do atraso de ignição em função da variação da temperatura ambiente. Os resultados mostram que os tempos de atraso de ignição estão condizentes com os dados experimentais. Apenas nos casos de $800 K$ e $900 K$ mostram um desvio significativo. Isso se deve ao mecanismo de cinética química utilizado [9], que se mostra menos preciso no regime de baixa temperatura, como também é relatado por Ayyapureddi et al. [85].

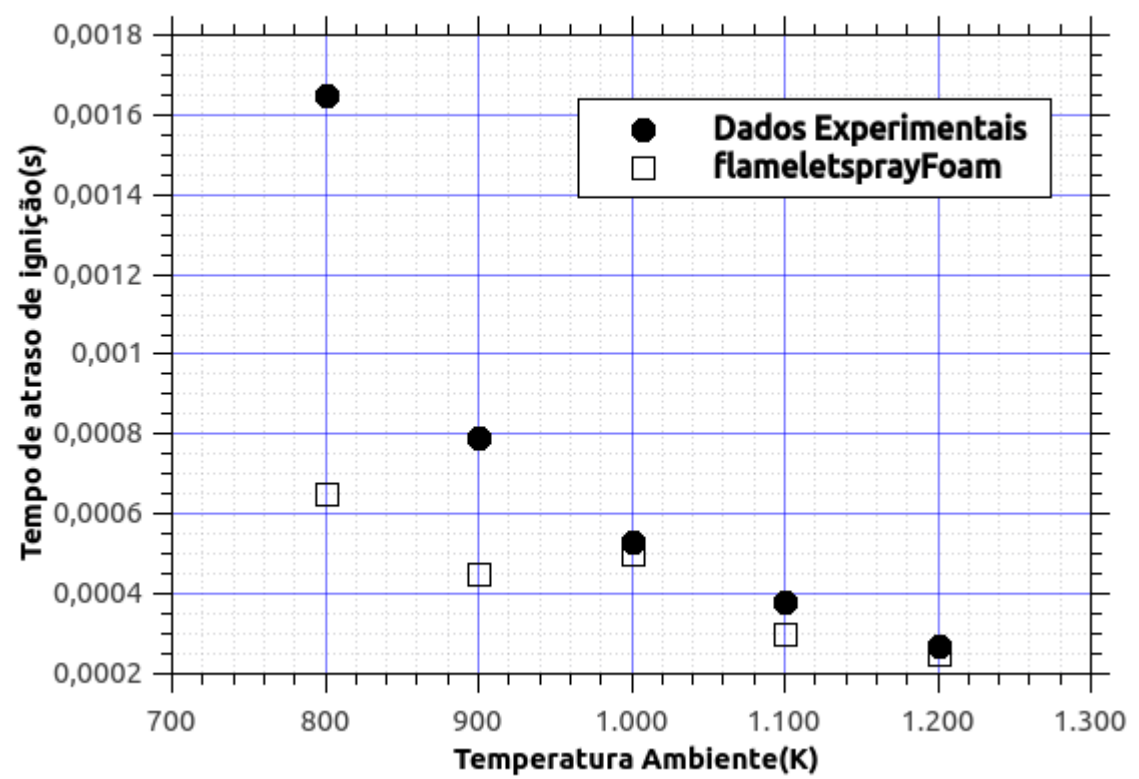

Figura 6.19: Atraso de ignição para a variação da temperatura ambiente 


\subsection{3}

\section{Comprimento de ancoramento da chama-CAC}

Nesta seção os resultados para o comprimento de ancoramento da chama são apresentados juntamente com uma discussão sobre os critérios para determinar essa quantidade de dados de simulação.

Os casos experimentais do CAC em spray são baseados em imagens, onde CAC é definido como ponto onde $O H^{*}$ atinge metade do valor máximo na linha visão do $O H^{*}$. Em estudos numéricos, o grupo de modelagem da ECN [3] propôs tomar um limiar da fração de massa de $O H\left(Y_{O H}=2.5 \times 10^{-4}\right)$ como uma medida para o CAC. Enquanto esta definição funciona bem para uma parte dos casos, para os outros, especialmente os casos de baixa concentração de $O_{2}$, ele falha devido a concentrações relativamente baixas $O H$ (limiar não é atingido) e/ou distribuição $\mathrm{OH}$ sensíveis ao valor limite constante. Neste estudo, o comprimento do CAC é definido como local em que a temperatura atingiu metade do aumento máximo de temperatura total no domínio, ou seja, $T_{\text {lift }}=\left(T_{a}+T_{\max }\right) / 2$. Esta definição leva em conta a diferença de temperatura (refletida na temperatura máxima que é alcançada) para cobrir uma vasta gama de condições em questão. Outra definição é a posição axial do injector, onde a temperatura média é acima de $1600 K$. Na Fig. (6.20), percebe-se um comportamento parecido ao atraso de ignição, ou seja, para temperaturas menores, especialmente no caso da temperatuara ambiente igual a $800 \mathrm{~K}$, existe uma discrepância para o CAC. E, assim como no caso do atraso de ignição, isso se deve a uma deficiência do mecanismo de cinética química na reprodução de regimes de baixa temperatura. O estudo da influência do mecanismo de cinética química sobre a ignição realizado na seção (6.1), embora o mecanismo de Liu at al. [9] tenha se mostrado eficiente, para a modelagem da chama difusiva, no presente trabalho o mecanismo não foi capaz de captar o atraso de ignição e o comprimento de ancoramento da chama para o spray à baixa temperatura de $800 K$. 


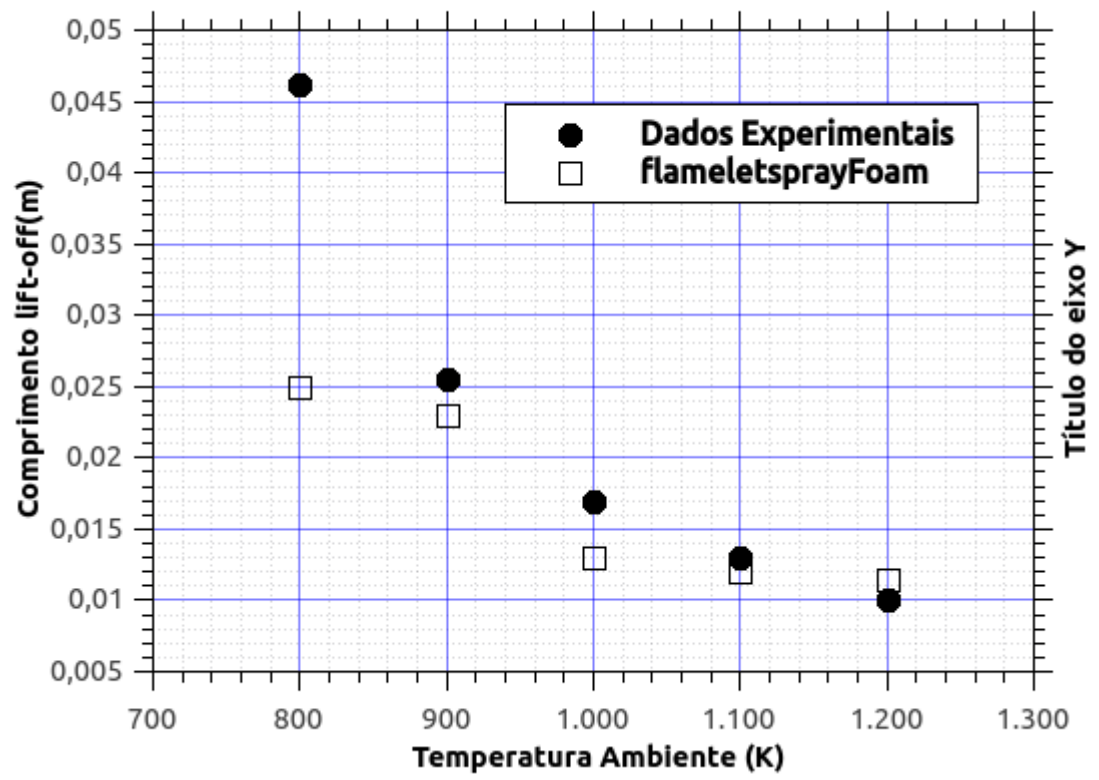

Figura 6.20: comprimento de ancoramento da chama para a variação da temperatura ambiente 


\section{Conclusões e Recomendações}

A combustão do Diesel necessita ser modelada com um número grande de hidrocarbonetos, como o n-Heptano, que modelam a combustão durante a variação de pressão e de temperatura no sistema. O momento da ignição é um parâmetro crucial para esta aplicação, pois afeta tanto a eficiência do motor quanto as suas emissões. Do ponto de vista conceitual sobre a combustão Diesel, a modelagem flamelet é formada pelo conjunto de chamas de difusivas armazenados em tabelas geradas pelo software flameMaster, onde a fração de massa $(Y)$ e a temperatura $(T)$ estão em função da fração de mistura $(Z)$ e da dissipação escalar $(\chi)$. Neste estudo, a escolha da dissipação escalar foi feita com cuidado para cobrir os tempos ignição, reignição e de desenvolvimento de chama de forma adequada.

A baixa temperatura, alta pressão e uma combustão eficiente são de interesse para as pesquisas dentro da próxima geração de motores de ignição por compressão. Essas pesquisas visam reduzir as emissões e economizar o combustível em uma ampla gama de condições de funcionamento. Estes modos de combustão são muito diferentes da combustão Diesel tradicional, e modelálas exige um aperfeiçoamento das modelos físicos que podem acomodar forte acoplamento entre o spray, turbulência, e a química.

O trabalho proposto mostra que, embora a abordagem tenha se mostrado eficiente na maioria das simulações, que há muitos caminhos a serem explorados para as simulações e modelos expostos, diante da crescente demanda de experimentos com sprays Diesel. O modelo proposto mostrou-se mais eficiente computacionalmente com um custo computacional reduzido, o que é importante para aplicações industriais utilizando geometrias complexas. Para as simulações não reativas, os resultados foram condizentes com os resultados experimentais, mostrando que o modelo de turbulência $k-\epsilon$, corresponde às expectativas das simulações e se adapta bem a geometria da câmara.

Nos casos para o atraso de ignição e para o comprimento de ancoramento da chama, embora os resultados obtidos tivessem uma considerável coerência com os resultados experimentais, constatou-se uma deficiência do mecanismo de cinética química na reprodução de regimes de baixa temperatura de $800 \mathrm{~K}$. O estudo da influência do mecanismo de cinética química sobre a ignição, onde foi utilizado o mecanismo de cinética química Liu at al. [9], justificou-se pela sua capacidade em reproduzir os tempos de ignição, reignição e extinção do spray. 
O estudo da chama difusiva é de estrema importância para o spray com a formulação flamelet pois, como foi definido anteriormente, o princípio flamelet se baseia em um conjunto de chamas difusivas. Sendo assim, o estudo das chamas difusivas a baixas temperaturas, torna-se importante para o entendimento tanto para o atraso de ignição como para o comprimento de ancoramento da chama. Mostrando que o modelo proposto pode prever os efeitos da variação das concentrações de temperaturas ambiente nesses parâmetros. Contudo, verificou-se que o comprimento de ancoramento da chama foi subestimado e a sua dependência da temperatura. Para um caso sem combustão na mesma geometria, o OpenFOAM poderia prever muito bem a distribuição de vapor, além dos comprimentos de penetração de líquido e vapor.

Logo, metodologia proposta nesse trabalho mostra que os resultados obtidos possuem um alto ganho computacional com baixo custo computacional, o que importante para mecanismos de cinética química com um grande número de espécies e para estudos voltados para o ciclo Diesel completo.

\section{1}

\section{Recomendações Finais para Trabalhos Futuros}

Em decorrência do estudo desenvolvido nessa tese, algumas sugestões de trabalhos futuros foram elaboradas:

- Utilização de outros modelos de turbulência, como por exemplo, o modelo LES;

- implementação do estudo realizado para outros mecanismos de cinética química utilizados na seção (6.1);

- Simulação do spray em um ciclo diesel completo. Estudando as variações de pressão e de temperatura dentro do cilindro devido ao movimento do pistão e seus impactos na combustão;

- Estender o estudo do atraso de ignição e do comprimento de ancoramento da chama para a variação da concentração de $O_{2}$. Estudando o impacto da variação da concentração sobre a construção das tabelas no FlameMaster e consequentemente, sobre o mecanismo de cinética química;

- Realizar uma análise minuciosa sobre a influência do mecanismo de cinética química sobre baixas temperaturas para temperaturas menores que $800 K$ para comparar a capacidade do mecanismo de cinética química em reproduzir o atraso de ignição e do comprimento de ancoramento da chama. 


\section{Referências Bibliográficas}

[1] FOUNDATION, O.. Openfoam programmers guide, 2.3.0. OpenFoam, 2014.

[2] H. MÜLLER AND F. FERRARO AND M. PFITZNER. Implementation of a Steady Laminar Flamelet Model for non-premixed combustion in LES and RANS simulations. International OpenFoam Workshop, 2013.

[3] ECN. engine combustion network (ecn). Relatório Técnico, 2012.

[4] BAUMGARTEN, C.. Mixture formation in internal combustion engines. Springer, Heidelberg, 1 edition, 2006.

[5] SCHNEIDER, B.. Experimentelle Untersuchungen zur Spraystruktur in transienten, verdampfenden und nicht verdampfenden Brennstoffstrahlen unter Hochdruck. Tese de Doutorado, Technische Wissenschaften, Zurich, 2003.

[6] DE COMBUSTÃO E ENERGIA, S.. curso vse injetores. 2015.

[7] DEC, J. E.. A conceptual model of di diesel combustion based on laser-sheet imaging, journal = SAE Technical Papers. 1997.

[8] R. SEISER; H. PITSCH; K. SESHADRI; W. J. PITZ ; H. J. CURRAN. Extinction and Autoignition of n-Heptane in Counterflow Configuration. Proceedings of the Combustion Institute, 28:2029-2037, 2001.

[9] S. LIU AND J.C. HEWSON AND J.H. CHEN AND H. PITSCH. Effects of strain rate on high-pressure nonpremixed n-heptane autoignition in counterflow. Combustion and Flame, p. 137:320,339, 2004.

[10] PETERS, N.. Turbulent Combustion. Cambridge University Press, 1 edition, 2000.

[11] J.H. CHEN. Petascale direct numerical simulation of turbulent combustion fundamental insights towards predictive model. Proceedings of the Combustion Institute, 33:99-123, 2011.

[12] SADASIVUNI, S. K.. LES Modelling of Non-premixed and Partially Premixed Turbulent Flames. Tese de Doutorado, Loughborough University, 2009. 
[13] W.J. PITZ; C.J. MUELLER. Recent progress in the development of diesel surrogate fuels. Progress in Energy and Combustion Science, 37:330-350, 2011.

[14] C.K. WESTBROOK, ET AL.. A comprehensive detailed chemical kinetic reaction mechanism for combustion of $n$-alkane hydrocarbons from n-octane to $\mathbf{n}$-hexadecane. Combustion and Flame, 156:181-199, 2009.

[15] H. CURRAN; P. GAFFURI; W. PITZ ; C. WESTBROOK. A comprehensive modeling study of $\mathbf{n}$-heptane oxidation. Combustion and Flame, 114:149-177, 1998.

[16] A. PATEL, ET AL.. Development and Validation of a Reduced Reaction Mechanism for HCCI Engine Simulations. SAE, 200401-0558, 2004.

[17] V.I. GOLOVITCHEV, ET AL.. 3D Diesel Spray Simulations Using a New Detailed Chemistry Turbulent Combustion Model. SAE, 2000-01-1891, 2000.

[18] K.N.C. BRAY; J.B. MOSS. A Unified Statistical Model of the Premixed Turbulent Flame. Acta Astronautica, 4:291-319, 1977.

[19] M. HALSTEAD; L. KIRSCH ; C. QUINN. The autoignition of hydrocarbon fuels at high temperatures and pressures-fitting of a mathematical model. Combustion and Flame, 30:45-60, 1977.

[20] C.D. PIERCE; P.MOIN. Progress variable approach for large-eddy simulation of non-premixed turbulent combustion. Journal of Fluid Mechanics, 504:73-97, 2004.

[21] S.B. POPE. An improved turbulent mixing model. AIChE Journal, p. Combustion Science and Technology, 1982.

[22] R. BILGER; S. STARNER; R. KEE . On reduced mechanisms for methane-air combustion in nonpremixed flames. Combustion and Flame, 80:135-149, 1990.

[23] N. PETERS. Laminar diffusion flamelet models in non-premixed turbulent combustion. Progress in Energy and Combustion Science, p. 10, 19, 82, 83, 1984. 
[24] H. PITSCH; H. STEINER. Large-Eddy Simulation of a Turbulent Piloted Methane/Air Diffusion flame (Sandia Flame D). SAE Technical Papers, 12:2541-2554, 2000.

[25] PITSCH, H.. A C++ Computer Program for $0-D$ and 1-D Laminar Flame Calculations. Tese de Doutorado, RWTH Aachen, Aachen,Alemanha, 1988.

[26] H. BARTHS; C. ANTONI ; N. PETERS. Three-Dimensional Simulation of Pollutant Formation in a DI Diesel Engines Using Multiple Interactive Flamelets. SAE, 982459, 1998.

[27] P.A. LIBBY; K.N.C. BRAY. Counter-Gradient Diffusion in Premixed Turbulent Flames. AIAA Journal, 19:205-213, 1981.

[28] F. A. WILLIAMS. Recent Advances in Theoretical Descriptions of Turbulent Diffusion Flames. Turbulent Mixing in Nonreactive and Reactive Flows, p. 189-208, 1975.

[29] R.L CURL. Dispersed phase mixing: I. theory and effects in simple reactors. AIChE Journal, p. 175-181, 1963.

[30] S.K. LIEW; K.N.C. BRAY; J.B. MOSS. A Stretched Laminar Flamelet Model of Turbulent Nonpremixed Combustion. Combustion and Flame, 56:199-213, 1984.

[31] B. ROGG; F. BEHRENDT; J. WARNATZ. Turbulent Non-premixed Combustion in Partially Premixed Diffusion Famelets with Detailed Chemistry. Twenty-first Symposium (International) on Combustion, p. 1533-1541, 1986.

[32] P. T. ROBERTS AND J. B. MOSS. A Wrinkled Flame Interpretation of The Open Turbulent Diffusion Flame. Eighteenth Symposium (International) on Combustion/The Combustion Institute, 941, 1981.

[33] P. T. ROBERTS AND J. B. MOSS. Stretched Laminar Flamelet Analysis of Turbulent $\mathrm{H} 2$ and $\mathrm{CO} / \mathrm{H} 2 / \mathrm{N} 2$ Diffusion Flames. Twenty-first Symposium (International) on Combustion/The Combustion Institute, p. 1579-1589, 1986.

[34] D.C. HAWORTH; M.C. DRAKE; S.B. POPE ; R.J. BLINT. The Importance of Time Dependent Flame Structure In Stretched Laminar Flamelet Models For Turbulent Jet Diffusion Flames. TwentySecond Symposium (International) on Combustion/The Combustion Institute, p. 589-597, 1988b. 
[35] F. MAUSS; D. KELLER ; N. PETERS. A Lagrangian Simulation of Flamelet Extinction and Re-Ignition In Turbulent Jet Diffusion Flames. Twenty-third Symposium (International) on Combustion/The Combustion Institutee, p. 693-698, 1990.

[36] H. PITSCH; N. PETERS. A Consistent Flamelet Formulation for Non-Premixed Combustion Considering Differential Diffusion Effects. Combustion Flame, 114:26-40, 1998.

[37] S. LAM AND D. GOUSSIS. Understanding complex chemical kinetics with computational singular perturbation. Understanding complex chemical kinetics with computational singular perturbation 22, p. 931-941, 1989.

[38] U. MAAS AND S. POPE. Simplifying chemical kinetics: Intrinsic low-dimensional manifolds in composition space. Combustion and Flame, 34:239-264, 1992.

[39] O. GICQUEL AND D. THÉVENIN AND M. HILKA AND N. DARABIHA AND ET AL.. Direct numerical simulation of turbulent premixed flames using intrinsic low-dimensional manifolds. Combustion Theory and Modelling 3, 3:4790-502, 1999.

[40] B. MAGNUSSEN AND B. HJERTAGER. On mathematical modeling of turbulent combustion with special emphasis on soot formation and combustion. Symposium (International) on Combustion 16, 1:719729, 1977.

[41] J. LIVENGOOD; P. WU. Correlation of autoignition phenomena in internal combustion engines and rapid compression machines. Symposium (International) on Combustion 5, 1:347-35, 1955.

[42] KARLSSON, J.. Modeling Auto-ignition, Flame Propagation and Combustion in Non-stationary Turbulent Sprays. Tese de Doutorado, Chalmers University of Thechnology, 1995.

[43] H. BARTHS; H. HASSE ; N. PETERS. Computational Fluid Dynamics Modelling of Non-Premixed Combustion in Direct Injection Diesel Engines. International Journal of Engine Research, 1:249-267, 2000.

[44] H. BARTHS; N. PETERS; N. BREHM; A. MACK; M. PFITZNER ; V. SMILJANOVSKI. Simulation of Pollutant Formation in a GasTurbine Combustor Using Unsteady Flamelets. wenty-seventh 
Symposium (International) on Combustion/The Combustion Institute, p. 1841-1847, 1998.

[45] R. NOVELLA; A. GARCIA; J. PASTOR; V. DOMENECH. The role of detailed chemical kinetics on cfd diesel spray ignition and combustion modelling. Mathematical and Computer Modelling, 54:17061719, 2011.

[46] U. AZIMOV; K. S. KIM ; C. BAE. Modeling of flame lift-off length in diesel low-temperature combustion with multi-dimensional cfd based on the flame surface density and extinction concept. Mathematical and Computer Modelling, 14:155-175, 2010.

[47] GROUP, C.. cantera documentation. Relatório Técnico, 2012.

[48] M. C. YUEN AND L.W. CHEN. On drag of evaporating liquid droplets. Combustion Sci, p. 147-154, 1976.

[49] M. LINNE AND M. PACIARONI AND T. HALL. Ballistic imaging of the near field in a diesel spray. Experiments in Fluids, 40.6:836-846, 2006.

[50] M. LINNE. Imaging in the optically dense regions of a spray: A review of developing techniques. Progress in Energy and Combustion Science, 39.5:403-440, 2013.

[51] M. BARDI. Engine combustion network: Comparison of spray development, vaporization, and combustion in different combustion vessels. Atomization and Sprays, 22.12:807-842, 2012.

[52] L. M. PICKETT. Relationship Between Diesel Fuel Spray Vapor Penetration/Dispersion and Local Fuel Mixture Fraction. Atomization and Sprays, 4.1:764-799, 2011.

[53] ALDARAVÍ, P. M. G.. Development of a Computational Model for a Simultaneous Simulation of Internal Flow and Spray Breakup of the Diesel Injection Process. Tese de Doutorado, Universitat Politècnica de València, 2014.

[54] BEKDEMIR, C.. Tabulated Chemical Kinetics for Efficient and Detailed Simulations of Diesel Engine Combustion. Tese de Doutorado, Eindhoven University of Technology, Eindhoven, Holanda, 2012.

[55] R. D. REITZ. Modeling atomization processes in high-pressure vaporizing sprays. Atomization Spray Technology, p. 309-337, 1987. 
[56] A. M. STERLING AND C. A. SLEICHER. The instability of capillary jets. Journal of Fluid Mechanics, 68.3:477-495, 1997.

[57] W.E. RANZ AND W.R. MARSHALL. Evaporation from Drops .1. Chemical Engineering Progress, 48:141-146, 1952.

[58] C. C. MIESSE. Correlation of Experimental Data on the Disintegration of Liquid Jets. Industrial and Engineering Chemistry, 47.9:16901701, 1955.

[59] A. WIERZBA. Deformation and breakup of liquid drops in a gas stream at nearly critical Weber numbers. Experiments in Fluids, 9.1-2:59-64, 1990.

[60] C. ARCOUMANIS AND M. GAVAISES AND B. FRENCH. Effect of Fuel Injection Processes on the Structure of Diesel Sprays. SAE Technical Paper, p. 52-54, 1997.

[61] ZHAO, H.. HCCI and CAI engines for the automotive industry. Woodhead Publishing Limited, 1 edition, 2007.

[62] J. CHANG ET AL. Characterizingg the termal sensitivity of a gasoline homogeneous charge compression ignition engine with measurements of instantaneous wall temperatura and heat flux. International Journal of Engine Research, p. 289-309, 2005.

[63] TENNEKeS, H.; LUMLEY, J. L.. A First Course in Turbulence. The MIT press, 1 edition, 1972.

[64] LAUNDER, B. E.; SPALDING, D.B.,. The Numerical Computation of Turbulent Flows. Computational Methods of Applied Mechanical Engineering, 3:269-287, 1974.

[65] J. JANICKA; N. PETERS . Prediction of Turbulent Jet Diffusion Flame Lift-Off Using a PDF Transport Equation. In Symposium (International) on Combustion, 19, 1982.

[66] XUAN, Y.. Progress in numerical modeling of non-premixed combustion. Tese de Doutorado, California Institute of Technology, 2014.

[67] N. N. AYOUB AND R. D. REITZ. Multidimensional Computation of Multicomponent Spray Vaporization and Combustion. SAE Technical Paper 950285, p. 2-56, 1995. 
[68] PATTERSON MA; REITZ RD. Modelling the Effects of Fuel Spray Characteristics on Diesel Engine Combustion and Emissions. SAE, 1998.

[69] R. D. REITZ. Modeling Atomization Processes in High-Pressure Vaporizing Spray. Atomization and Spray Technology, 3:309-337, 1987.

[70] FERRARI, G.. Motori a combustione interna. Torino, 4 edition, 2008.

[71] STIESCH, G.. Modeling engine spray and combustion processes. Springer, 1 edition, 2008.

[72] S. HOSSAINPOUR AND A. R. BINESH. Investigation of fuel spray atomization in a DI heavy-duty diesel engine and comparison of various spray breakup modelss. Fuel, p. 799-805, 2009.

[73] KRALJ, C.. Numerical Simulation of Diesel Spray Processes. Tese de Doutorado, Imperial College of Science Technology and Medicine, 1995.

[74] S. KIMURA AND H. KOSAKA AND Y. MATSUI AND R. HIMENO. A numerical simulation of turbulent mixing in transient spray by les. SAE, 2004-01-2014, 2004.

[75] P. J. O'ROURKE AND A. A. AMSDEN. The tab method for numerical calculation of spray droplet breakup. SAE, 872089, 2004.

[76] R. ROTONDI; G. BELLA; C. GRIMALDI ; L. POSTRIOTI. Atomization of High-Pressure Diesel Spray: Experimental Validation of a New Breakup Model. SAE paper 2001-01-1070, 2001.

[77] FOUNDATION, O.. openfoam programmers guide. 2016.

[78] T.F. LU; C.K. LAW. Linear time reduction of large kinetic mechanisms with directed relation graph: n-Heptane and iso-octane. Combustion and Flame, 144:24-36, 2006.

[79] T.F. LU; C.K. LAW ; C.S. YOO. Dynamic Stiffness Removal for Direct Numerical Simulations. Combustion and Flame, 156:1542-1551, 2009.

[80] J.S. KIM; F.A. WILLIAMS. Effects of Non-Homogeneitties on the Eigenmodes of Acoustic Pressure in Combustion-Chambers. Journal of sound and vibration, 209:821-843, 1998.

[81] C. A. ISICHERIA; L. M. PICKETT. Effects of EGR on Diesel Premixed-Burn Equivalence Ratio. Proceedings of the Combustion Institute, 31:2931-2938, 2007. 
[82] SUTRADHAR, S. C.. validation of atomization and evaporation models for fuel spray in constant-volume experiments under non-reacting conditions. Dissertação de Mestrado, Politecnico di Milano, 2011.

[83] COMPARISONS: N-HEPTANE SESSION, M.. The session compared models and experiments of non-reacting and reacting $n$-heptane sprays performed in the Sandia constant volume chambe. University of New South Wales, Sydney.

[84] BOLLA, M.. Modeling Soot Formation in Diesel Engines Using Conditional Moment Closure. Tese de Doutorado, ETH ZURICH, 2013.

[85] S. AYYAPUREDDI; U. EGUZ; C. BEKDEMIR; L. SOMERS ; L. DE GOEY. Spray a simulations with the fgm method. Proceedings of the 12th ICLASS, 1 edition, 2012. 